
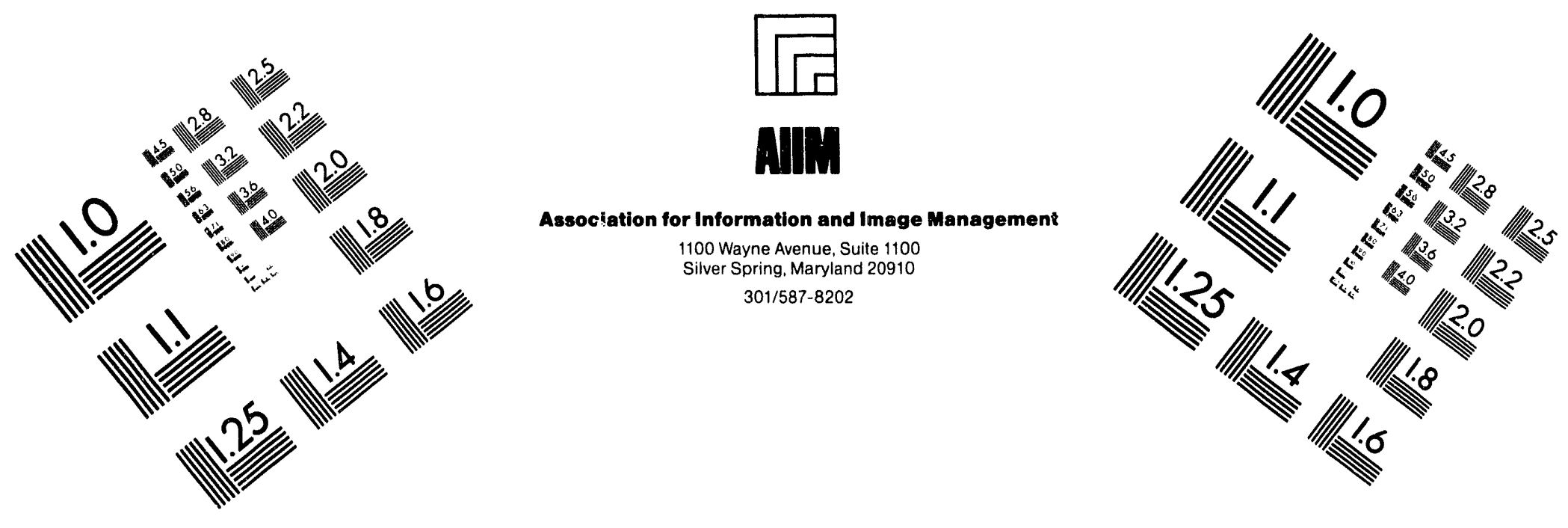

\title{
Centimeter
}

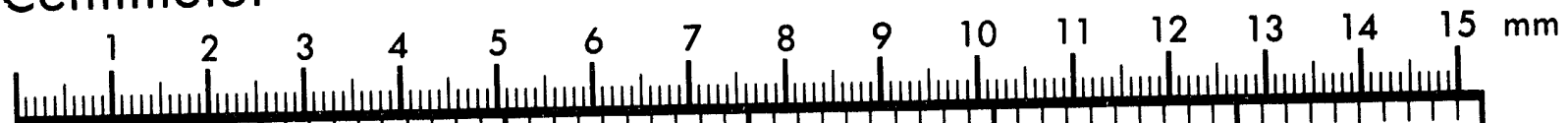
| Inches
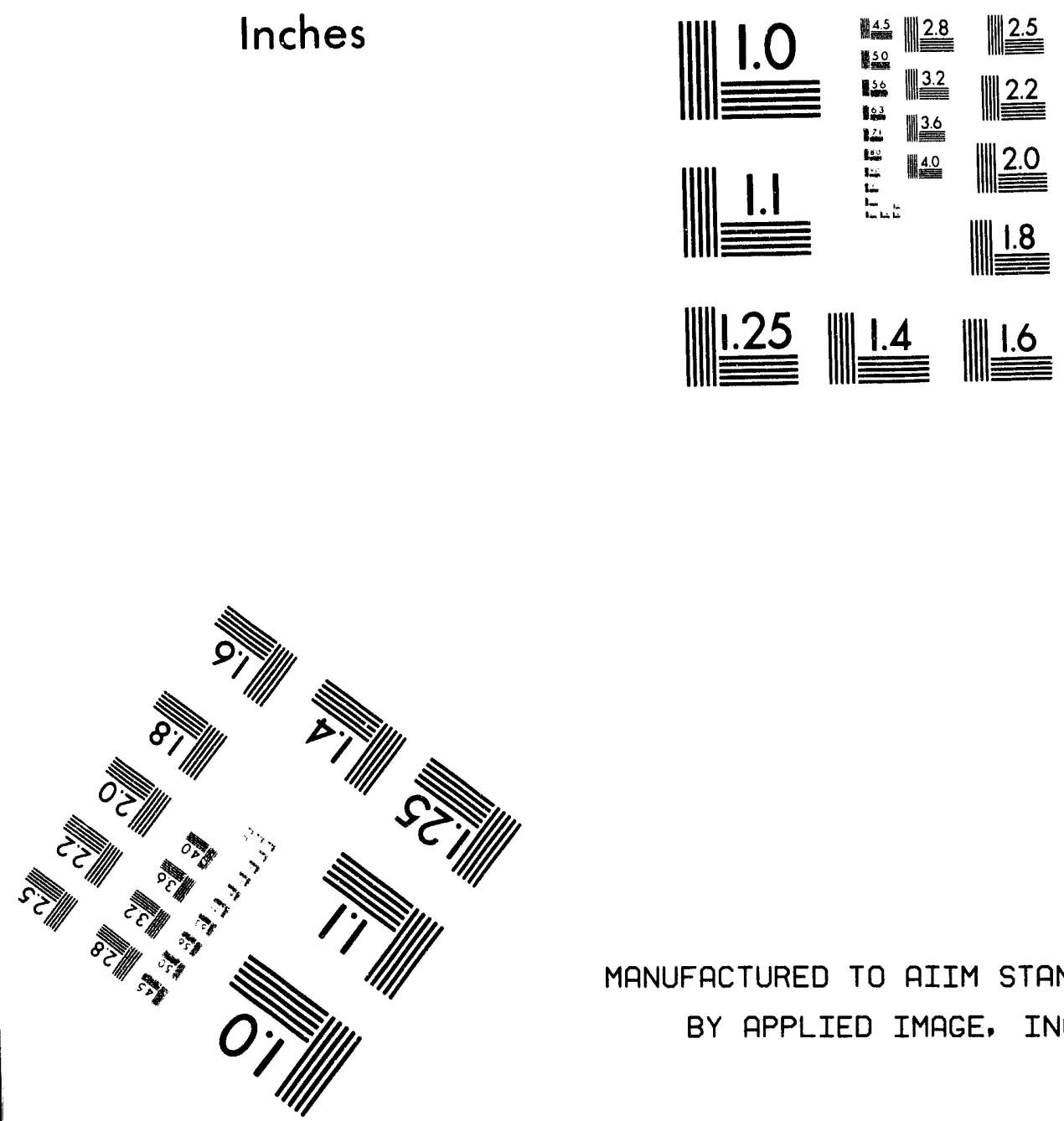

MANUFACTURED TO AIIM STANDARDS

$$
\text { BY APPLIED IMAGE, INC. }
$$

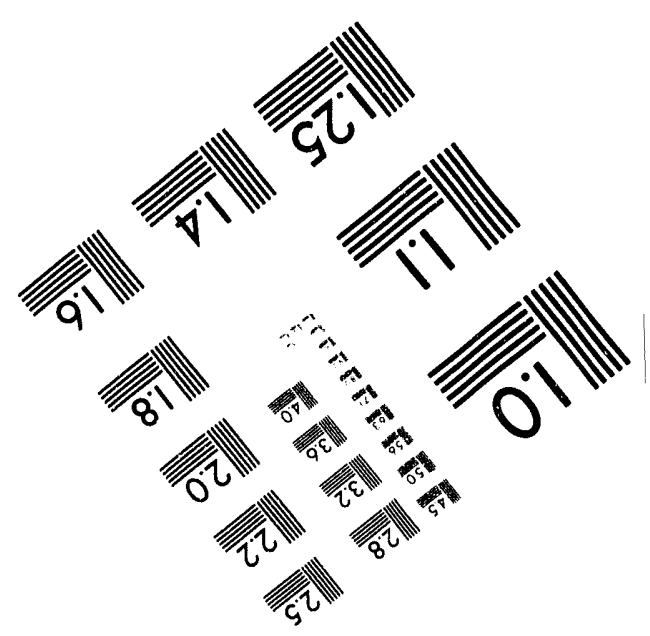



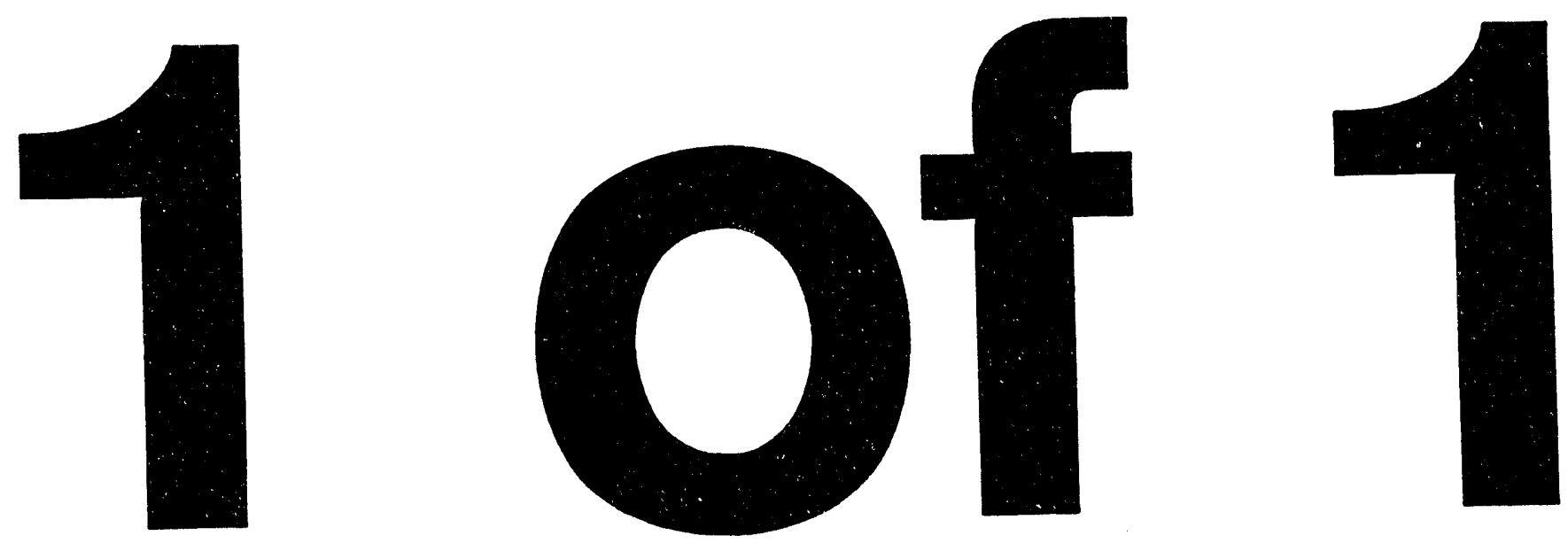
WSRC-TR-93-454

\section{Solubility of Uranium in Alkaline Salt Solutions (U)}

by

D. T. Hobbs

T. B. Edwards

Issued: $\quad$ March 29, 1994

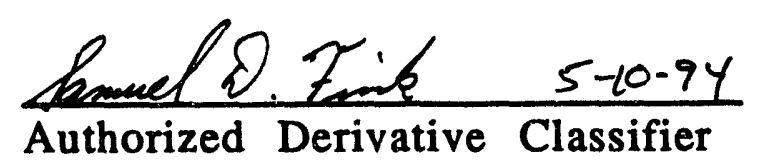

$\frac{\text { Samuel D. Fink, GRoup MGR. IWT-LWP }}{\text { Reviewing Official }}$

\section{SRTC}

Savannah River Technology Center, Aiken, SC 29802

Westinghouse Savannah River Company

Prepared by the. U. S. Department of Energy under Contract DE-AC09-8\&SR18035

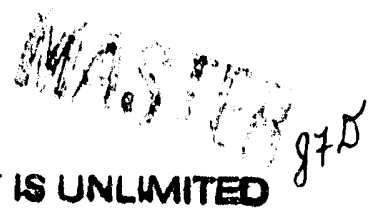


Document:

Title:
W SR C - TR - $93-454$

Solubility of Plutonium and Uranium in Alkaline Salt Solutions (U)

Approvals

$\frac{0 . T \cdot \sigma_{3} h}{\text { D. T. Hobbs, Author, WM\&ET/IWT }}$

$\frac{\text { 2. B. Edwards }}{\text { T. B. Edwards, Author, STD/ATS }} \frac{5-9-94}{\text { Date }}$

$\frac{\mathrm{A} \cdot \mathrm{W} \cdot \text { Weller }}{\text { J. H.U Weber, Technical Reviewer, STD/ATS }} \frac{5-11-94}{\text { Date }}$

$\frac{\text { O.W.W. Weber }}{5-11-94}$

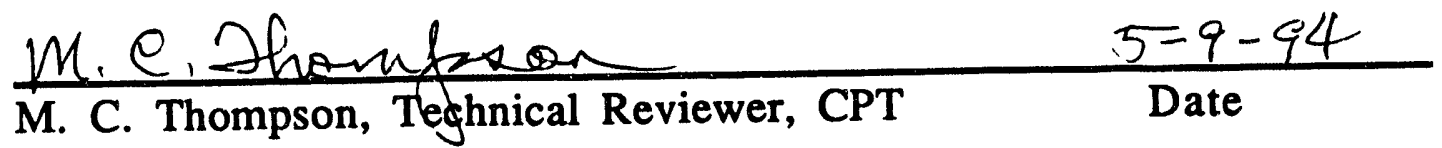

S. D. Fink, Responsible Manager, WM\&ET/IWT

$5-10-24$

Date

Michael C. Chard

M. C. Chandler, WME, Customer

$5-13-94$

Date 


\section{Table of Contents}

Section Page

1.0 Summary ........................................................

$2.0 \quad$ Introduction ......................................................... 1

$3.0 \quad$ Experimental ....................................................... 1

4.0 Results ………........................................................ 3

5.0 Discussion ............................................................. 7

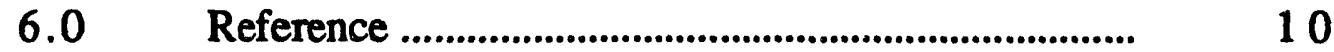

7.0 Appendix ................................................................ 11 


\subsection{SUMMARY}

The solubility of uranium in alkaline salt solutions was investigated to screen for significant factors and interactions among the major salt components and temperature. The components included in the study were the sodium salts of hydroxide, nitrate, nitrite, aluminate, sulfate, and carbonate. General findings from the study included: (1) uranium solubilities are very low $(1-20 \mathrm{mg} / \mathrm{L})$ for all solution compositions at hydroxide concentrations from 0.1 to 17 molar, (2) carbonate, sulfate, and aluminate are not effective complexants for uranium at high hydroxide concentration, (3) uranium solubility decreases with increasing temperature for most alkaline salt solutions, and (4) uranium solubility increases with changes in solution chemistry that reflect aging of high level waste (increase in nitrite and carbonate concentrations, decrease in nitrate and hydroxide concentrations). A predictive model for the concentration of uranium as a function of component concentrations and temperature was fitted to the data. All of the solution components and temperature were found to be significant. There is significant lack of fit for the model, which suggests that the dependence of the uranium solubility over the wide range of solution compositions is non-linear and/or that there are other uncontrolled parameters which are important to the uranium solubility.

\subsection{INTRODUCTION}

From nuclear safety assessments of Tank Farm operations, recent questions have been raised concerning the behavior of uranium during storage and processing. To assess whether an amount of uranium necessary to produce a nuclear criticality concern could be achieved during operations, the solubility of uranium is needed for solutions which bound those which will occur during each of the process steps. Previously, a test program was conducted over a range of solution compositions [1] in which the concentrations of nitrate, nitrite, hydroxide, aluminate, carbonate, and sulfate, and the temperature were varied over the range expected during In-Tank Precipitation (ITP) processing. Since this range does not include all possible compositions and expected temperatures for all Tank Farm operations, an additional test program was planned and conducted to determine the solubility of uranium over a broader range of compositions and temperatures.

\subsection{EXPERIMENTAL}

\subsection{Experimental Method}

All salt solutions for the solubility tests were prepared in calibrated volumetric glassware using reagent grade chemicals. A single batch of deionized, distilled water was collected and stored in large polyethylene bottles for use in all solution preparations. All solutions were filtered through a $0.45 \mu \mathrm{m}$ filter to remove any undissolved solids prior to use. 
For each test, a 60-mL Teflon TEF bottle was filled with $50 \mathrm{~mL}$ of salt solution. Each bottle was spiked with between 50 and $300 \mu \mathrm{L}$ of depleted uranyl nitrate (Noah Chemical Co., Lot \#34619) dissolved in $0.1 \mathrm{M}$ nitric acid ( $[U]=287.6 \mathrm{~g} / \mathrm{L}$ ) in $50 \mu \mathrm{L}$ increments. Immediately prior to the addition of the uranyl nitrate solution, an equal volume of $5.01 \mathrm{M} \mathrm{NaOH}$ solution was added to each test bottle. The addition of uranyl nitrate solution was stopped upon observation of a solid precipitate. The bottles were stoppered and placed on a orbital shaker (Labline Instruments, Model \#3520) for ambient temperature tests or in a water bath (Blue M, Model \#MSB$1122 \mathrm{~A}-1)$ for the elevated temperature tests.

Each bottle was sampled and analyzed for soluble uranium content after 4, 7, 14, 21,48 , and 129 days. Since the time between sampling and analysis was not strictly controlled (and in some cases varied by as much as several days), time effects of the early stages of the test may not be as discernible as those of the latter test stages. The sampling procedure consisted of filtering 2-3 $\mathrm{mL}$ of the test solution into a clean vial, acidifying a known quantity of the filtered solution with nitric acid, and diluting to a known volume. The uranium content was determined by kinetic phosphorescence spectroscopy. The uranium content of the four-day, ambient-temperature samples was also determined by inductively-coupled plasma mass spectrometry.

The salt solutions were analyzed for chemical composition before and after the test. Vitrate, nitrite, and sulfate concentrations were determined by ion chromatography. For concentrated salt solutions, the free hydroxide, aluminate, and carbonate were determined gravimetrically. For dilute salt solutions, the free hydroxide was determined by a standard-addition pH measurement, the carbonate by total inorganic carbon analysis, and the aluminum by inductively-coupled plasma emission spectroscopy.

\subsection{Experimental Design}

The experimental design used for this study was comprised of 44 treatment combinations and is presented in Exhibit 1 of the Appendix. The experiment conducted involved the factors: hydroxide $(\mathrm{OH})$, nitrite (NO2), aluminate (AIO2), nitrate (NO3), carbonate (CO3), sulfate (SO4), and temperature of the solution. Exhibit 1 provides the levels of the factors in both moles/liter $(M)$ and $\log _{10}(M)$ for all factors except temperature. The temperature values are given in degrees Celsius $\left({ }^{\circ} \mathrm{C}\right)$ : the high value was $85^{\circ} \mathrm{C}$ and "Room Temperature" was $27^{\circ} \mathrm{C}$.

Exhibit 1 also provides the treatment combination defining each of the 44 experimental units. These levels of the factors have been scaled to values from -1 to 1. The experimental design started with two levels of each factor except $\mathrm{OH}$. For all factors except temperature and hydroxide, some center points were also added to this design. For hydroxide, five different levels were investigated. For temperature only the two levels were investigated. A total of 22 treatment combinations was required to complete this preliminary design. The final experiment included a complete replicate giving a total of 44 treatment combinations. 
The experiment was designed to investigate the main effect for each factor as well as the two-way interactions of $\mathrm{OH}$ with each of the other factors, the two-way interaction of NO2"NO3, the three-way interaction of $\mathrm{OH}^{*} \mathrm{NO2}{ }^{*} \mathrm{NO} 3$, and a quadratic effect for $\mathrm{OH}$.

\subsection{Experimental Data}

The results of the analyses of the salt solutions for chemical composition before and after the test are reported in Tables 1 and 2, respectively, of the Appendix. These values are given in moles/liter $(M)$ for all factors except temperature which is given in degrees Celsius. The common logarithms of these values except for the temperatures are used for the statistical analyses reported in this document.

The measurements over time of the uranium concentrations in milligrams per liter ( $\mathrm{mg} / \mathrm{L}$ ) were made using a kinetic phosphorescence technique (Chemchek or CC). An additional, early measurement was made using inductively-coupled plasma mass spectrometry (ICP/MS). The two measurements are represented by $U$ CCmg/L-n and U-ICPmg/L-n, respectively, where $n$ represents the number of days into the study at which the analysis was made. These data are presented by bottle number in Table 3 of the Appendix. Some analytical results are missing as a result of lost samples and each of these is indicated by a dot in the table.

The response of interest for each sample bottle prepared in the study was the common logarithm of the uranium concentration.

\subsection{RESULTS}

The data from this extended uranium (U) solubility experiment were statistically analyzed. The objectives of the analysis were to:

- $\quad$ perform exploratory data analysis on the test results,

- estimate the effects of the main factors and interactions,

- determine prediction equations and prediction limits with a $95 \%$ confidence level, and

- compare the results with those from a previous uranium solubility study [1].

In this section, the time relationship of the data is investigated graphically. The factors are screened for importance. Prediction equations and corresponding . confidence and prediction intervals for uranium concentrations are developed.

\subsection{Time Effect for Uranium Solubility}

Plots of the various treatment solubilities over time are presented in Exhibits $2-4$ in the Appendix. For solution numbers 1 through 16, the solutions are grouped in 
pairs with the corresponding bottles plotted together. Solutions 17,18 , and 19 are plotted separately; each plot containing the uranium solubilities for the bottles prepared from only one of these solutions.

Although there is no evidence of a systematic time effect in the uranium concentrations across all bottles, there do appear to be patterns of behavior for bottles prepared from the same solution. Therefore, models presented below investigate initial measurements of uranium concentrations against initial measurements of the factor levels and final measurements of uranium concentrations against final factor lovel measurements.

\subsection{Histograms of Common Logarithms of Uranium Solubilities}

Exhibits 5-8 in the Appendix provide histograms of the common logarithms of the uranium solubility measurements by bottle. Summary statistics such as sample averages and standard deviations are also provided. The sample standard deviations are plotted against the sample averages in Exhibit 9 of the Appendix. The three points on this chart with the largest standard deviations belong to bottles 39,21 , and 27. The percent relative standard deviations for bottles 39,21 , and 27 are $587.2 \%, 420.5 \%$, and $107.2 \%$, respectively. Bottles 39 and 21 were prepared from solution number 2.

\subsection{Main Effects and Interactions}

In addition to the main effect for each factor, the experiment was designed to investigate the two-way interactions of $\mathrm{OH}$ with each of the other factors, the twoway interaction of $\mathrm{NO}^{*} \mathrm{NO}$, the three-way interaction of $\mathrm{OH}^{*} \mathrm{NO}^{*} \mathrm{NO} 3$, and the quadratic term for $\mathrm{OH}$. An Analysis of Variance (ANOVA) approach was used to investigate these effects. Since the uranium concentrations were measured over time and two measurements (initial and final) were made of the factor levels, a number of data sets were available for analysis. Many of these data sets were analyzed as part of this study; some of these are discussed below.

The values of the uranium concentrations made at day 4 of the study using ICP/MS and $\mathrm{CC}$ were averaged and analyzed against the initial values of the factor levels. The common logarithm of the average uranium concentrations as measured in $\mathrm{mg} / \mathrm{L}$, which was denoted by $\mathrm{LOG}(U<=4)$, was used as the response variable. The common logarithm of the initial molar concentrations of the components of the salt solutions were used as the factor levels.

Exhibit 10 in the Appendix provides the results for the ANOVA for the full model under investigation. The factors and interactions that are considered to be significant are those with a Probs $|t|$ value less than or near 0.05 . Thus, $\log (\mathrm{OH})$ is indicated as a significant factor, and the following interactions are significant: $\log (\mathrm{CO} 3)^{*} \log (\mathrm{OH}), \log (\mathrm{NO} 2)^{*} \log (\mathrm{OH})$, and $\operatorname{Temp}\left({ }^{\circ} \mathrm{C}\right)^{*} \log (\mathrm{OH})$. The quadratic term for $\mathrm{Log}(\mathrm{OH})$ is also significant. 
Exhibit 11 in the Appendix provides the results when the more insignificant factors and interactions of the ANOVA are sequentially eliminated from the model. Thus, there are more degrees of freedom available for estimating the error variance. For this analysis, the main effects for factors involved in interactions are retained in the model regardless of their significance. Nitrate is marginally significant.

This model is given by

$$
\begin{aligned}
& \log (U<=4)=1.063-0.003 \mathrm{Temp}\left({ }^{\circ} \mathrm{C}\right)-0.004 \log (\mathrm{CO} 3)-1.326 \log (\mathrm{OH}) \\
& \text { - } 0.121 \log (\mathrm{NO} 3)+0.003 \log (\mathrm{NO} 2)-0.250 \log (\mathrm{CO})^{*} \log (\mathrm{OH}) \\
& +0.102 \log (\mathrm{NO} 2)^{*} \log (\mathrm{OH})+0.006 \mathrm{Temp}\left({ }^{\circ} \mathrm{C}\right)^{*} \mathrm{Log}(\mathrm{OH}) \\
& \text { - } 0.206[\log (\mathrm{OH})]^{2}
\end{aligned}
$$

Exhibit 12 in the Appendix provides results for a similar ANOVA analysis for the full model using the common logarithm of final factor level measurements and as a response the common logarithm of the CC measurements of the uranium concentrations for day 129 of the study. This response variable is designated by $\log (\mathrm{U}-129 \mathrm{CC})$. The significant factors are Temp $\left({ }^{\circ} \mathrm{C}\right), \log (\mathrm{CO} 3), \log (\mathrm{NO} 3)$, and Log(NO2). All of the interactions appear to be significant except the $\log (\mathrm{SO} 4)^{*} \mathrm{Log}(\mathrm{OH})$ and $\mathrm{Log}(\mathrm{NO} 3)^{*} \log (\mathrm{OH})$ interactions, but note that the threeway interaction is significant. The quadratic $\mathrm{Log}(\mathrm{OH})$ term does not appear to be significant.

The fitted model is given by

$$
\begin{aligned}
& \log (\mathrm{U}-129 \mathrm{CC})=1.415-0.009 \mathrm{Temp}\left({ }^{\circ} \mathrm{C}\right)+0.202 \mathrm{Log}(\mathrm{OH})-0.022 \log (\mathrm{AlO} 2) \\
& +0.619 \log (\mathrm{CO} 3)-0.360 \log (\mathrm{NO})-0.321 \log (\mathrm{NO} 2) \\
& \text { - } 0.125 \log (\mathrm{SO} 4)+0.319 \log (\mathrm{AlO} 2)^{*} \log (\mathrm{OH}) \\
& \text { - } 0.266 \log (\mathrm{CO} 3)^{*} \log (\mathrm{OH}) \text { - } 0.129 \log (\mathrm{NO})^{*} \log (\mathrm{OH}) \\
& \text { - } 0.117 \log (\mathrm{NO} 2)^{*} \log (\mathrm{OH})-0.108 \log (\mathrm{SO} 4)^{*} \log (\mathrm{OH}) \\
& +0.007 \text { Temp }\left({ }^{\circ} \mathrm{C}\right){ }^{*} \log (\mathrm{OH})-0.123 \log (\mathrm{NO} 2)^{*} \log (\mathrm{NO} 3) \\
& \text { - } 0.088 \log (\mathrm{NO} 3)^{*} \log (\mathrm{NO} 2)^{*} \log (\mathrm{OH})+0.121 \log (\mathrm{OH})^{2}
\end{aligned}
$$

Several reduced models were considered for the ANOVA of the final values of the factor levels. If the quadratic $\log (\mathrm{OH})$ is removed, then the $\mathrm{Log}(\mathrm{SO} 4)$ and LogiSO4)" $\mathrm{Log}(\mathrm{OH})$ terms are significant. If the $\mathrm{Log}(\mathrm{SO} 4)$ and $\mathrm{Log}(\mathrm{SO} 4)^{*} \mathrm{Log}(\mathrm{OH})$ terms are removed, then the quadratic $\mathrm{Log}(\mathrm{OH})$ term is significant. Therefore, the full model will be used as the "best" fitted model.

A Lack of Fit section is provided for each of the ANOVA's given in Exhibits 10-12. This check is based on the comparison of the estimate of pure error as measured for the replicates of the experiment and the residual error from the model. The difference between these estimates of the error is called the lack of fit error, and if 
its is significantly larger than the pure error, there is an indication of an inadequate functional form for the model. For the uranium solubility results, there is an indication of a lack of fit in the models. Thus, a functional form involving quadratic terms for one or more of the factors other than hydroxide might be more appropriate to approximate the uranium solubility over this range of salt solutions. Or there may be other uncontrolled parameters which are important to the uranium solubility.

\subsection{Prediction Intervals for Uranium Solubilities}

The models developed in Exhibits 10,11, and 12 can be used to predict uranium solubilities and to determine $95 \%$ confidence and prediction intervals for salt solutions within the range of those included in this test. The prediction equations are the equations for the fitted models provided in Section 4.3. A 95\% confidence interval for the uranium solubility provides limits on the expected uranium solubility for a given salt solution. For the models based on the initial levels of the factors and the day four uranium measurements, the confidence interval is for the expected initial uranium solubility. For the model based on the final levels of the factors and the day 129 uranium measurements, the confidence interval is for the expected final uranium solubility. A $95 \%$ prediction interval is a confidence interval for an individual uranium concentration measurement for a given salt solution with the intervals based on the initial factor levels covering initial uranium measurements and intervals based on the final factor levels covering final uranium measurements. Tables 5, 6, and 7 in the Appendix provide prediction intervals for salt solutions corresponding to the full model for initial factor levels, the reduced model for initial factor levels, and the full model for final factor levels, respectively. For the initial factor level models, solution number 4 is predicted to have the highest uranium solubility over all the solutions tested with solution number 14 the second highest. For the final factor level model, solution number 14 is predicted to have the highest uranium solubility over all the solutions tested with solution number 4 the second highest.

\subsection{Comparison to Previous Study}

Data from the previous ITP study [1] provide an opportunity to compare the results obtained there to those of the current, expanded study. The levels of the factors, initial and final, of the previous study are given in Tables 8 and 9, respectively, of the Appendix. Included in each of the tables is the average uranium solubility ( $\mathrm{mg} / \mathrm{L}$ ) from the Chemcheck measurements for each of the salt solutions (bottles) of the previous study.

The prediction equations developed in Section 4.3 can be used to predict the uranium concentrations for these salt solutions. These predictions are given in Tables 10,11 and 12 of the Appendix. These tables also provide a $95 \%$ confidence interval for the expected uranium solubility for each of these salt solutions and $95 \%$ prediction intervals for an individual uranium solubility for each of these salt solutions.

These confidence and prediction intervals along with the average uranium solubilities are plotted by bottle in Exhibits 13-18 in the Appendix. 


\subsection{DISCUSSION}

General Tank Farm operation deals with concentrated salt solutions, several molar in sodium ion. During storage of the waste, the temperature of supernate is typically between 30 and $70^{\circ} \mathrm{C}$. With the startup of the ITP and Extended Sludge Processing (ESP) operations, significant changes in the composition of salt solutions will occur as a result of dilution and the addition of nitrite as a corrosion inhibitor. Salt solution compositions may be diluted by as much as a factor of 100 during these processes. Chemical and radiolytic reactions will further decrease hydroxide, nitrate, and nitrite concentrations. Solution compositions were selected to encompass all possible ranges that will occur during the storage and processing of high-level waste (HLW) for permanent disposal. The maximum temperature was set to include the maximum temperature during processing exclusive of evaporation.

\subsection{Effect of Hydroxide}

Exhibit 19 in the Appendix shows a plot of the uranium concentrations versus the hydroxide concentration for each test solution. Over the five orders of magnitude change in the hydroxide concentrations tested in this study $\left(10^{-4} \mathrm{M}\right.$ to $\left.16 \mathrm{M}\right)$, the concentration of uranium varied by over four orders of magnitude $(0.05 \mathrm{mg} / \mathrm{L}$ to $1600 \mathrm{mg} / \mathrm{L}$ ). At any one hydroxide concentration, the concentration of uranium could vary by as much as a factor of ten due to other components in the solution. Clearly, the level of hydroxide is not sufficient alone to predict the solubility of uranium in alkaline salt solutions which span the wide range of compositions encompassing all Tank Farm operations.

\subsection{Effect of Other Solution Components}

Exhibits 20 through 24 in the Appendix show three-dimensional plots of the measured uranium concentrations versus various combinations of hydroxide and the other solution components (initial concentrations). Inspection of these graphs indicates some general trends in the solubility of uranium: i) uranium concentration is high at low hydroxide concentrations and cecreases to a minimum between $0.1-1.0 \mathrm{M}$, and then increases again at higher hycroxide concentrations, (2) carbonate is not particularly effective in increasing the solubility of uranium at hydroxide concentrations above $0.01 \mathrm{M}$, and (3) sulfate and aluminate do not strongly influence the solubility of uranium.

\subsection{Effect of Aging}

During the storage of high-level waste, the composition of the aqueous phase is continuously changing due to radiolysis and chemical reactions. For example, radiolysis of nitrate produces nitrite. Another significant change is the reaction of atmospheric carbon dioxide with hydroxide to produce bicarbonate and carbonate. Because of the large excess of hydroxide to prevent corrosion of the waste tanks, essentially all of the carbon dioxide is converted to carbonate. Hydroxide, 
carbonate, nitrate, and nitrite were all identified as key parameters in predicting the concentration of uranium.

During storage of high-level waste, the ratios of nitrate to nitrite and hydroxide to carbonate are decreasing. Nitrite is produced during storage by the radiolytic decomposition of nitrate. Carbonate is produced by the absorption and reaction of atmospheric carbon dioxide with hydroxide. For fresh waste, the ratios of nitrate to nitrite and hydroxide to carbonate are both high. With time however, the ratios decrease such that the ratios approach 1:1. In the case of nitrate:nitrite, the ratio can fall below 0.1 for the washed precipitate and washed sludge slurries produced in the ITP and ESP facilities.

Using the fitted model for the prediction of uranium concentration, values for the uranium concentration were calculated for decreasing nitrate:nitrite and hydroxide:carbonate ratios. A plot of the predicted values versus the ratios is shown in Exhibit 25 in the Appendix. The shape of the curve indicates that the solubility of uranium increases with aging (decreasing nitrate:nitrite and hydroxide:carbonate ratios). From the initial composition (high nitrate:nitrite and hydroxide:carbonate ratios), the solubility increases significantly upon a small change in the nitrite and carbonate concentrations. After that, the solubility gradually increases upon increases in the nitrite and carbonate concentrations and decreases in the nitrate and hydroxide concentrations. Since the solubility of uranium is predicted to increase during aging, precipitation of uranium solids would not be expected during the long-term storage of HLW.

\subsection{Effect of Temperature}

The effect of temperature on the solubility of uranium in alkaline salt solutions is small compared to other parameters. For example, the ranges of predicted uranium solubilities for compositions representing fresh Purex and fresh HM wastes from 27 to $85^{\circ} \mathrm{C}$ are 9.6 to $9.8 \mathrm{mg} / \mathrm{L}$ and 7.6 to $7.1 \mathrm{mg} / \mathrm{L}$, respectively. Temperature has a much stronger effect on uranium solubility in dilute solutions ( $<0.1$ molar). The solubility of uranium is predicted to decrease by a factor of about 3 upon a 10 -fold dilution of concentrated waste and by a factor of about 5 upon a 100 -fold dilution over the temperature range from $27^{\circ}$ to $85^{\circ} \mathrm{C}$.

An inverse relationship between temperature and solubility is rare. A number of uncontrolled factors may be responsible in part for the behavior. Possible factors include: (1) changes in the chemical composition of the solution due to chemical reactions (e.g., absorption and reaction with carbion dioxide) and physical changes (water evaporation), and (2) polymerization of uranium species that results in the precipitation of uranium.

\subsection{Time Effects}

Over the 129-day period of the test, the concentration of uranium was observed to change significantly in some of the test bottles (see Exhibits 2-4). Five of the test solutions exhibited increases in uranium concentration of greater than a factor of 
three, and five solutions exhibited decreases of greater than a factor of three. The remaining solutions show changes of less than a factor of three. Four of the five solutions that showed an increase were kept at $27^{\circ} \mathrm{C}$, whereas four of the five solutions which showed a decrease were kept at $85^{\circ} \mathrm{C}$. One of the intermediate hydroxide solutions, solution $\# 18$, showed no changes with time at $27^{\circ} \mathrm{C}$, but exhibited a decrease when kept at $85^{\circ} \mathrm{C}$. As described in the Experimental Sestion, the time between sampling and analysis was not strictly controlled and may have varied by as much as several days. Thus, the time effects of the early stages of the test may not be as discernible as those of the latter test siages.

These results suggest that equilibrium is slow to be obtained for some of the test conditions. Increasing the temperature may increase the rate of the dissolution, polymerization, and precipitation reactions of the uranium phases resulting in equilibrium being obtained sooner (i.e., decrease in uranium concentration with time). At lower temperatures, the rates are slower, and thus, the time to reach equilibrium is longer (increase in uranium solubility with time). In previous investigations [2-4] of uranium solubility in alkaline solutions, a series of polymeric uranium species have been reported. The extent of polymerization will depend on the liquid phase chemical composition and temperature.

This behavior is also consistent with data reported recently by Karraker [5]. In tests simulating the evaporation of high-level waste, the solubility of uranium precipitated during evaporation was reported to be lower than that of freshly precipitated uranium from dilute acid solution. The apparent higher uranium solubility in freshly precipitated systems is the result of a non-equilibrium system.

\subsection{Changes in Chemical Composition}

Chemical analysis of the test solutions before and after the tests indicated that significant changes in the concentrations of hydroxide, carbonate, and aluminate did occur during the course of the experiment. The greater changes occurred in solutions with fairly dilute concentrations of these species. In most cases, the aluminate concentration decreased and the carbonate concentration increased over time. These results are consistent with the precipitation of aluminum hydroxides and the absorption of atmospheric carbon dioxide which reacts with hydroxide to produce carbonate. The precipitation of aluminum hydroxide would release hydroxide into solution. in general, hydroxide concentrations decreased indicating that the amount of hydroxide released by the precipitation of aluminum hydroxides is less than that reacted with carbon dioxide to form carbonate. In two solutions (\#16 and \#18) the hydroxide concentrations increased during the test period.

\subsection{Comparison of the Expanded-Matrix and ITP-Matrix Results}

Exhibit 26 in the Appendix shows a plot of the uranium concentration versus the hydroxide concentration for both sets of experimental data: the expanded-matrix which is the current test and the ITP-matrix which is from reference [1]. The ITP set which covered the range of hydroxide concentrations from 0.3 molar to 2.0 molar 
are within the range of concentrations bounded by solutions in the expandedmatrix tests. For salt solutions having a hydroxide concentration ranging from 0.1 to 17 molar, the range of uranium solubilities is about a factor of 20 from 1.0 to 20 $\mathrm{mg} / \mathrm{L}$. At lower hydroxide concentrations, the solubility of uranium can vary by over 4 orders of magnitude, from 0.05 to $1600 \mathrm{mg} / \mathrm{L}$.

The full and reduced parameter models fitted to the initial and final solution parameters were used to calculate predicted uranium concentrations for the 20 test bottles in the previous solubility study [1]. Prediction and confidence intervals were also calculated. These results are presented in Exhibits 13-18.

With the exception of one test solution (Bottle \#1 compared against the full model and final factor levels), all of the measured results are within the prediction limits determined from the expanded matrix models. The lack of agreement between the predicted and measured values was highest for the bottles having solutions at low hydroxide concentration. In the ITP matrix study, the lowest hydroxide concentration tested was 0.5 molar. The expanded matrix study included much lower hydroxide concentrations (e. g., $1 \times 10^{-4}$ molar). Because of the generally higher uranium concentrations at low hydroxide concentrations, the expanded matrix model is weighted somewhat to higher uranium concentrations at lower hydroxide concentrations. In general, the uranium concentrations predicted using the expanded-matrix model based on initial factor levels are greater than those measured in the ITP-matrix study. Only three of the 20 ITP average measurements exceed the predictions based on the full model and initial factor levels. Six of the 20 values exceed the predictions based on the reduced model and initial factor levels. However, 9 of the 20 (nearly 50\%) exceed the predictions based on the full model and final factor levels.

\subsection{REFERENCES}

[1] D. T. Hobbs, T. B. Edwards, S. D. Fleischman, "Solubility of Plutonium and Uranium in Alkaline Salt Solutions (U)," WSRC-TR-93-056, February 12, 1993.

[2] J. Sutton, J.Chem. Soc, 1949, S275.

[3] C. A. Wamser, J. Belle, E. Bernsohn, and B. Williamson, J.Amer. Chem. Soc. 74, 1028 (1952).

[4] J. E. Ricci and F. J. Loprest, J.Amer. Chem. Soc, 77, 2119 (1955).

[5] D. G. Karraker, "Uranium Solubility Studies During Waste Evaporation (U)," WSRC-TR-93-433, August 16, 1993. 


\subsection{APPENDIX}

Table 1: Initial Measurements of Factor Levels

Table 2: $\quad$ Final Measurements of Factor Levels

Table 3: Uranium Concentrations by Bottle Number

Table 4: $\quad$ Summary of Descriptive Statistics for Uranium Solubilities by Bottlo

Table 5: Prediction and Confidence Intervals for Uranium Solubilities by Bottle for Full Model and Initial Levels of the Factors

Table 6: Prediction and Confidence Intervals for Uranium Solubilities by Bottle for Reduced Model and Initial Levels of the Factors

Table 7: Prediction and Confidence Intervals for Uranium Solubilities by Bottle for Full Model and Final Levels of the Factors

Table 8: Initial Levels of Factors for Previous Study

Table 9: Final Levels of Factors for Previous Study

Table 10: Prediction and Confidence Intervals for Previous Study's Uranium Solubilities by Bottle for Full Model and Initial Levels of the Factors

Table 11: Prediction and Confidence Intervals for Previous Study's Uranium Solubilities by Bottle for Reduced Model and Initial Levels of the Factors

Table 12: Prediction and Confidence Intervals for Previous Study's Uranium Solubilities by Bottle for Full Model and Final Levels of the Factors

Exhibit 1: Exf nental Design

Exhibit 2: Time Plots for Bottles Prepared From Solutions 1 - 8

Exhibit 3: Time Plots for Bottles Prepared From Solutions 9 - 16

Exhibit 4: Time Plots for Bottles Prepared From Solutions 17 - 19

Exhibit 5: Histogram and Descriptive Statistics for Uranium Solubilities for Bottles 1-12

Exhibit 6: Histogram and Descriptive Statistics for Uranium Solubilities for Bottles 13, 15, 16, 18-26 
Exhibit 7: Histogram and Descriptive Statistics for Uranium Solubilities for Bottles 27-38

Exhibit 8: Histogram and Descriptive Statistics for Uranium Solubilities for Bottles 39, 41-43, 45-48

Exhibit 9: Scatter Plot of Sample Averages versus Sample Standard Deviations of the Uranium Solubilities for the Sample Bottles

Exhibit 10: Analysis of Variance for the Full Model Using the Initial Levels of the Factors

Exhibit 11: Analysis of Variance for the Reduced Mod $\exists$ I Using the Initial Levels of the Factors

Exhibit 12: Analysis of Variance for the Full Model Using the Final Levels of the Factors

Exhibit 13: Plot of Confidence Intervals for Previous Study's Uranium Solubilities by Bottle Based on Full Model and Initial Levels of the Factors

Exhibit 14: Plot of Prediction Intervals for Previous Study's Uranium Solubilities by Bottle Based on Full Model and Initial Levels of the Factors

Exhibit 15: Plot of Confidence Intervals for Previous Study's Uranium Solubilities by Bottle Based on Reduced Model and Initial Levels of the Factors

Exhibit 16: Plot of Prediction Intervals for Previous Study's Uranium Solubilities by Bottle Based on Reduced Model and Initial Levels of the Factors

Exhibit 17: Plot of Confidence Intervals for Previous Study's Uranium Solubilities by Bottle Based on Full Model and Final Levels of the Factors

Exhibit 18: Plot of Prediction Intervals for Previous Study's Uranium Solubilities by Bottle Based on Full Model and Final Levels of the Factors

Exhibit 19: Uranium Concentration Versus Hydroxide Concentration

Exhibit 20: Uranium Concentration Versus Nitrate and Hydroxide Concentrations

Exhibit 21: Uranium Concentration Versus Nitrite and Hydroxide Concentrations 
Exhibit 22: Uranium Concentration Versus Carbonate and Hydroxide Concentrations

Exhibit 23: Uranium Concentration Versus Sulfate and Hydroxide Concentrations

Exhibit 24: Uranium Concentration Versus Aluminate and Hydroxide Concentrations

Exhibit 25: Predicted Uranium Concentration for Decreasing Nitrate/Nitrite and Hydroxide/Carbonate Ratios

Exhibit 26: Uranium Concentration Versls Hydroxide Concentration Expanded-Matrix and ITP-Matrix Solutions 


\section{Table 1: Initial Measurements of Factor Levels}

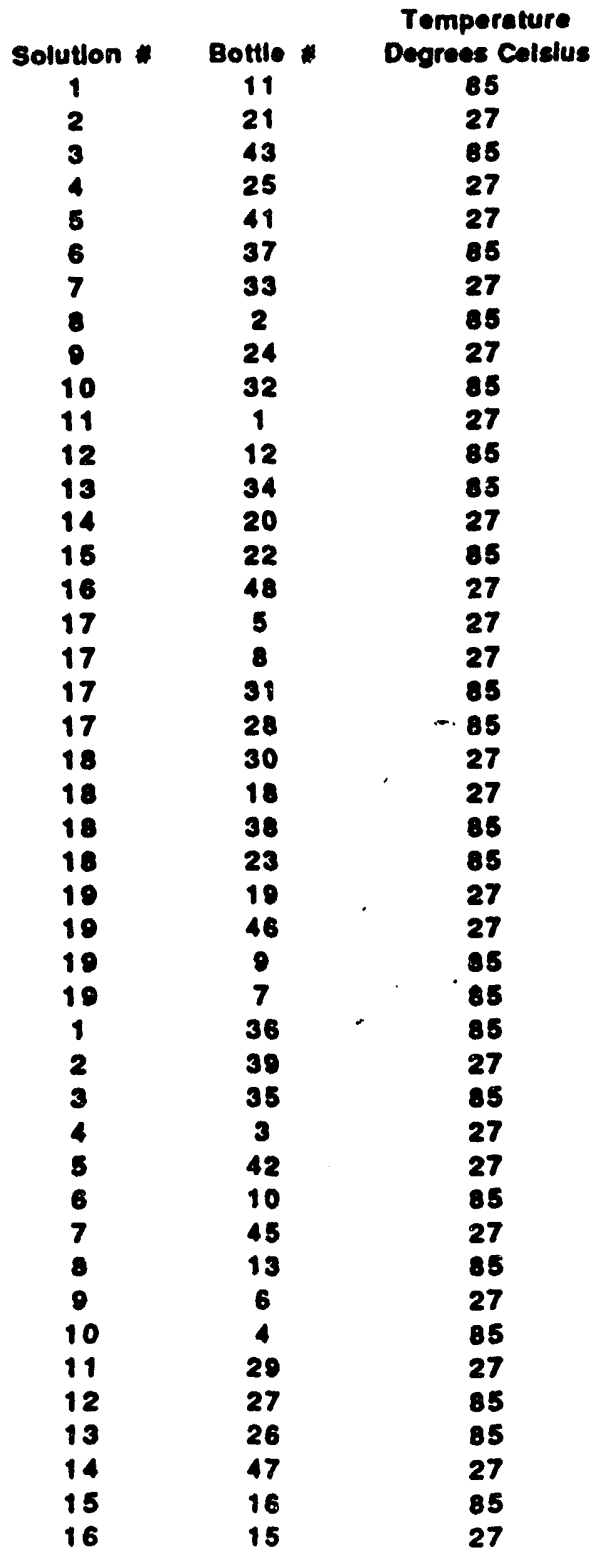

\begin{tabular}{|c|c|c|}
\hline $\begin{array}{r}\mathrm{OH} \\
2.72 E+00\end{array}$ & $\begin{array}{r}A 102 \\
1.02 E+00\end{array}$ & $\begin{array}{r}\infty 03 \\
3.32 E-01\end{array}$ \\
\hline $.38 E-04$ & 255E-04 & $1.95 E-03$ \\
\hline $\begin{array}{l}.50 E+00 \\
.25 E-02\end{array}$ & $\begin{array}{l}1.95 E+00 \\
3.48 E-04\end{array}$ & $\begin{array}{l}1.64 E-04 \\
0.03 E-01\end{array}$ \\
\hline $64 E+01$ & $1.00 E-03$ & 8.66E-05 \\
\hline 19E-03 & $3.87 E-04$ & 8.85E-01 \\
\hline $32 E+01$ & $9.61 E-04$ & $1.63 E-04$ \\
\hline 27E-04 & $5.38 E-04$ & 1.02E-03 \\
\hline i2E+01 & 4.11E-04 & 4.61E-05 \\
\hline Q1E-04 & 3.28E-04 & $1.43 E-03$ \\
\hline $38 E+01$ & $3.41 E-01$ & 4.13E-05 \\
\hline $38 E-01$ & 1.47E-01 & 9.61E-01 \\
\hline $\begin{array}{l}1 E+01 \\
0 O E-00\end{array}$ & $1.79 E-03$ & 4.76E-05 \\
\hline SAE+01 & $4.42 E-04$ & 5.11E-0S \\
\hline$\theta E-04$ & $3.17 E-04$ & $4.60 E-04$ \\
\hline D6E-01 & 2.04E-02 & 4.51E-02 \\
\hline 06E-01 & 2.04E-02 & 4.51E-02 \\
\hline O6E-01 & $2.04 E-02$ & 4.51E-02 \\
\hline D6E-01 & 2.04E-02 & 4.51E-02 \\
\hline S4E-0s & 2.88E-02 & 2.72E-04 \\
\hline SAE-OS & 2.89E-02 & 2.72E-04 \\
\hline $\begin{array}{l}3.54 E-03 \\
3.64 E-03\end{array}$ & $\begin{array}{l}2.08 E-02 \\
2.08 E-02\end{array}$ & $\begin{array}{l}2.72 E-04 \\
2.72 E-04\end{array}$ \\
\hline $1.18 E+00$ & $2.68 E-02$ & $4.48 E-02$ \\
\hline $0 E+00$ & 2.08E-02 & $4.48 E-02$ \\
\hline $9 E+00$ & $2.08 E-02$ & $4.48 E-02$ \\
\hline$E+\infty$ & 2.08E-02 & $4.48 E-02$ \\
\hline $12 E+\infty 0$ & $1.02 E+00$ & $3.32 E-01$ \\
\hline 1.38E-04 & 2.55E-04 & $1.95 E-03$ \\
\hline $1.25 E-02$ & $3.48 E-04$ & $0.93 E-01$ \\
\hline $1.64 E+01$ & $1.00 E-03$ & 8.68E-0S \\
\hline 4.18E-03 & $3.87 E-04$ & 8.85E-01 \\
\hline $1.52 E+01$ & $0.51 E-04$ & $1.53 E-04$ \\
\hline 1.27 E-04. & 5.38E-04 & $1.02 E-03$ \\
\hline $1.62 E+01$ & $4.11 E-04$ & 4.61E-05 \\
\hline 5.21E-04 & $3.28 E-04$ & $1.43 E-03$ \\
\hline E+01 & $3.41 E-01$ & 4.13E-05 \\
\hline E-01 & 1.47E-01 & 9.61E-01 \\
\hline 0 & 1.70E-03 & 4.76E-05 \\
\hline & 2.75E-04 & $9.18 E-01$ \\
\hline & 4.42E-04 & 5.11E-05 \\
\hline & $3.17 E-04$ & $4.69 E-04$ \\
\hline
\end{tabular}

\begin{tabular}{|c|c|}
\hline $\mathrm{NO3}$ & $1.78 E+C$ \\
\hline $\begin{array}{l}27 E+\infty \\
92 E+\infty\end{array}$ & $1.78 E+0$ \\
\hline $1.68 E+\infty 0$ & $1.09 E-0$ \\
\hline $.62 E+\infty$ & \\
\hline $0.75 E-02$ & 1.00 \\
\hline $.09 E+\infty 0$ & \\
\hline $3.28 E-02$ & 1.09 \\
\hline $.18 E+\infty 0$ & $1.09 E$ \\
\hline $1.21 E-03$ & \\
\hline 1.15E-02 & 3.47E+0 \\
\hline 5.81E-04 & \\
\hline 8.89E-04 & $1.33 E$ \\
\hline $0.26 E-\infty s$ & 9.7 \\
\hline 1.18E-02 & $3.32 E$ \\
\hline $1.08 E-03$ & $2.17 E$ \\
\hline 0.61E-04 & $9.82 E$ \\
\hline 8.21E-02 & 4.751 \\
\hline 8.21E-02 & $4.75 E$ \\
\hline 8.21E-02 & $4.75 E$ \\
\hline $8.21 E-02$ & $4.75 E$ \\
\hline B.5EE-02 & 5.45E \\
\hline 8.58E-02 & 5.45E \\
\hline $8.58 E-02$ & 5.485 \\
\hline O.58E-OR & \\
\hline 7.90E-02 & 5 \\
\hline 7.90E-02 & 6.28 \\
\hline 7.00E-02 & $\begin{array}{l}5.281 \\
8.281\end{array}$ \\
\hline $3.27 E+00$ & $1.78 E+C$ \\
\hline $4.92 E+\infty 0$ & 4.18E* \\
\hline $3.68 E+\infty 0$ & 1.008 \\
\hline $6.62 E+\infty$ & 1.08 \\
\hline $0.78 E-02$ & $1.09 E$ \\
\hline $4.09 E+\infty 0$ & $4.50 E$ \\
\hline 8.26E-02 & 1.005 \\
\hline $7.18 E+C$ & 1.09 \\
\hline $1.21 E$ & $6.46 !$ \\
\hline $1.15 E-$ & $3.47 E$ \\
\hline & \\
\hline 8.89 & \\
\hline 8.26 & \\
\hline 1.18 & 3.32E \\
\hline & \\
\hline & \\
\hline
\end{tabular}

SO4 1.83E-01 $1.38 E-01$ 2.60E-04 2.60E-04 2.60E-04 1.33E-03 $4.02 E-03$ 3.25E-01 Y.04E-04 Q.15E-04 $1.00 E-02$ 2.03E-01 4.42E-03 4.35E-01 5.21E-05 Q.65E-04 1.07E-02 1.07E-02 1.97E-02 1.97E-02 2.17E-02 2.17E-02 2.17E-02 2.17E-08 1.88E-02 1.80E-02 1.88E-02 1.88E-02 1.83E-01 1.30E-O 2.60E-04 2.60E-04 2.00E-04 1.33E-03 4.02E-03 3.25E-01 1.04E-OA 0.15E-04 1.00E-02 2.83E-01 4.42E-03 4.35E-01 5.21E-05 9.65E-04 
Table 2: Final Measurements of Factor Levels

\begin{tabular}{|c|c|c|}
\hline Solution * & $\begin{array}{c}\text { Bottle } \\
11\end{array}$ & $\begin{array}{c}\text { Temperature } \\
\text { Degrees Celsius } \\
85\end{array}$ \\
\hline 2 & 21 & 27 \\
\hline 3 & 43 & 85 \\
\hline 4 & 25 & 27 \\
\hline $\boldsymbol{6}$ & 41 & 27 \\
\hline 6 & 37 & 85 \\
\hline 7 & 33 & 27 \\
\hline 8 & 2 & 85 \\
\hline - & 24 & 27 \\
\hline 10 & 32 & 85 \\
\hline 11 & 1 & 27 \\
\hline 12 & 12 & 85 \\
\hline 13 & 34 & 86 \\
\hline 14 & 20 & 27 \\
\hline 15 & 22 & 85 \\
\hline 16 & 48 & 27 \\
\hline 17 & $\mathbf{5}$ & 27 \\
\hline 17 & 8 & 27 \\
\hline 17 & 31 & 85 \\
\hline 17 & 28 & 85 \\
\hline 18 & 30 & 27 \\
\hline 18 & 18 & 27 \\
\hline 18 & 38 & 85 \\
\hline 18 & 23 & 88 \\
\hline 10 & 19 & 27 \\
\hline 10 & 46 & 27 \\
\hline 10 & 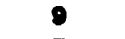 & 85 \\
\hline 10 & 7 & 85 \\
\hline 1 & 36 & 85 \\
\hline 2 & 38 & 27 \\
\hline 3 & 35 & 85 \\
\hline 4 & 3 & 27 \\
\hline 5 & 42 & 27 \\
\hline 6 & 10 & 85 \\
\hline 7 & 45 & 27 \\
\hline 8 & 13 & 85 \\
\hline$\theta$ & 6 & 27 \\
\hline 10 & 4 & 85 \\
\hline 11 & 29 & 27 \\
\hline 12 & 27 & 85 \\
\hline 13 & 26 & 85 \\
\hline 14 & 47 & 27 \\
\hline 15 & 16 & 85 \\
\hline 16 & 15 & 27 \\
\hline
\end{tabular}

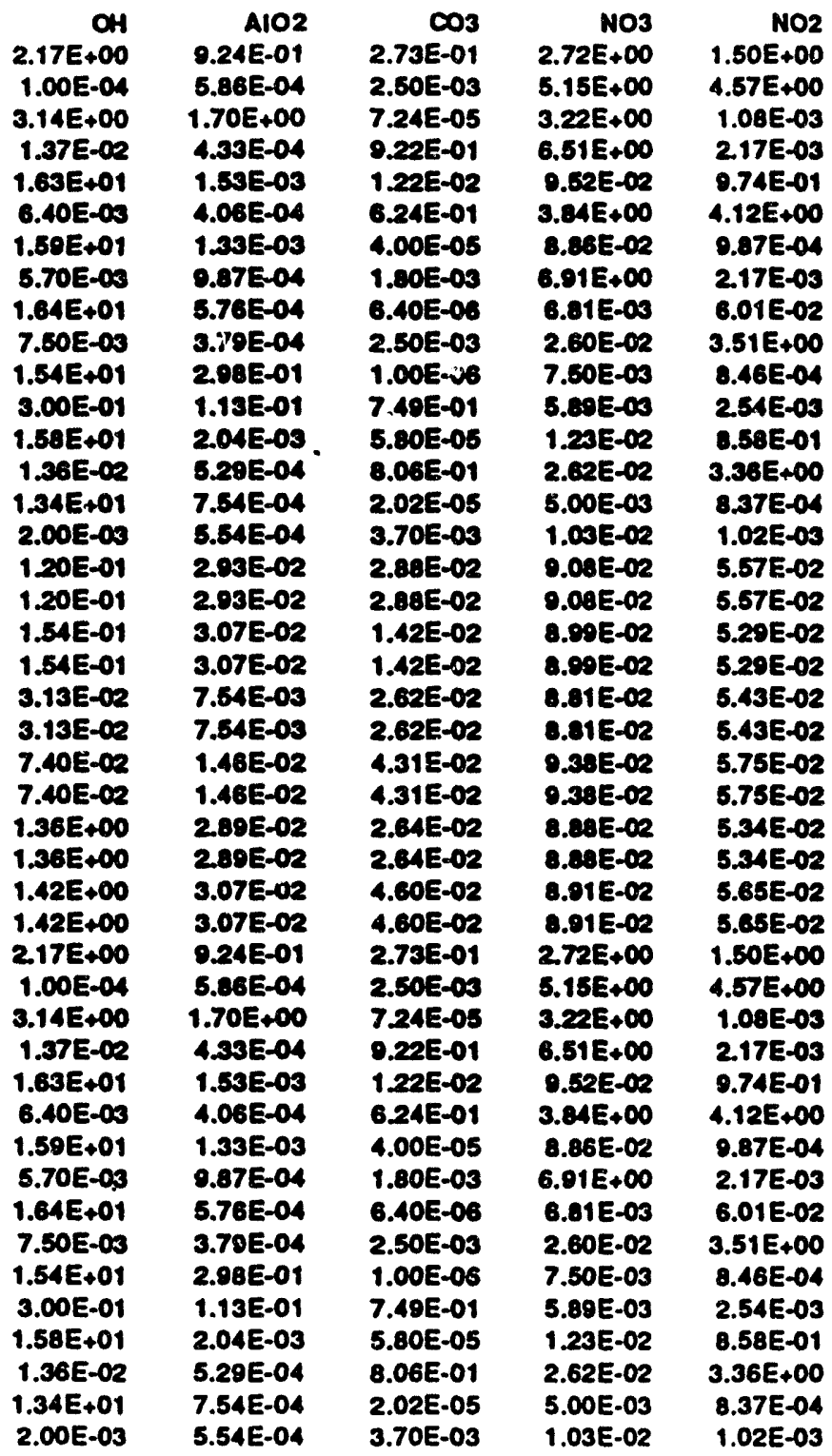

SO4 1.08E-01 $1.33 E-01$ 6.02E-04 $0.23 E-04$ 6.20E-04 1.03E-03 $1.83 E-03$ 3.22E-01 5.20E-04 8.72E-04 1.41E-02 4.96E-01 S.19E-0S 4.68E-01 5.20E-04 1.03E-03 2.19E-02 2.19E-02 2.12E-02 2.12E-02 2.14E-02 2.14E-02 2.25E-02 2.25E-02 $2.30 E-02$ 2.30E-02 2.10E-02 2.10E-02 1.08E-01 1.33E-01 6.02E-O4 $0.23 E-04$ 5.20E-04 1.03E-03 1.63E-03 3.22E-01 5.20E-04 8.72E-04 1.41E-02 4.86E-01 5.19E-03 4.68E-01 5.20E-04 1.03E-03 


\section{Table 3: Uranlum Concentrations by Bottle Number}

$$
\begin{array}{ll}
\text { CC } & \begin{array}{l}
\text { indicates measurement by Chemcheck method } \\
\text { indicates measurement by inductively coupled } \\
\text { ICP/asma-mass spectrometry }
\end{array}
\end{array}
$$

- represents missing value

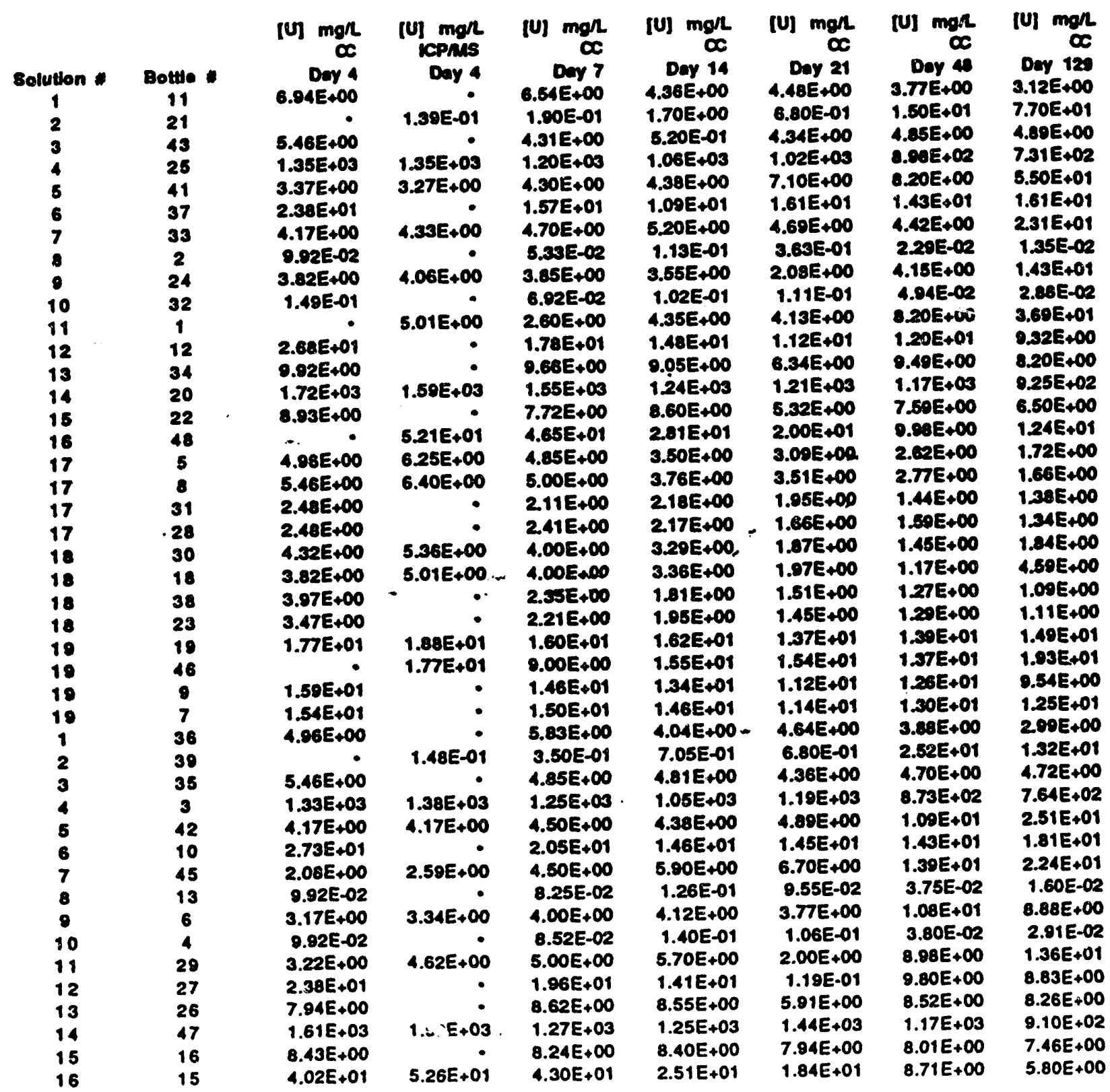


Table 4: Summary of Descriptive Statistics for Uranium Solubilities by Bottle

Average and standard deviation are computed from the $\log _{10}([\mathrm{U}] \mathrm{mg} / \mathrm{L})$ values for each bottle.

\begin{tabular}{|c|c|c|c|c|}
\hline Bottle : & Solution \# 11 & $\begin{array}{c}\text { Average } \\
0.8083\end{array}$ & $\begin{array}{l}\text { Std Dev } \\
0.4047\end{array}$ & $\begin{array}{r}\text { \% Rel S D } \\
50.1\end{array}$ \\
\hline $\begin{array}{l}1 \\
2\end{array}$ & $\begin{array}{r}11 \\
8\end{array}$ & $\begin{array}{r}0.8083 \\
-1.1956\end{array}$ & 0.5153 & $\begin{array}{l}50.1 \\
43.1\end{array}$ \\
\hline 3 & 4 & 3.0249 & 0.0963 & 3.2 \\
\hline 4 & 10 & -1.1430 & 0.2714 & 23.7 \\
\hline 5 & 17 & 0.5199 & 0.1850 & 35.6 \\
\hline 6 & 9 & 0.7146 & 0.2186 & 30.6 \\
\hline 7 & 19 & 1.1326 & 0.0515 & 4.5 \\
\hline 8 & 17 & 0.5423 & 0.1960 & 36.1 \\
\hline 9 & $: 19$ & 1.1037 & 0.0802 & 7.3 \\
\hline 10 & 6 & 1.2478 & 0.1119 & . 9.0 \\
\hline 11 & 1 & 0.6697 & 0.1353 & 20.2 \\
\hline 12 & 12 & 1.1578 & 0.1645 & 14.2 \\
\hline 13 & 8 & -1.2048 & 0.3408 & 28.3 \\
\hline 15 & 16 & 1.1773 & 0.3656 & 31.1 \\
\hline 16 & 15 & 0.9070 & 0.0198 & 2.2 \\
\hline-18 & 18 & 0.4656 & 0.2361 & 50.7 \\
\hline 19 & 19 & 1.1879 & 0.0468 & 3.9 \\
\hline 20 & 14 & 3.1032 & 0.0910 & 2.9 \\
\hline 21 & 2 & 0.2579 & 1.0843 & 420.5 \\
\hline 22 & 15 & 0.8653 & 0.0837 & 9.7 \\
\hline 23 & 18 & 0.2487 & 0.1811 & 72.8 \\
\hline 24 & 9 & 0.6371 & 0.2767 & 43.4 \\
\hline 25 & 4 & 3.0108 & 0.0939 & 3.1 \\
\hline 26 & 13 & 0.8977 & 0.0632 & 7.0 \\
\hline 27 & 12 & 0.8051 & 0.8635 & 107.2 \\
\hline 28 & 17 & 0.2769 & 0.1093 & 39.5 \\
\hline 29 & 11 & 0.7382 & 0.2893 & 39.2 \\
\hline 30 & 18 & 0.4166 & 0.2118 & 50.8 \\
\hline 31 & 17 & 0.2742 & 0.1028 & 37.5 \\
\hline 32 & 10 & -1.1299 & 0.2617 & 23.2 \\
\hline 33 & 7 & 0.7828 & 0.2861 & 36.5 \\
\hline 34 & 13 & 0.9386 & 0.0729 & 7.8 \\
\hline 35 & 3 & 0.6818 & 0.0317 & 4.7 \\
\hline 36 & 1 & 0.6331 & 0.1000 & 15.8 \\
\hline 37 & 6 & 1.1965 & 0.1092 & 9.1 \\
\hline 38 & 18 & 0.2580 & 0.2038 & 79.0 \\
\hline 39 & 2 & 0.1528 & 0.8974 & 587.2 \\
\hline 41 & 5 & 0.8836 & 0.4447 & 50.3 \\
\hline 42 & 5 & 0.8402 & 0.3155 & 37.5 \\
\hline 43 & 3 & 0.5167 & 0.3941 & 76.3 \\
\hline 45 & 7 & 0.8515 & 0.3511 & 41.2 \\
\hline 46 & 19 & 1.1671 & 0.1164 & 10.0 \\
\hline 47 & 14 & 3.0984 & 0.0838 & 2.7 \\
\hline 48 & 16 & 1.3711 & 0.2945 & 21.5 \\
\hline
\end{tabular}


Table 5: Prediction and Confidence Intervals for Uranlum Solubilities by Bottle for Full Model and Initial Levels of the Factors

Log [U] milligramentier at 4 days

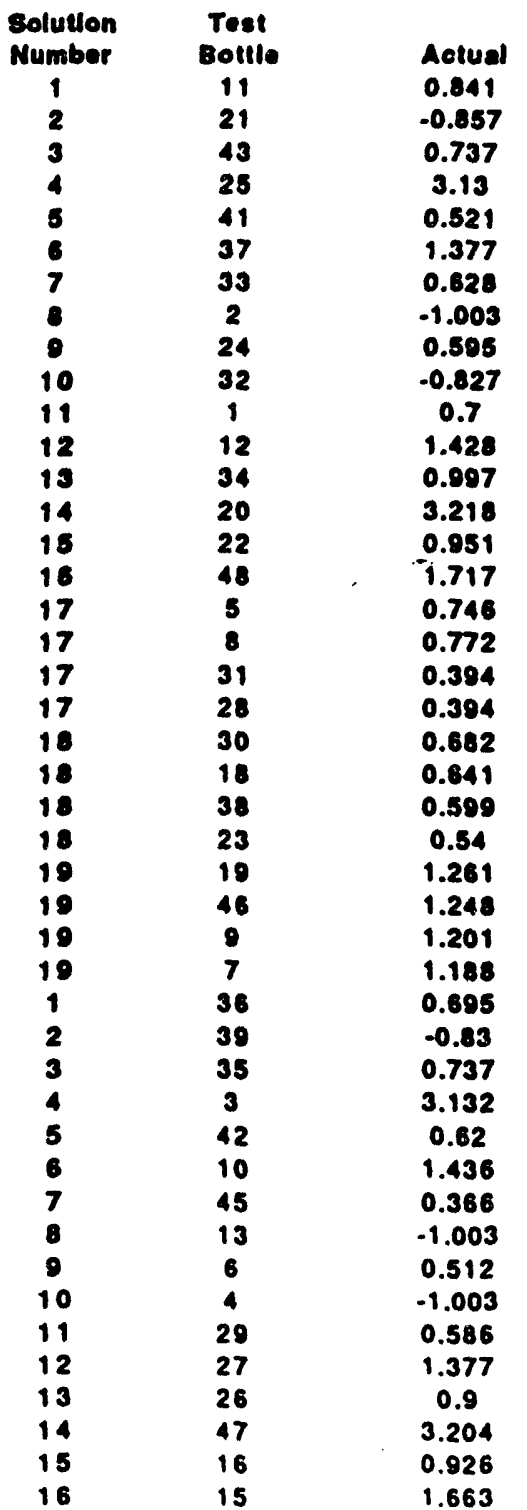

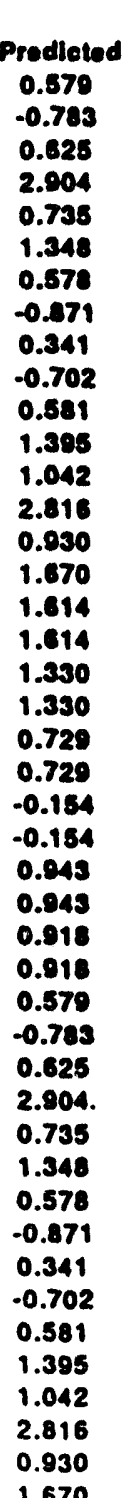

Os\% Confldenee Interval

Lower Limit Upper Umil 0.018

$-0.018$

.1 .418

$-0.028$

2.296

0.190

0.736

$-0.080$

$-1.818$

$-0.197$

$-1.352$

$-0.080$

0.749

0.413

2.184

0.284

1.015

1.312

1.312

0.002

0.092

0.182

0.182

0.04

$-0.641$

0.828

0.528

0.495

0.498

$-0.018$

$-1.418$

$-0.028$

2.286

0.199

0.736

$-0.069$

$-1.515$

$-0.197$

$-1.352$

.0 .069

0.749

0.413

2.184

0.284

1.015
1.174

$-0.147$

1.277

3.821

1.270

1.080

1.226

$-0.228$

0.880

$-0.051$

1.230

2.041

1.870

3.449

1.577

2.324

1.918

1.910

1.669

1.889

1.277

1.277

0.333

0.333

1.357

1.357

1.342

1.342

1.174

$-0.147$

1.277

3.521

1.271

1.960

1.226

$-0.228$

0.880

$-0.051$

1.230

2.041

1.670

3.449

1.577

2.324
95\% Predletion Interval

Lower Umit Upper Umit

$\begin{array}{ll}-0.525 & 1.883\end{array}$

$-1.000$

$-0.510 \quad 1.761$

1.788

$.0 .338 \quad 1.308$

$0.235 \quad 2.461$

$0.558 \quad 1.711$

$-2.002 \quad 0.280$

$-0.735$

$-1.836 \quad 0.433$

$-0.584 \quad 1.715$

$0.243 \quad 2.627$

$\begin{array}{cc}0.080 & 2.164\end{array}$

1.892

$\begin{array}{ll}-0.202 & 2.063\end{array}$

0.532

$0.638 \quad 2.591$

$0.638 \quad 2.691$

$0.341 \quad 2.320$

$0.341 \quad 2.320$

.0 .350

$-0.350 \quad 1.808$

$-1204$

-1.204 0.096

$-0.075 \quad 1.061$

$-0.075 \quad 1.061$

$-0.103 \quad 1.840$

$-0.103$

$-0.626 \quad 1.683$

$-1.009$

$-0.510 \quad 1.761$

$1.788 \quad 4.020$

$-0.338 \quad 1.908$

$0.235 \quad 2.461$

$0.555 \quad 1.711$

$-2.002 \quad 0.260$

$-0.733$

$-1.836 \quad 0.433$

$-0.554$

$0.263 \quad 2.527$

$-0.080 \quad 2.164$

1.692

$-0.202 \quad 2.063$

0.532 
Table 6: Predlctlon and Confldence Intervals for Uranium Solubillties by Bottle for Reduced Model and Initlal Levels of the Factors

Log (U] milligrameniter af 4 daya

\begin{tabular}{|c|c|c|}
\hline $\begin{array}{l}\text { Solution } \\
\text { Number }\end{array}$ & $\begin{array}{l}\text { Tost } \\
\text { Bottle }\end{array}$ & Aetua \\
\hline 1 & 11 & 0.041 \\
\hline 2 & 21 & .0 .057 \\
\hline 3 & 43 & 0.737 \\
\hline 4 & 25 & 3.13 \\
\hline 8 & 41 & 0.821 \\
\hline 6 & 37 & 1.377 \\
\hline 7 & 33 & 0.828 \\
\hline 8 & 2 & -1.003 \\
\hline 0 & 24 & 0.508 \\
\hline 10 & 32 & -0.027 \\
\hline 11 & 1 & 0.7 \\
\hline 12 & 12 & 1.428 \\
\hline 13 & 34 & 0.097 \\
\hline 14 & 20 & 3.218 \\
\hline 18 & 22 & 0.981 \\
\hline 16 & 48 & .7 .717 \\
\hline 17 & 5 & 0.746 \\
\hline 17 & 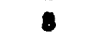 & 0.772 \\
\hline 17 & 31 & 0.394 \\
\hline 17 & 28 & 0.394 \\
\hline 18 & 30 & 0.082 \\
\hline 18 & 18 & 0.641 \\
\hline 18 & 38 & 0.809 \\
\hline 18 & 23 & 0.54 \\
\hline 19 & 10 & 1.261 \\
\hline 10 & 48 & 1.248 \\
\hline 10 & ๑ & 1.201 \\
\hline 10 & 7 & 1.188 \\
\hline 1 & 36 & 0.698 \\
\hline 2 & 39 & -0.03 \\
\hline 3 & 35 & 0.737 \\
\hline 4 & 3 & 3.132 \\
\hline 5 & 42 & 0.62 \\
\hline 6 & 10 & 1.436 \\
\hline 7 & 45 & 0.368 \\
\hline 8 & 13 & -1.008 \\
\hline 9 & 6 & 0.512 \\
\hline 10 & 4 & -1.008 \\
\hline 11 & 29 & 0.586 \\
\hline 12 & 27 & 1.377 \\
\hline 13 & 26 & 0.9 \\
\hline 14 & 47 & 3.204 \\
\hline 15 & 16 & 0.926 \\
\hline 16 & 15 & 1.663 \\
\hline
\end{tabular}

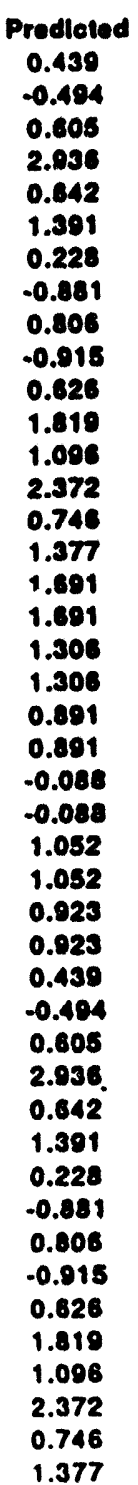

95\% Confidence interval Lower Umit Upper Limli $-0.093$ $-1.108$

0.121

2.412

0.204

0.871

$-0.183$

$-1.403$

0.442

$-1.403$

0.226

1.348

0.857

1.988

0.258

0.888

1.396

1.396

1.030

1.030

0.457

0.457

$-0.539$

$-0.539$

0.698

0.690

0.627

0.627

$-0.083$

$-1.108$

0.121

2.412

0.204

0.071

$-0.183$

$-1.493$

0.442

$-1.403$

0.226

1.348

0.557

1.968

0.258

0.858
95\% Predieflon Inlorval Lower Umll Upper LImlt

$\begin{array}{ll}-0.657 & 1.535\end{array}$

$-1.635 \quad 0.648$

$\begin{array}{rl}-0.474 & 1.883\end{array}$

$1.839 \quad 4.039$

$\begin{array}{ll}-0.418 & 1.701\end{array}$

$0.296 \quad 2.486$

$\begin{array}{ll}-0.820 & 1.270\end{array}$

$\begin{array}{ll}-2.023 & 0.260\end{array}$

$\begin{array}{rl}-0.224 & 1.038\end{array}$

$-1.098 \quad 0.165$

$\begin{array}{ll}-0.418 & 1.669\end{array}$

$0.748 \quad 2.891$

$\begin{array}{ll}-0.008 & 2.200\end{array}$

$1.327 \quad 3.417$

$-0.334 \quad 1.026$

$0.283 \quad 2.472$

$0.084 \quad 2.609$

$0.684 \quad 2.608$

$0.304 \quad 2.308$

$0.304 \quad 2.308$

$-0.188 \quad 1.048$

$.0 .168 \quad 1.048$

$\begin{array}{ll}-1.152 & 0.076\end{array}$

$-1.152 \quad 0.070$

$0.026 \quad 2.078$

0.0262 .078

$\begin{array}{ll}-0.025 & 1.031\end{array}$

$-0.085 \quad 1.031$

$-0.057 \quad 1.856$

$-1.038 \quad 0.848$

$-0.474 \quad 1.683$

$1.839 \quad 4.033$

$\begin{array}{ll}-0.416 & 1.701\end{array}$

$0.298 \quad 2.486$

$\begin{array}{ll}-0.820 & 1.276\end{array}$

$-2.023 \quad 0.260$

$-0.224 \quad 1.836$

$-1.095 \quad 0.165$

$\begin{array}{ll}-0.418 & 1.669\end{array}$

$0.746 \quad 2.891$

$\begin{array}{ll}0.008 & 2.200\end{array}$

$1.327 \quad 3.417$

$-0.334 \quad 1.826$

$0.283 \quad 2.472$ 


\section{Table 7: Prediction and Confidence Intervals for Uranium Solubilities by Bottle for Full Model and Final Levels of the Factors}

Log [U] milligramentiter at 129 days

\begin{tabular}{|c|c|c|}
\hline $\begin{array}{l}\text { Solution } \\
\text { Number }\end{array}$ & $\begin{array}{l}\text { Boltle } \\
\text { Number }\end{array}$ & Actual \\
\hline 1 & 11 & 0.494 \\
\hline 2 & 21 & 1.087 \\
\hline 3 & 43 & 0.689 \\
\hline 4 & 28 & 2.864 \\
\hline s & 41 & 1.740 \\
\hline 6 & 37 & 1.207 \\
\hline 7 & 33 & 1.384 \\
\hline 8 & 2 & -1.870 \\
\hline 9 & 24 & 1.158 \\
\hline 10 & 32 & $-1.84 i$ \\
\hline 11 & 1 & 1.567 \\
\hline 12 & 12 & 0.980 \\
\hline 13 & 34 & 0.914 \\
\hline 14 & 20 & 2.968 \\
\hline 18 & 22 & 0.813 \\
\hline 16 & 48 & 1.093 \\
\hline 17 & 8 & 0.236 \\
\hline 17 & 8 & 0.220 \\
\hline 17 & 31 & 0.140 \\
\hline 17 & 28 & 0.127 \\
\hline 18 & 30 & 0.265 \\
\hline 18 & 10 & 0.662 \\
\hline 18 & 38 & 0.037 \\
\hline 18 & 23 & 0.045 \\
\hline 19 & 10 & 1.173 \\
\hline 10 & 46 & 1.286 \\
\hline 10 & $\bullet$ & 0.980 \\
\hline 10 & 7 & 1.097 \\
\hline 1 & 36 & 0.476 \\
\hline 2 & 39 & 1.121 \\
\hline 3 & 35 & 0.674 \\
\hline 4 & 3 & 2.883 \\
\hline 5 & 42 & 1.400 \\
\hline 6 & 10 & 1.258 \\
\hline 7 & 45 & 1.350 \\
\hline 8 & 13 & $\cdot 1.796$ \\
\hline 9 & 6 & 0.948 \\
\hline 10 & 4 & -1.536 \\
\hline 11 & 29 & 1.134 \\
\hline 12 & 27 & 0.946 \\
\hline 13 & 26 & 0.917 \\
\hline 14 & 47 & 2.959 \\
\hline 15 & 16 & 0.873 \\
\hline 16 & 13 & 0.763 \\
\hline
\end{tabular}

\begin{tabular}{c} 
Predloted \\
0.518 \\
1.442 \\
0.802 \\
2.772 \\
1.585 \\
1.358 \\
1.344 \\
-1.709 \\
1.004 \\
-1.396 \\
1.265 \\
1.262 \\
1.086 \\
2.077 \\
0.094 \\
0.071 \\
0.581 \\
0.581 \\
-0.466 \\
-0.466 \\
0.835 \\
0.833 \\
-0.190 \\
-0.190 \\
1.143 \\
1.143 \\
0.029 \\
0.029 \\
0.518 \\
1.442 \\
0.802 \\
2.772 \\
1.585 \\
1.358 \\
1.344 \\
-1.709 \\
1.004 \\
-1.396 \\
1.265 \\
1.262 \\
1.056 \\
2.877 \\
0.894 \\
0.871 \\
\hline
\end{tabular}

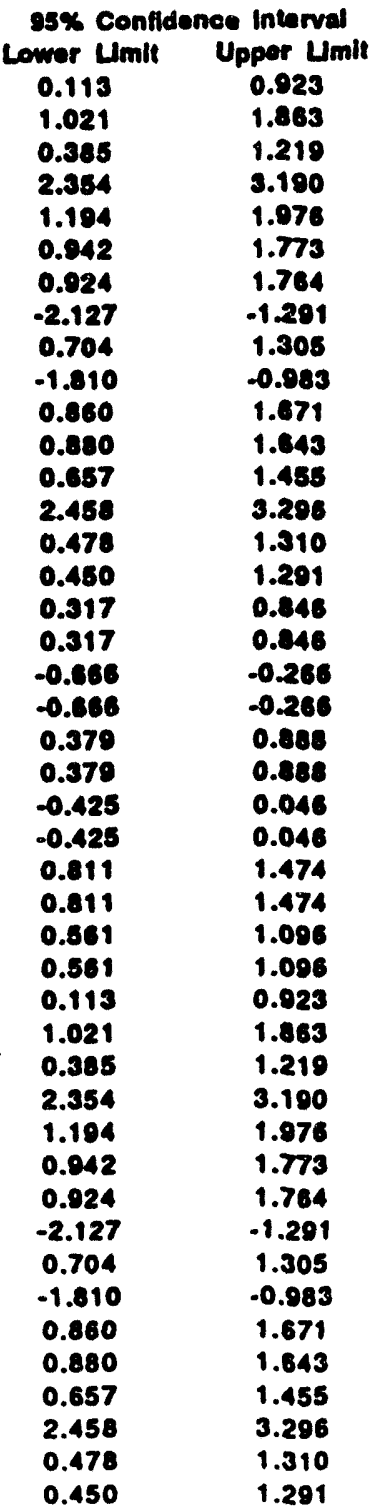

95\% Prediction Interval

Lower Umit Upper Umit

$\begin{array}{ll}-0.203 & 1.240\end{array}$

$0.712 \quad 2.173$

$0.074 \quad 1.631$

$2.043 \quad 3.801$

$0.871 \quad 2.290$

$0.630 \quad 2.085$

$0.614 \quad 2.074$

$-2.438 \quad-0.080$

$0.336 \quad 1.673$

$\begin{array}{ll}-2.123 & -0.670\end{array}$

$0.543 \quad 1.987$

$0.583 \quad 1.970$

$0.338 \quad 1.775$

$2.148 \quad 3.607$

$0.166 \quad 1.622$

$0.140 \quad 1.601$

$\begin{array}{ll}-0.072 & 1.235\end{array}$

$-0.072 \quad 1.235$

$-1.096 \quad 0.164$

$-1.096 \quad 0.184$

$-0.018 \quad 1.283$

$-0.018 \quad 1.229$

$\begin{array}{ll}-0.832 & 0.452\end{array}$

$\begin{array}{ll}-0.832 & 0.452\end{array}$

$0.460 \quad 1.028$

$0.460 \quad 1.826$

$0.174 \quad 1.483$

$0.174 \quad 1.489$

$\begin{array}{ll}-0.203 & 1.240\end{array}$

$0.712 \quad 2.173$

$0.074 \quad 1.531$

$2.043 \quad 3.501$

$\begin{array}{ll}0.071 & 2.208\end{array}$

$0.630 \quad 2.085$

$0.614 \quad 2.074$

$-2.438 \quad-0.080$

$0.336 \quad 1.673$

$\begin{array}{ll}-2.123 & -0.670\end{array}$

$0.543 \quad 1.987$

$\begin{array}{ll}0.553 & 1.970\end{array}$

$0.338 \quad 1.775$

$2.148 \quad 3.607$

$0.166 \quad 1.622$

$0.140 \quad 1.601$ 


\section{Table 8: Initial Levels of Factors for Previous Study}

Tompercture

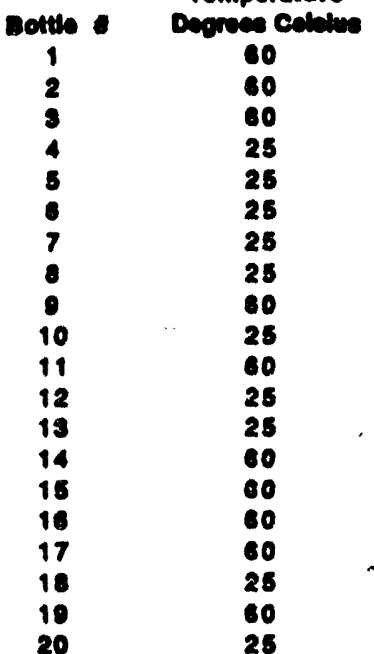

Ceneanxraton in moleanter

01
$1.07 E+00$
$1.30 E+00$
$1.20 E+00$
$1.30 E+00$
$5.67 E+01$
$8.12 E+01$
$1.07 E+00$
$2.07 E+00$
$2.04 E+00$
$5.40 E-01$
$2.00 E+00$
$4.22 E-01$
$1.30 E+00$
$1.44 E+00$
$4.07 E-01$
$3.20 E-01$
$5.02 E-01$
$4.05 E-01$
$4.06 E-01$
$1.08 E+00$

402 8.245-09 1.2AE-01 1.SAE-OT 1.04E-O1 3.SIE-01 3.01E-01 $3.30 \mathrm{E}-01$ $3.31 E-01$ 6.29E-02 $3.2 E-01$ 3.34E-01 $7.60 \mathrm{E}-02$ 1.04E-O1 $2.205-01$ 8.03E-02 6.17E-02 3.4501 6.07E-02 3.37E-01 6.20E-02

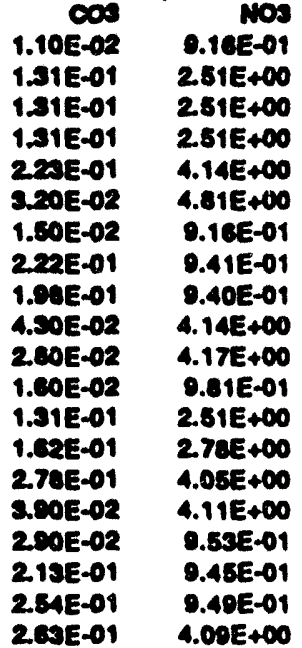

Awernes [U] men Owe AN

804 4.07E-01 2.07E-01

207E-01 207E-01 1.00E-02 1.02502 3.82E-01 1.00E-02

2.16E-02 3.84E 01 1.70E-02 $2.50 E-02$ 2.07E-O 2.72E-01 2.18E-02 3.exE-01 2.04E.02 3.eAE 01 a.erE-01 4.12E-01
Chemelied Values

7.11

3.05

3.68

3.24

3.75

4.98

9.89

4.98

0.87

2.07

4.84

3.60

3.27

3.10

1.37

3.08

2.01

2.28

4.08

4.28 
Table 9: Final Levels of Factors for Previous Study

\begin{tabular}{|c|c|c|}
\hline $\begin{array}{c}\text { Botelo } \\
1\end{array}$ & $\begin{array}{c}\text { Tomperature } \\
\text { Deorees Celolus } \\
60\end{array}$ & $\begin{array}{r}\mathrm{CH} \\
2.16 E+00\end{array}$ \\
\hline 2 & 60 & $1.34 E+\infty 0$ \\
\hline 3 & 60 & $1.38 E+00$ \\
\hline 4 & 25 & $1.30 E+00$ \\
\hline 5 & 25 & 8.23E-01 \\
\hline 6 & 25 & $1.01 E+\infty 0$ \\
\hline 7 & 25 & $2.21 E+\infty 0$ \\
\hline - & 25 & $2.27 E+\infty 0$ \\
\hline - & 60 & $2.1 \pi E+\infty 0$ \\
\hline 10 & 25 & 7.50E-01 \\
\hline 11 & 60 & $2.18 E+00$ \\
\hline 12 & 25 & 4.42E-01 \\
\hline 13 & 25 & $1.30 E+\infty 0$ \\
\hline 14 & 60 & $1.80 E+\infty 0$ \\
\hline 15 & 80 & $5.24 E-01$ \\
\hline 16 & 80 & 3.53E-01 \\
\hline 17 & 60 & 7.22E-01 \\
\hline 18 & 25 & S.74E-01 \\
\hline 10 & 60 & 7.5AE-01 \\
\hline 20 & 25 & $2.20 E+\infty 0$ \\
\hline
\end{tabular}

Conoentration in moteanter

ANO2
$4.49 E-02$
$1.57 E-01$
$6.95 E-02$
$1.00 E-01$
$1.23 E-01$
$2.00 E-01$
$2.76 E-01$
$2.91 E-01$
$3.08 E-02$
$1.60 E-01$
$3.03 E-01$
$6.62 E-02$
$1.07 E-01$
$2.25 E-01$
$5.16 E-02$
$4.02 E-02$
$2.05 E-01$
$4.96 E-02$
$2.04 E-01$
$4.00 E-02$

nos

Q.86E-01

$2.08 E+00$

$2.67 E+\infty 0$

$2.74 E+00$

$4.40 E+00$

$4.05 E+00$

$1.00 E+00$

9.62E-01

$0.44 E-01$

$4.00 E+\infty 0$

$4.26 E+00$

$1.00 E+\infty 0$

$2.51 E+00$

$2.73 E+00$

$4.12 E+00$

$20 \pi E+\infty$

Q.36E-01

Q.32E-01

$0.00 E-01$

$4.02 E+00$

$N O 2$
$2.04 E+00$
$1.04 E+00$
$1.04 E+00$
$1.06 E+00$
$0.60 E-02$
$1.91 E+00$
$1.08 E-01$
$1.95 E+00$
$1.61 E-02$
$1.04 E+00$
$1.05 E-01$
$0.41 E-02$
$0.90 E-01$
$1.30 E+00$
$1.96 E+00$
$0.57 E-02$
$1.01 E+00$
$1.02 E+00$
$9.50 E-02$
$0.00 E-02$

Average [U] mal Over All 804 4.00E-01 2.15E-01 2.12E-01 2.50E-01 2.17E-01 1.75E-01 3.71E-01 2.10E-02 2.00E-02 3. $62 E-01$ 2.31E-02 2.01E-02 2.20E-01 2.74E-01 1.90E-02 3.00E-01 2.08E-02 3.04E-01 $4.025-01$ 3.e8E-01
Chemencete Values 
Table 10: Prediction and Confidence Intervals for Previous Study's Uranium Solubilities by Bottle for Full Model and Initial Levels of the Factors

$\begin{array}{cc}\begin{array}{c}\text { Previous } \\ \text { Test }\end{array} & \\ \text { Bottle } & \text { Astual } \\ 1 & 0.852 \\ 2 & 0.484 \\ 3 & 0.548 \\ 4 & 0.523 \\ 5 & 0.572 \\ 6 & 0.641 \\ 7 & 0.995 \\ 8 & 0.688 \\ 9 & 0.843 \\ 10 & 0.458 \\ 11 & 0.857 \\ 12 & 0.568 \\ 13 & 0.513 \\ 14 & 0.504 \\ 15 & 0.136 \\ 16 & 0.484 \\ 17 & 0.464 \\ 18 & 0.348 \\ 10 & 0.611 \\ 20 & 0.631\end{array}$

Averege Log [U] milligramantiter for Provious Toet

Predicted
1.373
1.043
1.043
1.050
0.003
1.161
0.085
0.452
0.600
1.467
0.756
1.429
1.050
1.013
1.255
1.632
1.061
1.497
1.127
0.881

95\% Confidence Interval Lower Lumit Upper Umit

0.663

0.557

0.557

0.507

0.478

0.498

0.482

$-0.193$

0.133

0.786

0.350

0.000

0.507

0.496

0.720

0.908

0.687

1.002

0.745

0.264
95\% Predietion Interval

Lower Uimit Upper Umit

$0.203 \quad 2.543$

$\begin{array}{ll}-0.006 & 2.082\end{array}$

$-0.006 \quad 2.092$

$-0.028 \quad 2.127$

$\begin{array}{ll}-0.070 & 2.055\end{array}$

$0.019 \quad 2.303$

$-0.072 \quad 2.042$

$\begin{array}{ll}-0.679 & 1.584\end{array}$

$-0.447 \quad 1.624$

0.3142 .610

$-0.255 \quad 1.767$

$0.405 \quad 2.454$

$-0.026 \quad 2.127$

$-0.051 \quad 2.076$

$0.188 \quad 2.328$

$0.506 \quad 2.758$

$0.008 \quad 2.078$

$0.444 \quad 2.551$

$0.122 \quad 2.132$

$\begin{array}{ll}-0.235 & 1.097\end{array}$ 
Table 11: Prediction and Confldence Intervals for Previous Study's Uranium Solubllities by Bottle for Reduced Model and Initial Levels of the Factors

$\begin{array}{cc}\begin{array}{c}\text { Previous } \\ \text { Test }\end{array} & \\ \text { Bottle } & \text { Actual } \\ 1 & 0.852 \\ 2 & 0.484 \\ 3 & 0.548 \\ 4 & 0.523 \\ 5 & 0.572 \\ 6 & 0.641 \\ 7 & 0.905 \\ 8 & 0.688 \\ 0 & 0.843 \\ 10 & 0.458 \\ 11 & 0.657 \\ 12 & 0.568 \\ 13 & 0.513 \\ 14 & 0.504 \\ 15 & 0.136 \\ 16 & 0.484 \\ 17 & 0.464 \\ 18 & 0.348 \\ 19 & 0.611 \\ 20 & 0.631\end{array}$

Avorage Log [U] milligramanicar for Provious Tost

\begin{tabular}{|c|c|c|c|c|}
\hline \multirow{3}{*}{$\begin{array}{l}\text { Predieted } \\
0.762\end{array}$} & \multicolumn{2}{|c|}{ \$5\% Confidence Intarval } & \multicolumn{2}{|c|}{ 85\% Prediction Interval } \\
\hline & Lowor Lmit & Upper Umit & Lower Umit & Upper Umil \\
\hline & 0.400 & 1.116 & -0.264 & 1.780 \\
\hline 0.768 & 0.383 & 1.155 & -0.260 & 1.807 \\
\hline 0.769 & 0.383 & 1.185 & -0.269 & 1.807 \\
\hline 0.839 & 0.376 & 1.302 & -0.230 & 1.808 \\
\hline 1.192 & 0.771 & 1.613 & 0.141 & 2.244 \\
\hline 0.980 & 0.542 & 1.435 & -0.073 & 2.051 \\
\hline 0.744 & 0.340 & 1.130 & -0.288 & 1.785 \\
\hline 0.670 & 0.147 & 1.193 & -0.427 & 1.768 \\
\hline 0.607 & 0.185 & 1.029 & -0.446 & 1.650 \\
\hline 1.130 & 0.697 & 1.562 & 0.073 & 2.186 \\
\hline 0.500 & 0.220 & 0.980 & -0.442 & 1.622 \\
\hline 1.285 & 0.916 & 1.653 & 0.258 & 2.316 \\
\hline 0.830 & 0.376 & 1.302 & -0.220 & 1.008 \\
\hline 0.726 & 0.318 & 1.138 & -0.320 & 1.772 \\
\hline 1.060 & 0.604 & 1.428 & 0.029 & 2.090 \\
\hline 1.132 & 0.795 & 1.470 & 0.111 & 2.153 \\
\hline 1.034 & 0.697 & 1.371 & 0.013 & 2.054 \\
\hline 1.284 & 0.885 & 1.683 & 0.241 & 2.327 \\
\hline 1.178 & 0.876 & 1.481 & 0.168 & 2.188 \\
\hline 0.5 & 0.033 & 1.115 & -0.531 & 1.670 \\
\hline
\end{tabular}




\section{Table 12: Prediction and Confldence Intervals for Previous Study's Uranium Solubilities by Bottle for Full Model and Final Levels of the Factors}

$\begin{array}{lc}\text { Actual } & \text { Predictiod } \\ 0.852 & 0.261 \\ 0.484 & 0.452 \\ 0.548 & 0.453 \\ 0.524 & 0.672 \\ 0.572 & 1.115 \\ 0.642 & 0.103 \\ 0.995 & 1.037 \\ 0.688 & 1.228 \\ 0.843 & 1.328 \\ 0.458 & -0.037 \\ 0.657 & 0.754 \\ 0.567 & 0.497 \\ 0.515 & 0.718 \\ 0.504 & 0.454 \\ 0.137 & 0.364 \\ 0.484 & -0.179 \\ 0.464 & -0.066 \\ 0.348 & 0.848 \\ 0.611 & 0.845 \\ 0.631 & 1.214\end{array}$

Avernge Log [U] milligramantier for Provious Teat

95\% Confidence Interval

Lower Limit Upper Lmit $-0.266$

0.033

$-0.008$

0.203

0.690

$-0.481$

0.585

0.888

1.034

$-0.642$

0.445

0.167

0.267

0.019

$-0.088$

$-0.671$

$-0.416$

0.410

0.818

0.617
Upper Umit

0.871

0.910

1.141

1.540

0.667

1.488

1.507

1.623

0.567

1.063

0.827

1.170

0.880

0.798

0.314

0.283

1.285

1.175

1.812
95\% Prediction Intorval

Lower Umit Upper Umit

$-0.620 \quad 1.051$

$-0.277 \quad 1.182$

$-0.300 \quad 1.205$

$\begin{array}{ll}-0.087 & 1.431\end{array}$

$0.382 \quad 1.848$

$\begin{array}{ll}-0.718 & 0.025\end{array}$

$0.288 \quad 1.785$

$0.526 \quad 1.930$

$0.662 \quad 1.094$

$\begin{array}{ll}-0.887 & 0.813\end{array}$

$0.081 \quad 1.426$

$\begin{array}{ll}-0.185 & 1.180\end{array}$

$-0.080 \quad 1.467$

$-0.285 \quad 1.193$

$-0.373 \quad 1.101$

$-0.053 \quad 0.596$

$-0.758 \quad 0.626$

$0.107 \quad 1.588$

$0.163 \quad 1.628$

$\begin{array}{ll}0.370 & 2.050\end{array}$ 


\section{Exhibit 1: Experimental Design}

Lovels of Factore in Molca

\begin{tabular}{|c|c|c|c|c|c|}
\hline $\begin{array}{c}1 \\
\text { Hodroxide }\end{array}$ & $\begin{array}{c}2 \\
\text { Nitulte }\end{array}$ & $\begin{array}{c}3 \\
\text { Numinate }\end{array}$ & Nitrale & $\begin{array}{c}5 \\
\text { Carbonate }\end{array}$ & $\begin{array}{c}7 \\
\operatorname{Ten}(C)\end{array}$ \\
\hline $\begin{array}{l}0.001 \\
0.011\end{array}$ & 0.001 & 0.001 & 0.001 & 0.001 & 0.001 Poom Temp \\
\hline $\begin{array}{l}0.122 \\
1.355\end{array}$ & 0.050 & 0.045 & 0.071 & 0.028 & 0.022 \\
\hline 16.000 & 3.500 & 2.000 & 5.000 & 0.800 & 0.500 \\
\hline
\end{tabular}

Lovele of Factors in Loendols)

\begin{tabular}{|c|c|c|c|c|c|c|}
\hline $\begin{array}{l}\text { Factor } \\
\text { Lenels }\end{array}$ & Andoxids & 2 & $\begin{array}{c}3 \\
\text { Auminace } \\
\end{array}$ & Ninges & $\begin{array}{c}6 \\
\text { Centenate }\end{array}$ & $\begin{array}{cc}8 & 7 \\
\text { Sutface } & \operatorname{Tan}(0) \\
\end{array}$ \\
\hline $\begin{array}{r}-1 \\
-0.5\end{array}$ & $\begin{array}{l}-8.00 \\
-1.06\end{array}$ & -8.00 & -3.00 & -3.00 & -3.00 & -8.00 Poem Tenp \\
\hline $\begin{array}{r}0 \\
0.5\end{array}$ & $\begin{array}{r}-0.91 \\
0.13\end{array}$ & -1.23 & -1.35 & -1.15 & -1.85 & -1.86 \\
\hline 1 & 1.98 & 0.54 & 0.30 & 0.70 & -0.10 & -0.30 \\
\hline
\end{tabular}

Experimental Units

\begin{tabular}{|c|c|c|c|c|c|c|c|c|}
\hline $\begin{array}{c}\sin \\
1\end{array}$ & $\begin{array}{l}\text { Epp } \\
\text { Units }\end{array}$ & 1 & 2 & $\begin{array}{c}3 \\
\text { Aluminale }\end{array}$ & Nitres & $\begin{array}{c}5 \\
\text { Centoonate }\end{array}$ & $\begin{array}{c}6 \\
\text { Suffate }\end{array}$ & $\begin{array}{c}7 \\
\operatorname{Tem}(G)\end{array}$ \\
\hline 1 & 1 & 1 & 1 & 1 & 1 & 1 & 1 & 1 \\
\hline 2 & 2 & -1 & 1 & 1 & 1 & -1 & 8 & -1 \\
\hline 3 & 3 & 1 & -1 & 1 & 1 & -1 & -1 & 1 \\
\hline 4 & 4 & -1 & -1 & 1 & 1 & 1 & -1 & -1 \\
\hline s & 5 & 1 & 1 & -1 & 1 & -1 & .1 & -1 \\
\hline 6) & 6 & -1 & 1 & -1 & 1 & 1 & -1 & 1 \\
\hline 7 & 7 & 1 & -1 & -1 & 1 & 1 & 1 & -1 \\
\hline 이 & 8 & -1 & -1 & -1 & 1 & -1 & 1 & 1 \\
\hline o) & 9 & 1 & 1 & 1 & -1 & 1 & -1 & -1 \\
\hline 10 & 10 & -1 & 1 & 1 & -1 & -1 & -1 & 1 \\
\hline 11 & 11 & 1 & -1 & 1 & -1 & -1 & 1 & -1 \\
\hline 12 & 12 & -1 & -1 & 1 & -1 & 1 & 1 & 1 \\
\hline 13 & 13 & 1 & 1 & -1 & -1 & -1 & 1 & 1 \\
\hline 14 & 14 & -1 & 1 & -1 & -1 & 1 & 1 & -1 \\
\hline 15 & 15 & 1 & -1 & -1 & -1 & 1 & -1 & 1 \\
\hline 16 & 18 & -1 & -1 & -1 & -1 & -1 & -1 & -1 \\
\hline 17 & 17 & 0 & 0 & 0 & 0 & 0 & 0 & -1 \\
\hline 17 & 18 & 0 & 0 & 0 & 0 & 0 & 0 & -1 \\
\hline 17 & 10 & 0 & 0 & 0 & 0 & 0 & 0 & 1 \\
\hline 17 & 20 & 0 & 0 & 0 & 0 & 0 & 0 & 1 \\
\hline 18 & 21 & -0.5 & 0 & 0 & 0 & 0 & 0 & -1 \\
\hline 18 & 22 & -0.5 & 0 & 0 & 0 & 0 & 0 & -1 \\
\hline 18 & 23 & -0.5 & 0 & 0 & 0 & 0 & 0 & 1 \\
\hline 18 & 24 & -0.5 & 0 & 0 & 0 & 0 & 0 & 1 \\
\hline 10 & 25 & 0.5 & 0 & 0 & 0 & 0 & 0 & -1 \\
\hline 10 & 28 & 0.5 & 0 & 0 & 0 & 0 & 0 & -1 \\
\hline 10 & 27 & 0.5 & 0 & 0 & 0 & 0 & 0 & 1 \\
\hline 18 & 28 & 0.5 & 0 & 0 & 0 & 0 & 0 & 1 \\
\hline 1 & 20 & 1 & 1 & 1 & 1 & 1 & 1 & 1 \\
\hline 2 & 30 & -1 & 1 & 1 & 1 & -1 & 1 & -1 \\
\hline 3 & 31 & 1 & -1 & 1 & 1 & -1 & -1 & 1 \\
\hline 4 & 32 & -1 & -1 & 1 & 1 & 1 & -1 & -1 \\
\hline 5 & 33 & 1 & 1 & -1 & 1 & -1 & -1 & -1 \\
\hline 6 & 34 & -1 & 1 & -1 & 1 & 1 & -1 & 1 \\
\hline 7 & 35 & 1 & -1 & -1 & 1 & 1 & 1 & -1 \\
\hline 8) & 36 & -1 & -1 & -1 & 1 & -1 & 1 & 1 \\
\hline 9 & 37 & 1 & 1 & 1 & -1 & 1 & -1 & -1 \\
\hline 10 & 38 & -1 & 1 & 1 & -1 & -1 & -1 & 1 \\
\hline 11 & 39 & 1 & -1 & 1 & -1 & -1 & 1 & -1 \\
\hline 12 & 40 & -1 & -1 & 1 & -1 & 1 & 1 & 1 \\
\hline 13 & 41 & 1 & 1 & -1 & -1 & -1 & 1 & 1 \\
\hline 14 & 42 & .1 & 1 & -1 & -1 & 1 & 1 & -1 \\
\hline 15 & 43 & 1 & -1 & -1 & -1 & 1 & -1 & 1 \\
\hline 16] & 44 & -1 & -1 & -1 & -1 & -1 & -1 & -1 \\
\hline
\end{tabular}




\section{Exhibit 2: Time Plots for Bottles Prepared From Solutions 1 - 8}

$Y$ Axis is $\log _{10}([\mathrm{U}] \mathrm{mg} / \mathrm{L})$

Solutions: 1 and 2

5 and 6

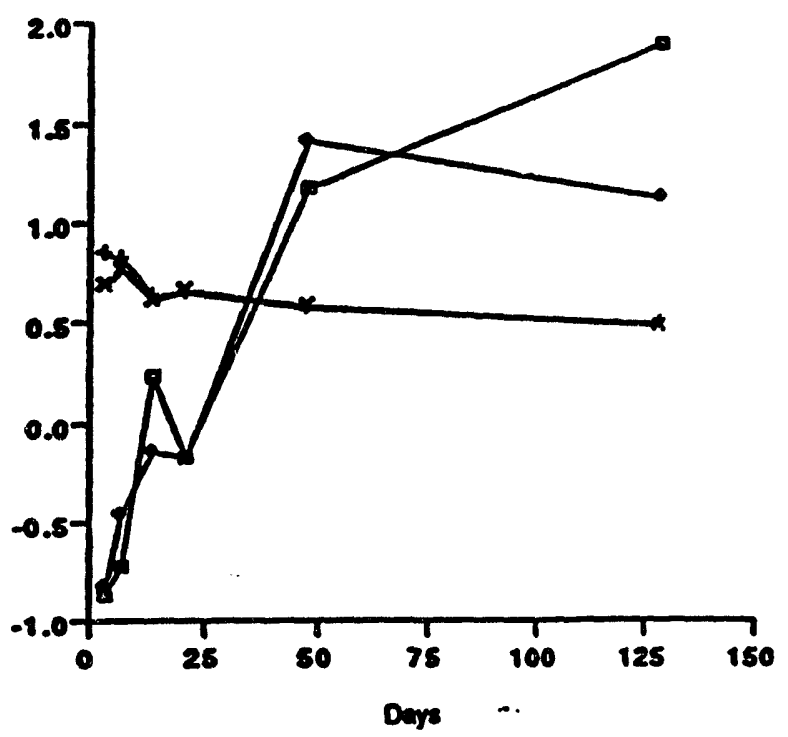

“ -

- 二 Bow $21>$ solution 2

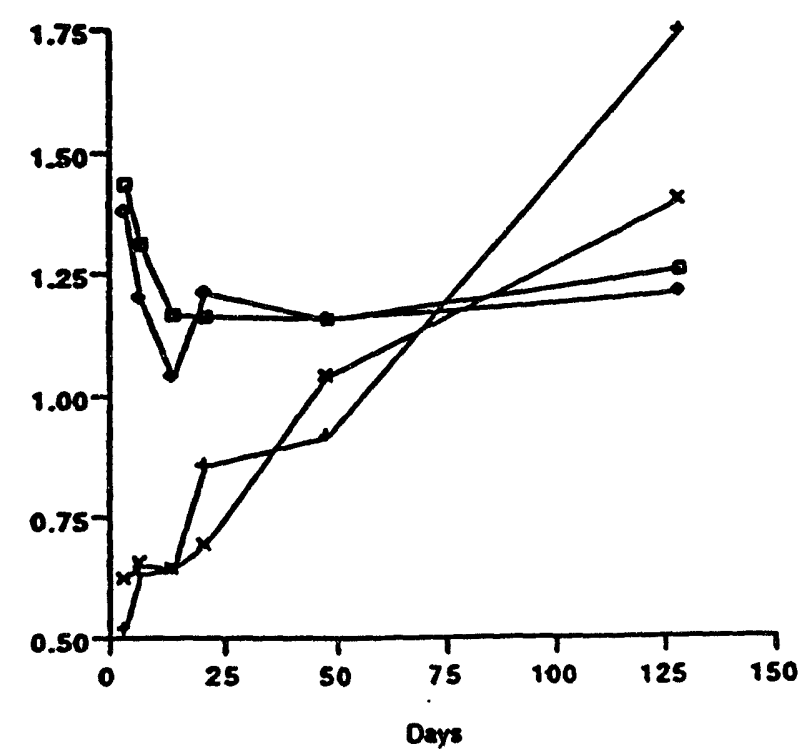

+ - Borth $41>$ Solution 5

$:$ - Botre $10>$ Bolle $37>$ Solution 6
3 and 4

7 and 8

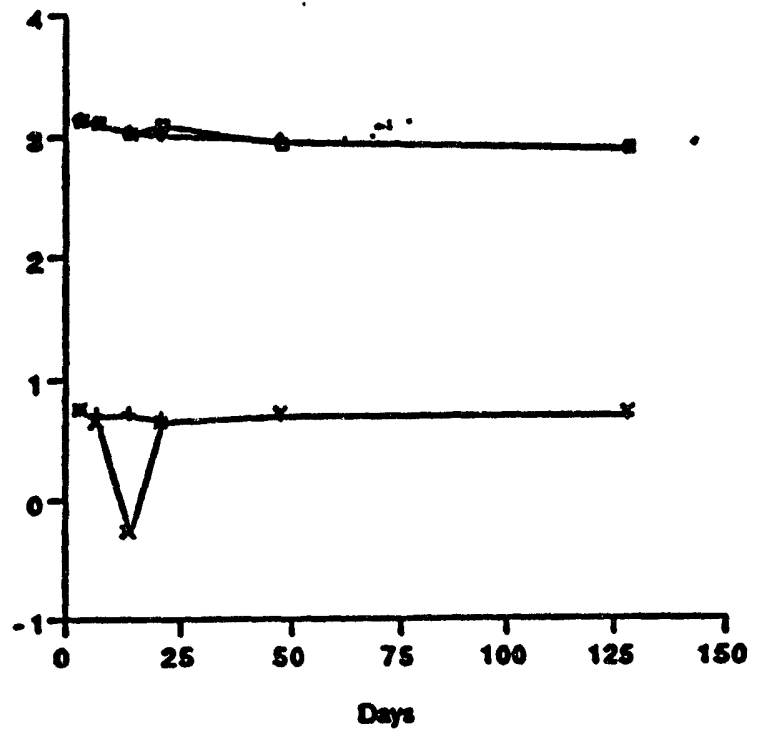

+ -

: - - 80000 $25>$ Solution 4

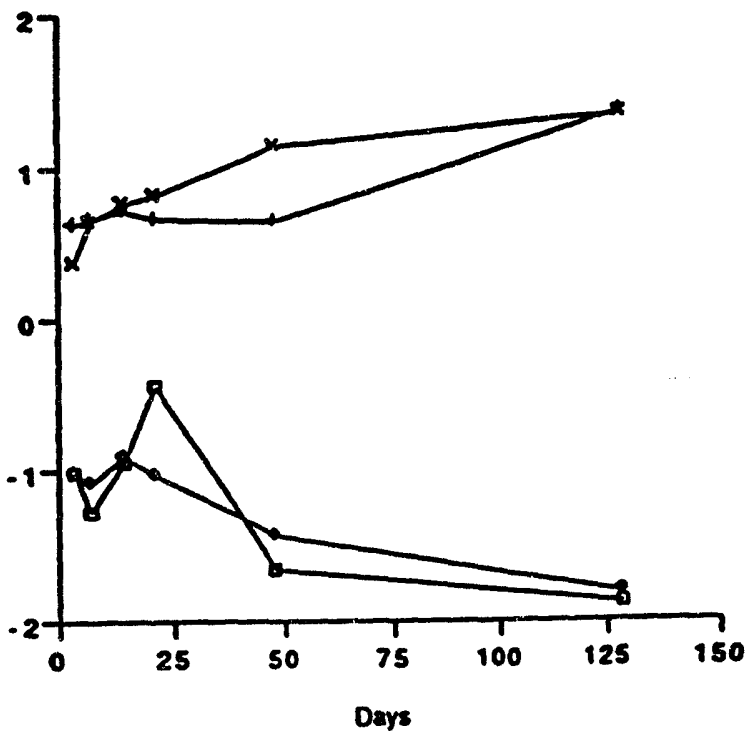

- - Bome $33>$ Solution 7

: - Botrle $27>$ Solution 8 
Exhibit 3: Time Plots for Bottles Prepared From Solutions 9 - 16 $Y$ Axis is $\log _{10}([\mathrm{U}] \mathrm{mg} / \mathrm{L})$

Solutions: 9 and 10

13 and 14

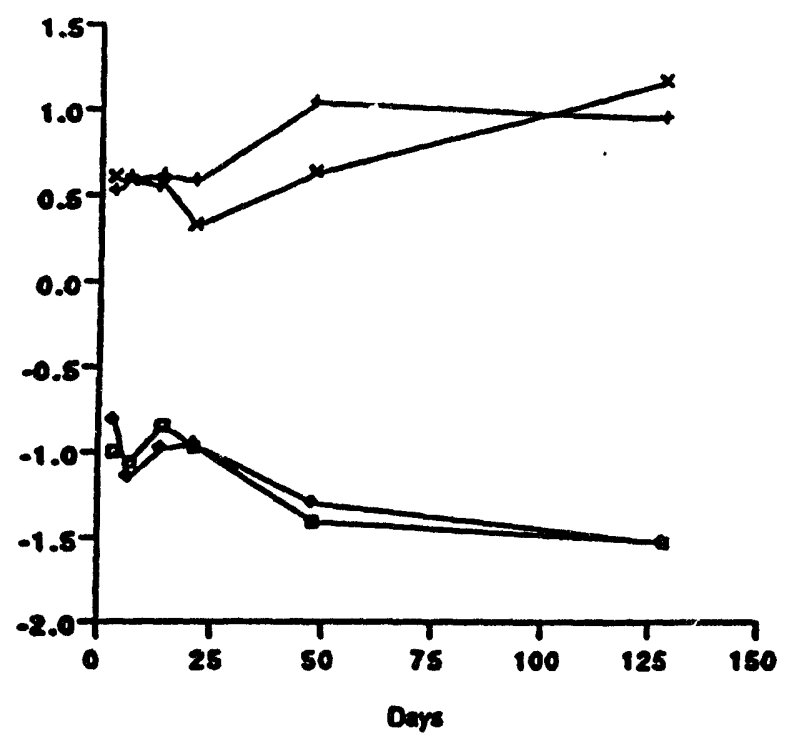

+- Bown $^{+} 24>$ Solution 9

: - - Bowe $32>$ Solution 10

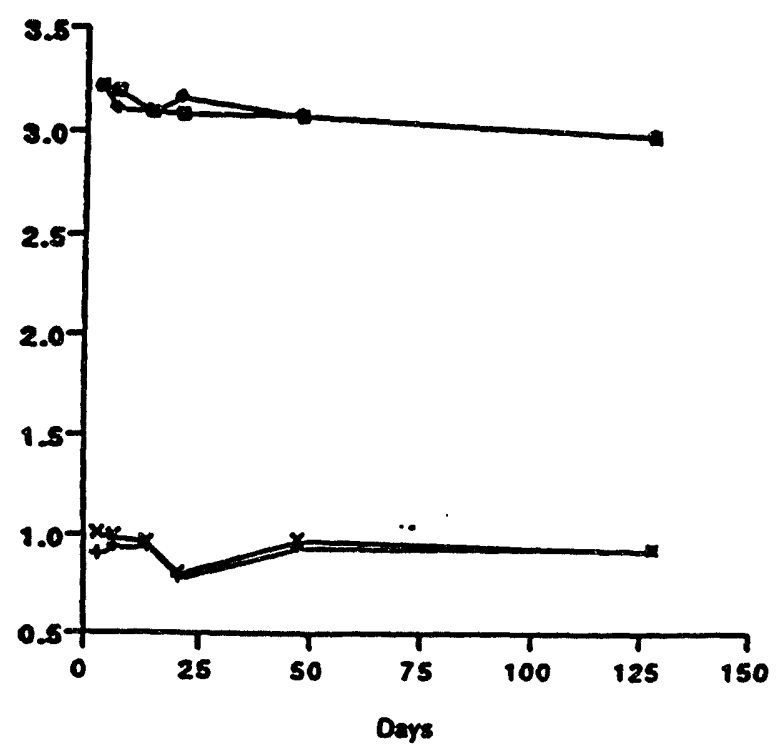

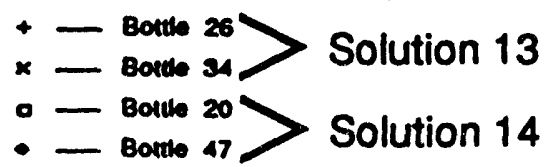

11 and 12

15 and 16

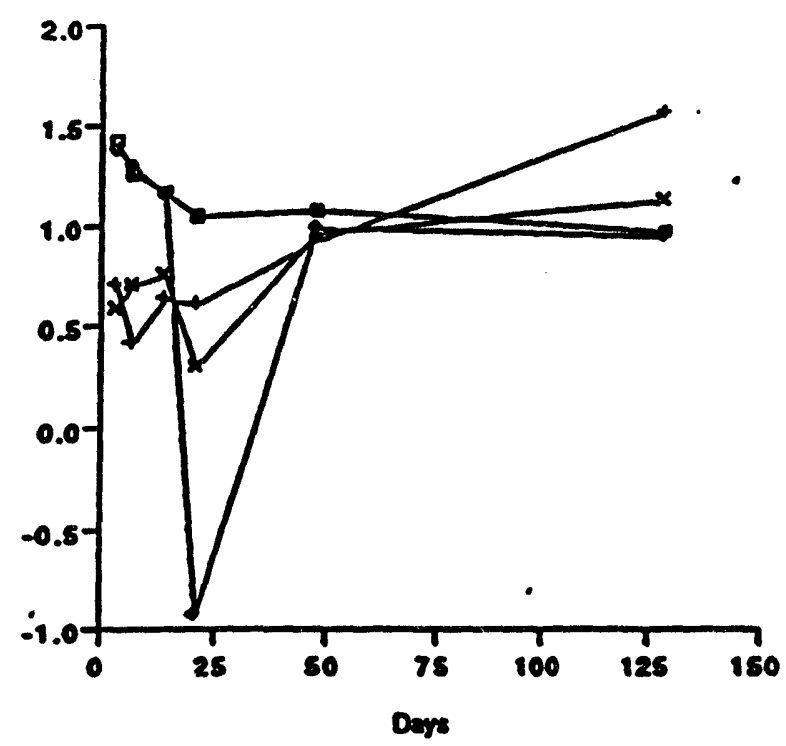

+ 二

$:$ 二 Boute $12>$ Solution 12

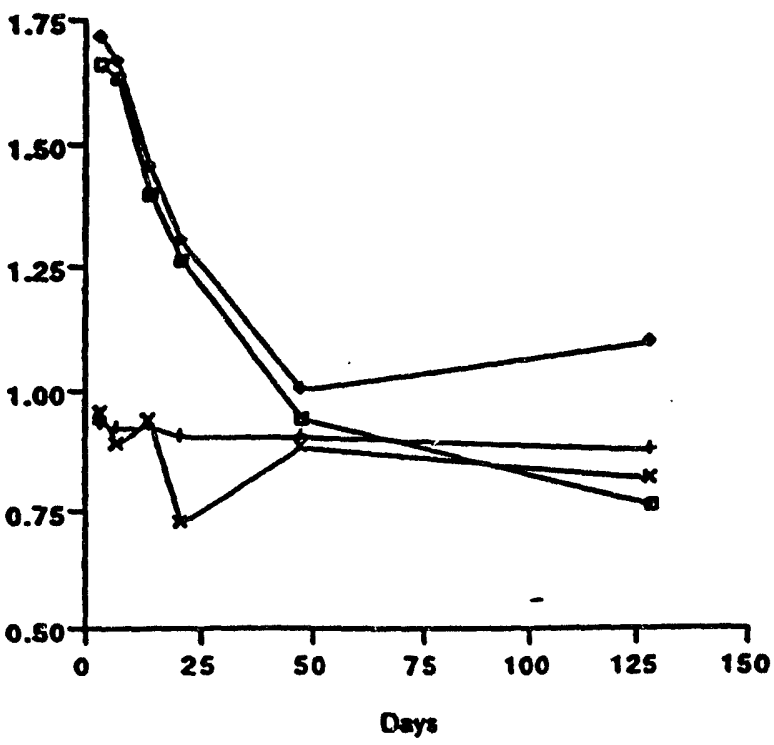

$\div$ 二 Botrese $16>$ Solution 15

$:$ - Borta is 48 Solution 16 
Exhiblt 4: Time Plots for Bottles Prepared From Solutions 17-19

$Y$ Axis is $\log _{10}([\mathrm{U}] \mathrm{mg} / \mathrm{L})$

Solutions: 17
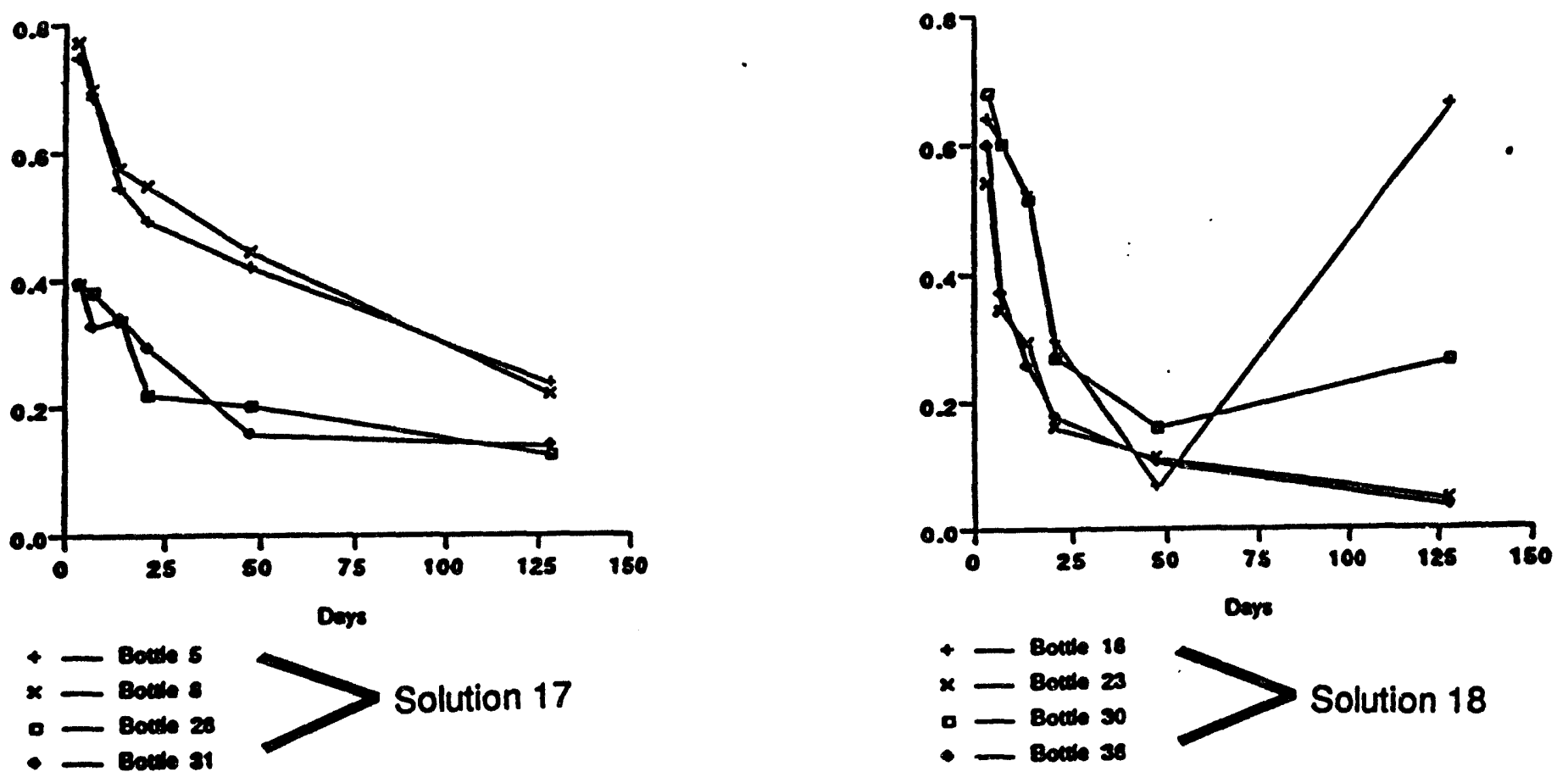

+ - Bome 18

$x$ - Bowa 23

- Dow 30

Solution 18

- Dowe se

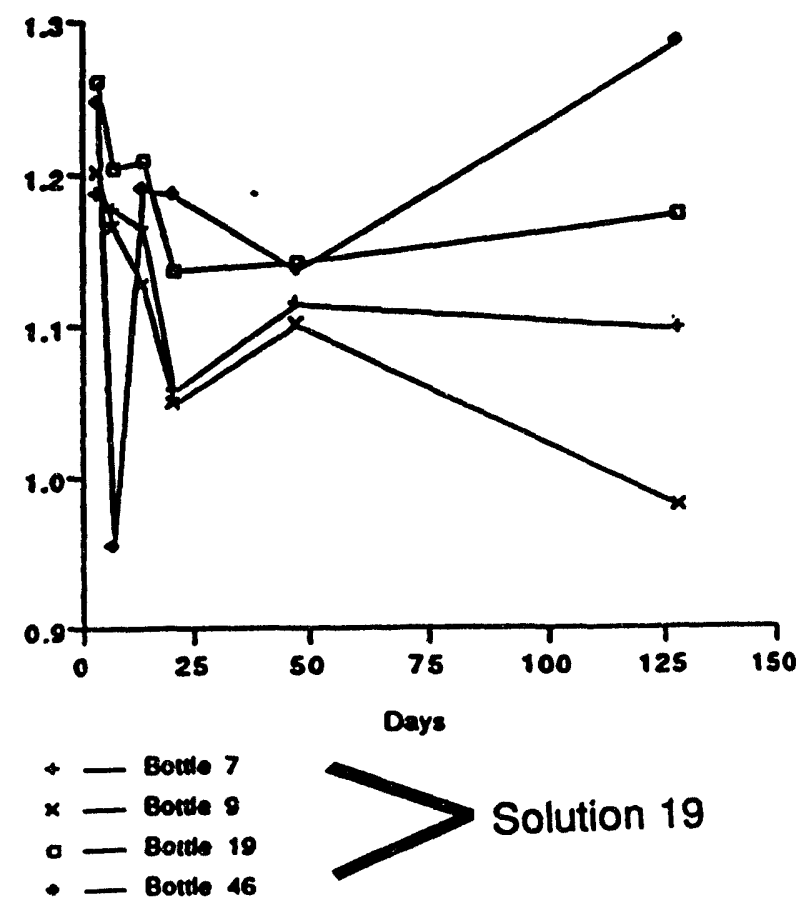




\section{Exhlbit 5: Histogram and Descriptive Statistics for Uranium Solubilities for Bottles 1-12}
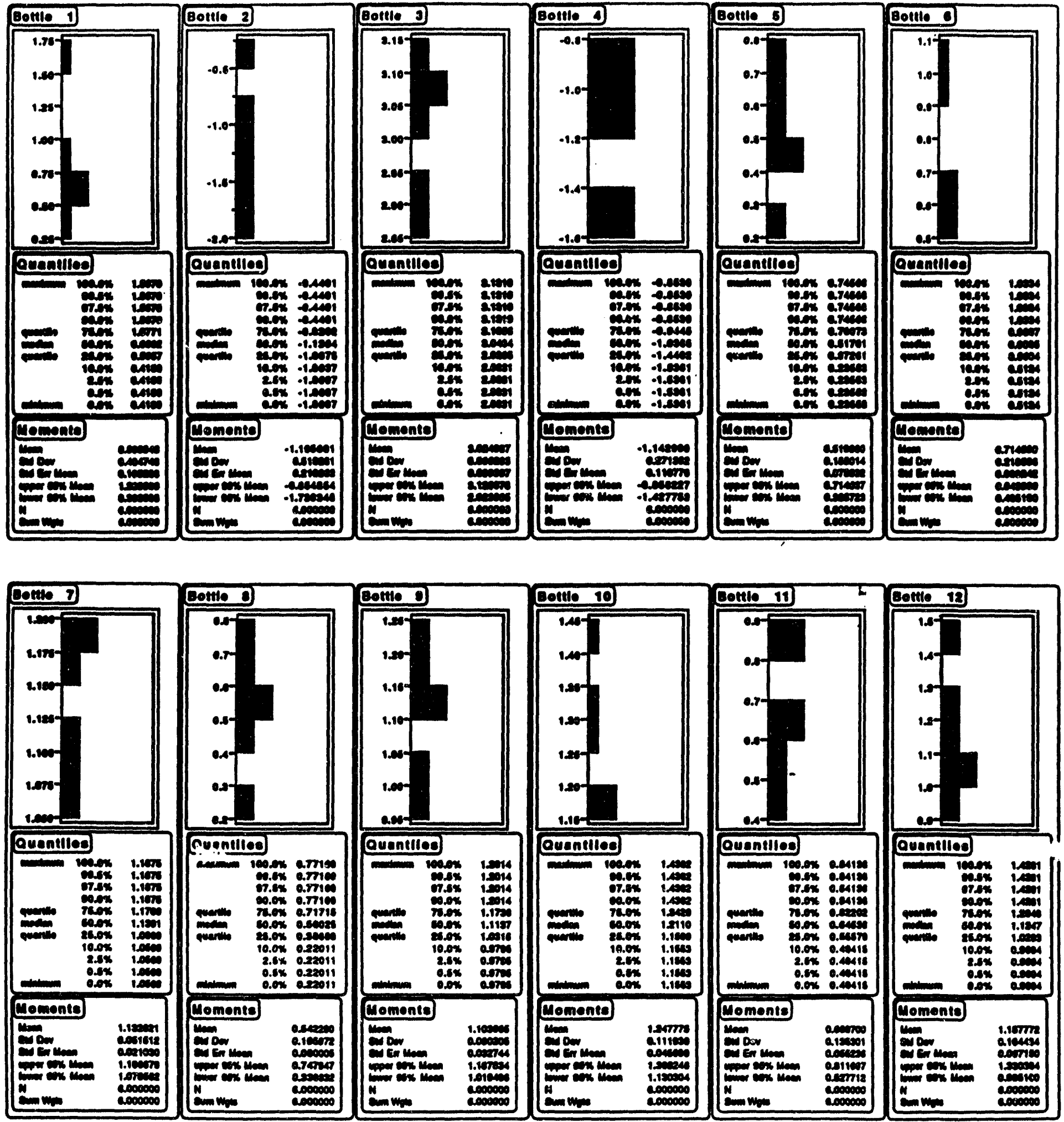


\section{Exhibit 6: Histogram and Descriptive Statistics for Uranium Solubilities for Bottles 13, 15,16,18-26}
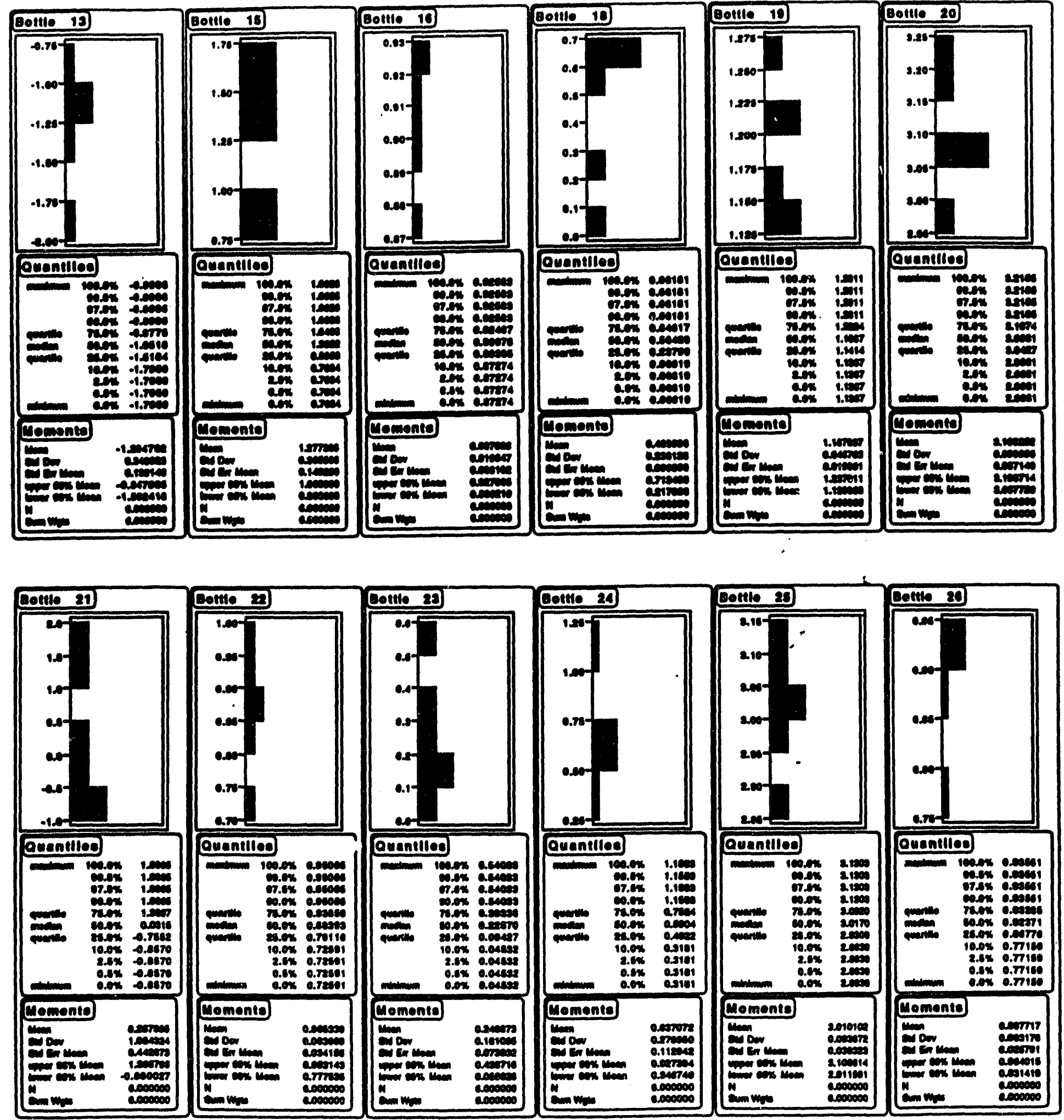


\section{Exhibit 7: Histogram and Descriptive Statistics for Uranium Solubilities for Bottles 27-38}
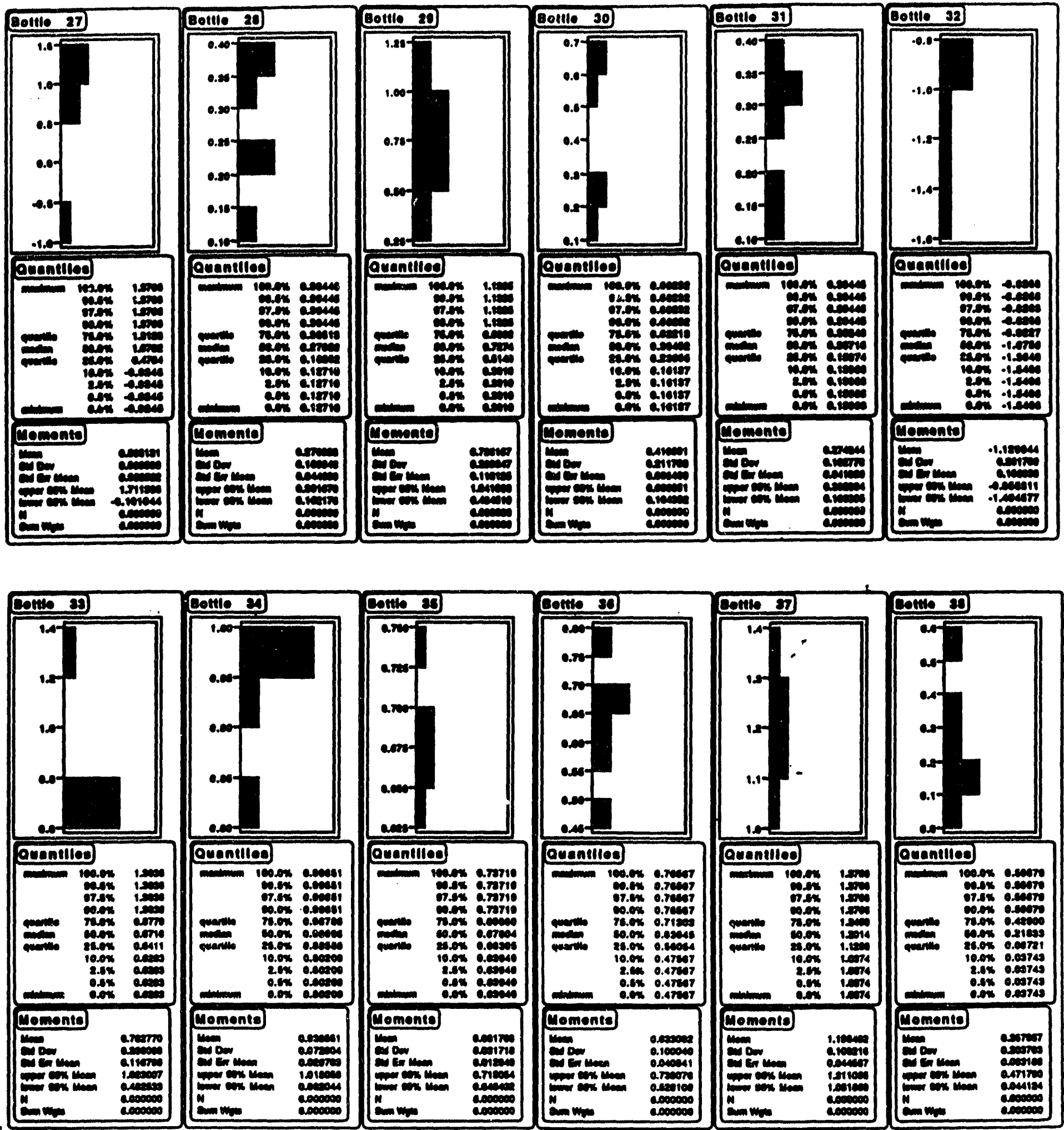

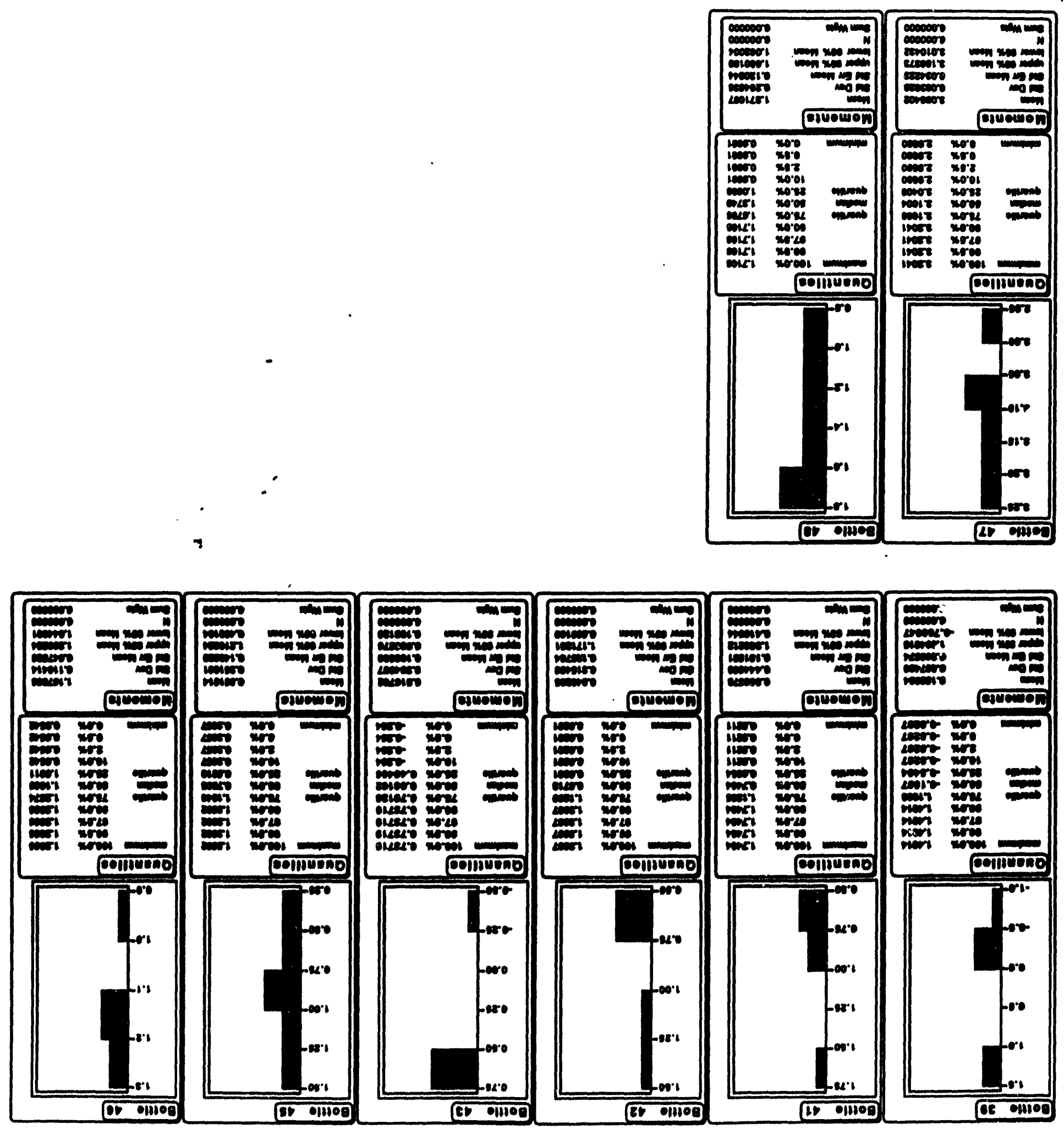

8b-St 'Eb-Lt '6E selu०g dol selllliqnjos

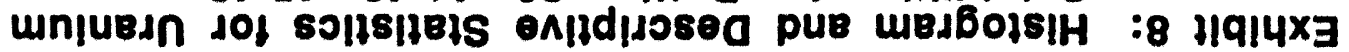

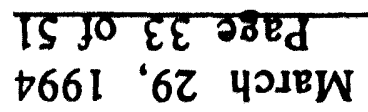

$t S t-\varepsilon 6-8 \perp-J \mathbf{d} S M$ 
Exhlblt 9: Scatter Plot of Sample Averages versus Sample Standard Devlations of the Uranium Solublitties for the Sample Bottles

Average and Standard Deviation of the $\log _{10}([\mathrm{U}] \mathrm{mg} / \mathrm{L})$ values.

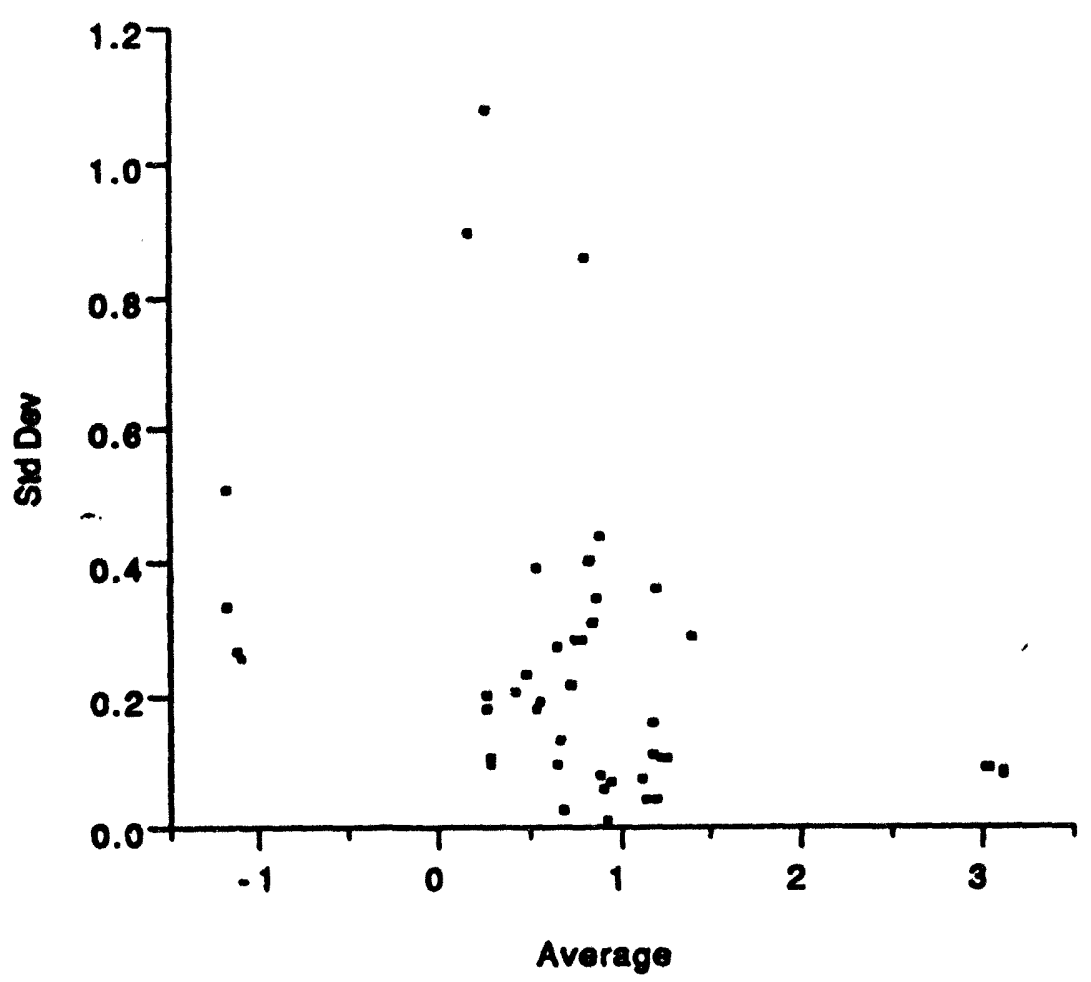




\section{Exhlbit 10: Analysis of Variance for the Full Model Using} the Initial Levels of the Factors

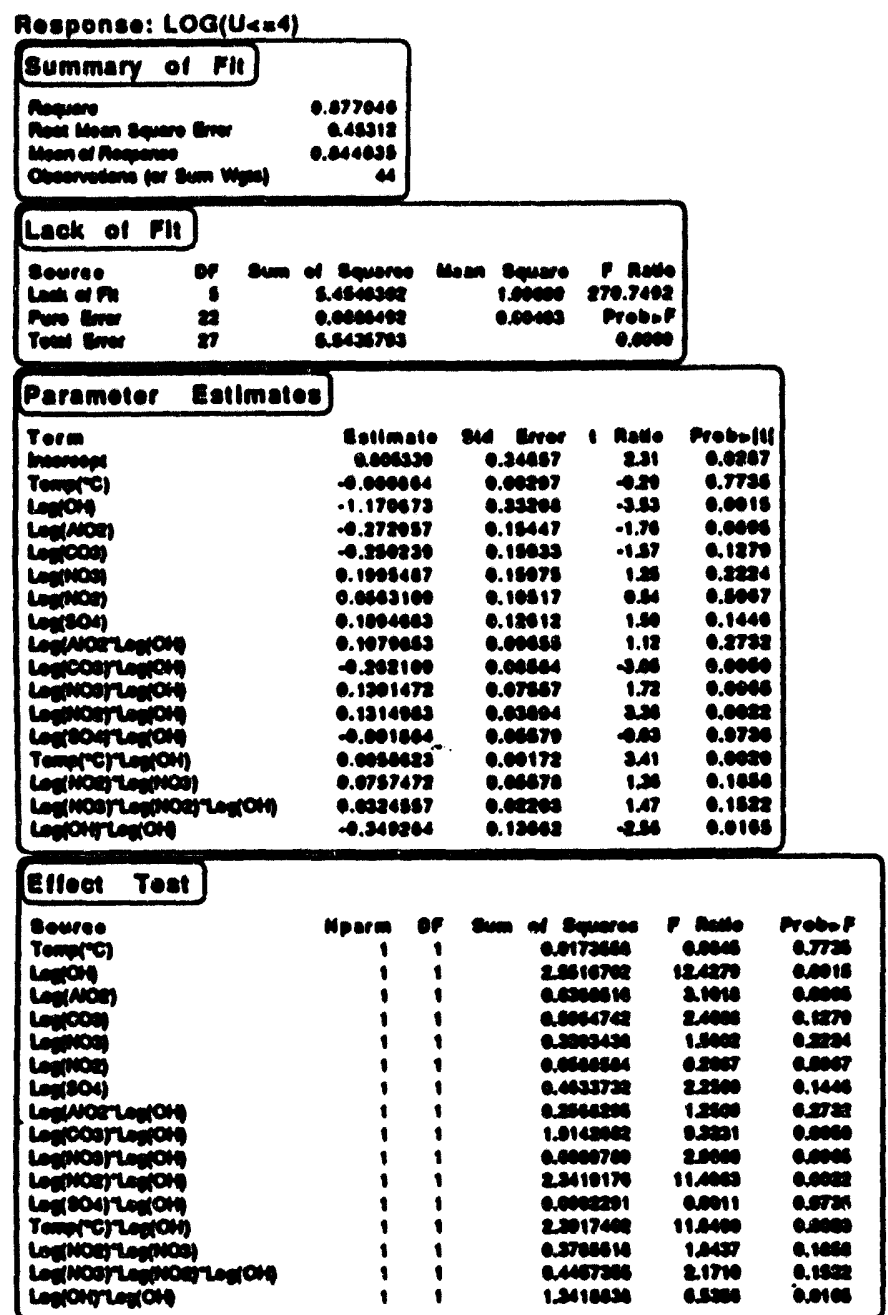

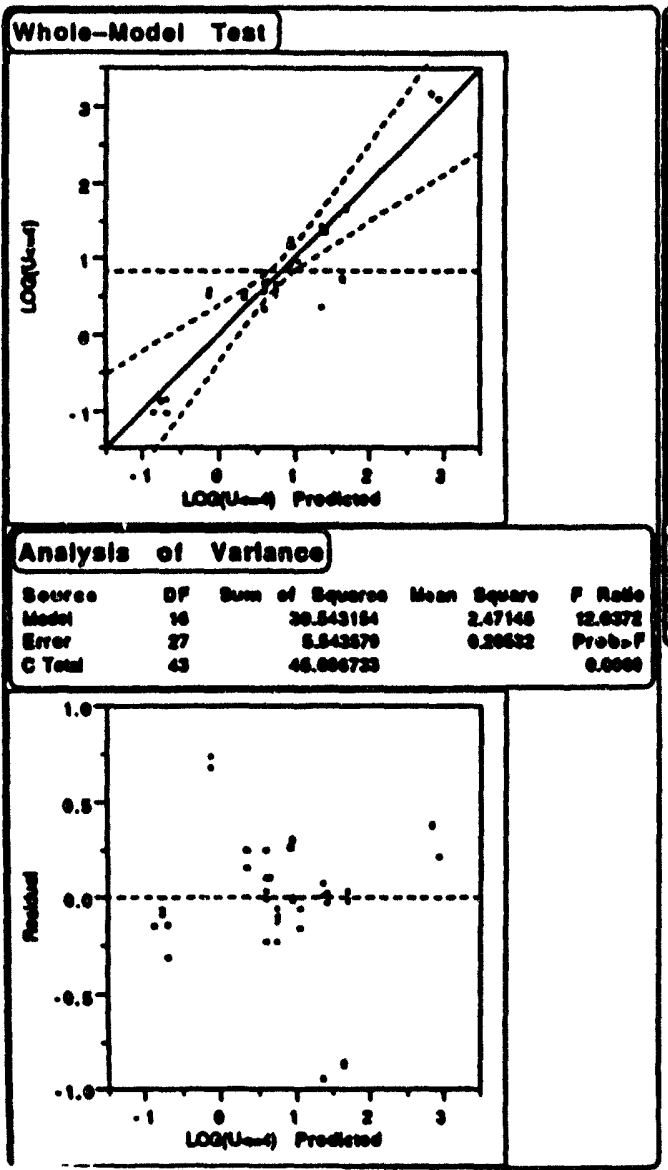




\section{Exhlbit 11: Analysis of Variance for the Reduced Model Using the Initial Levels of the Factors}

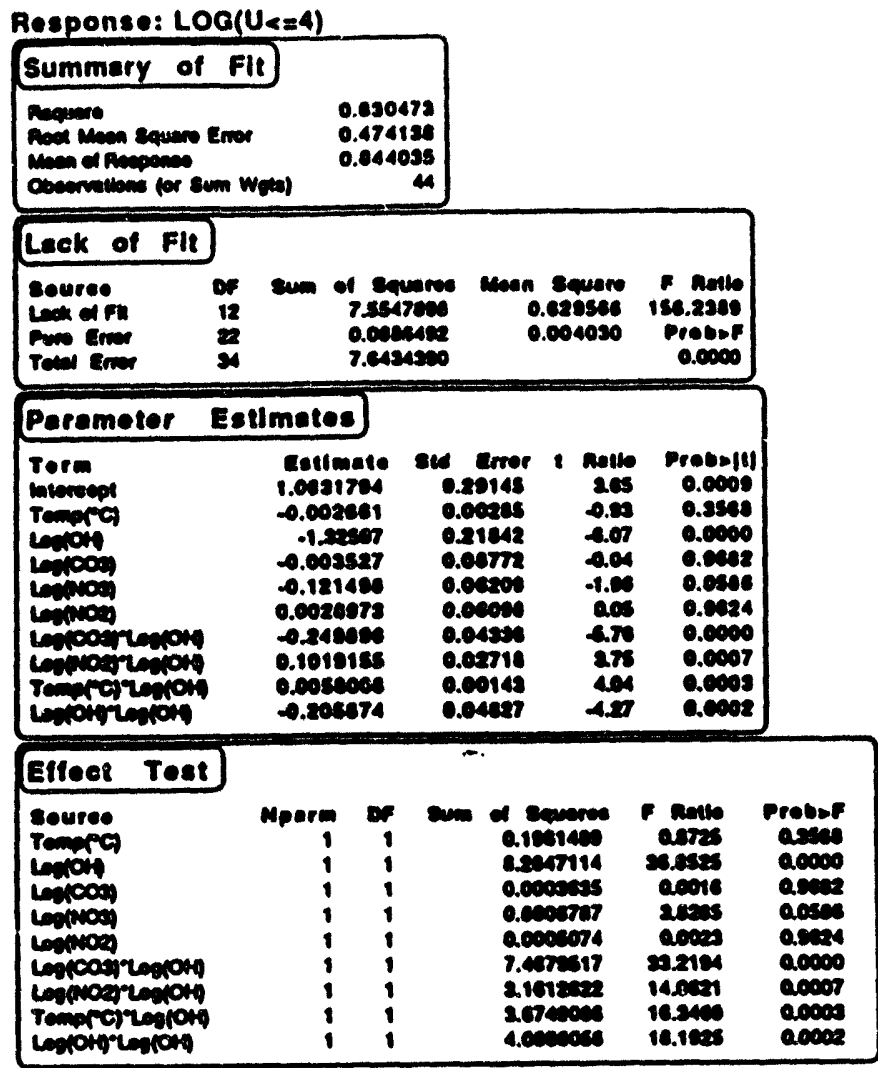

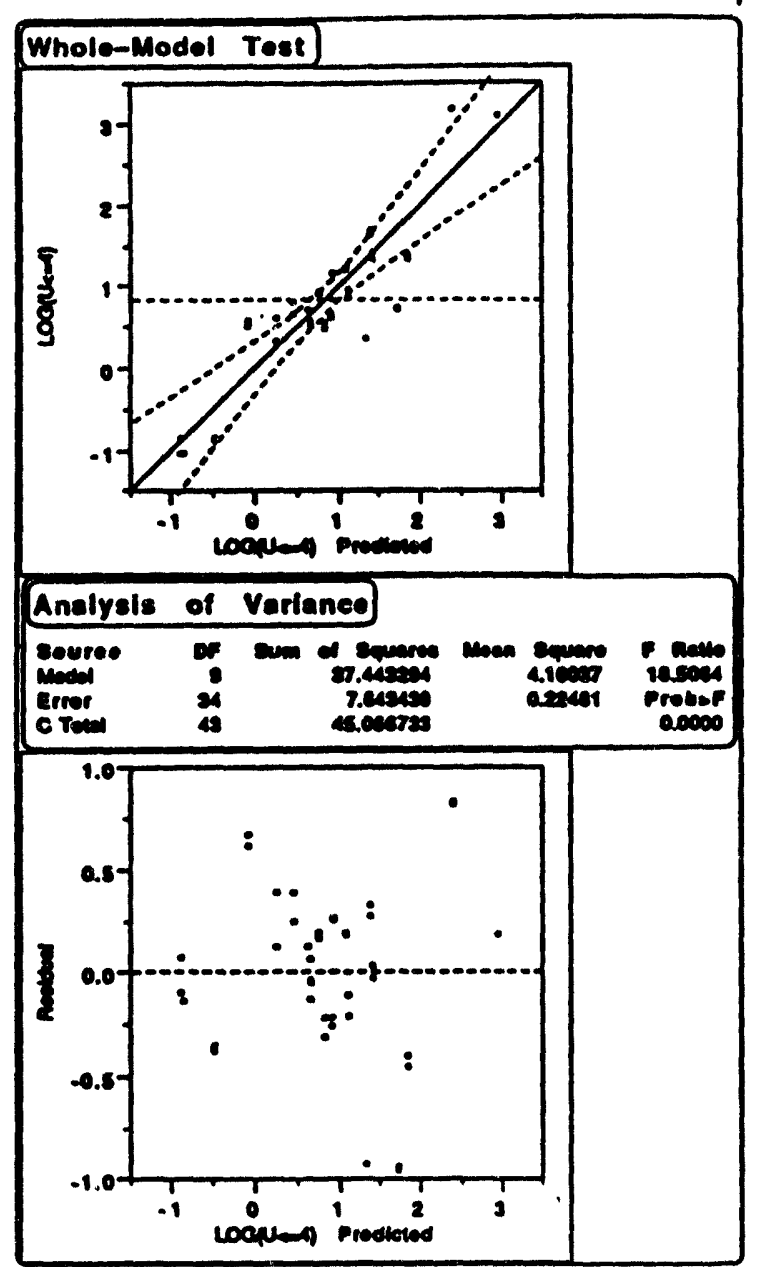


Exhibit 12: Analysis of Varlance for the Full Model Using the Final Levels of the Factors

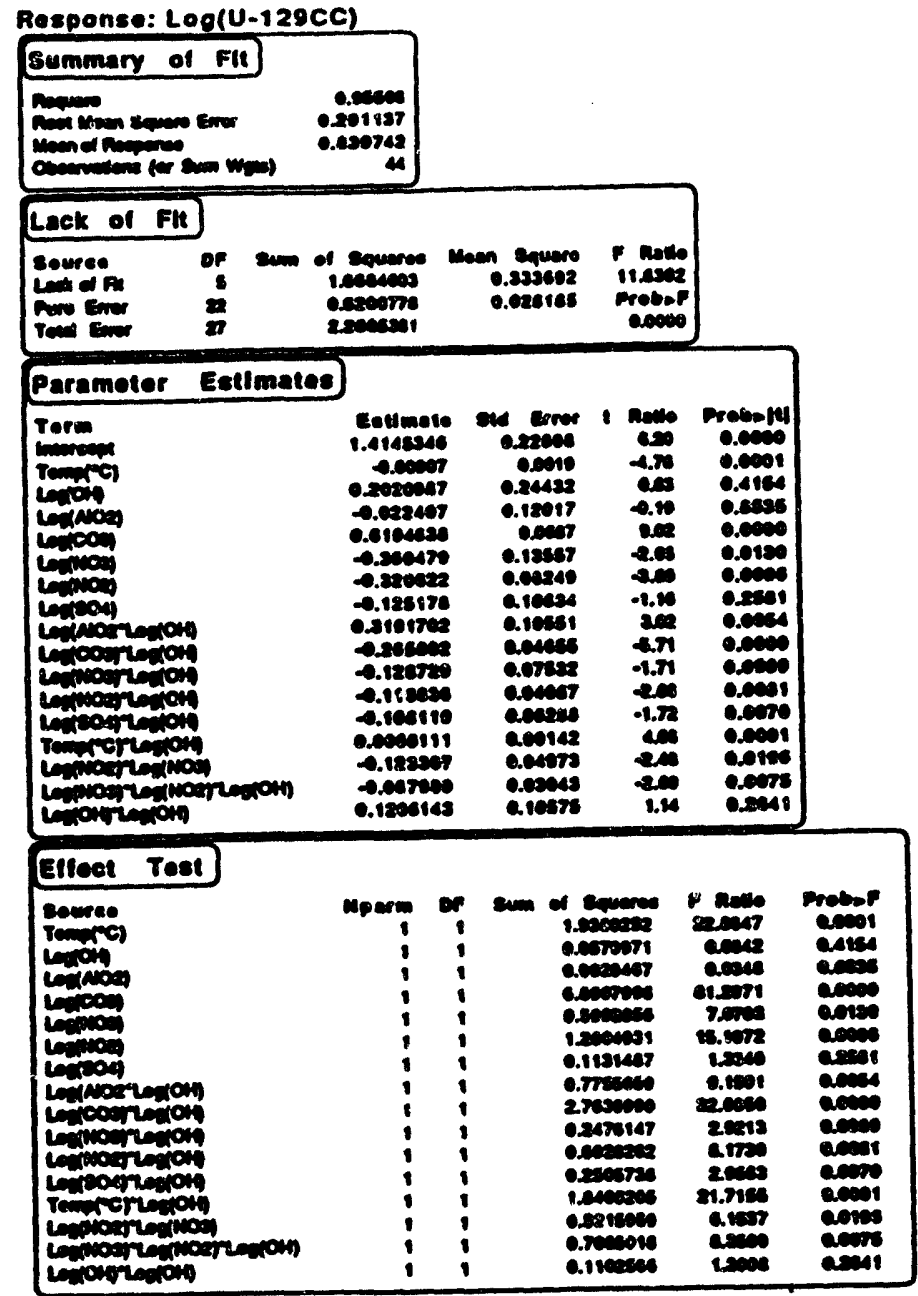

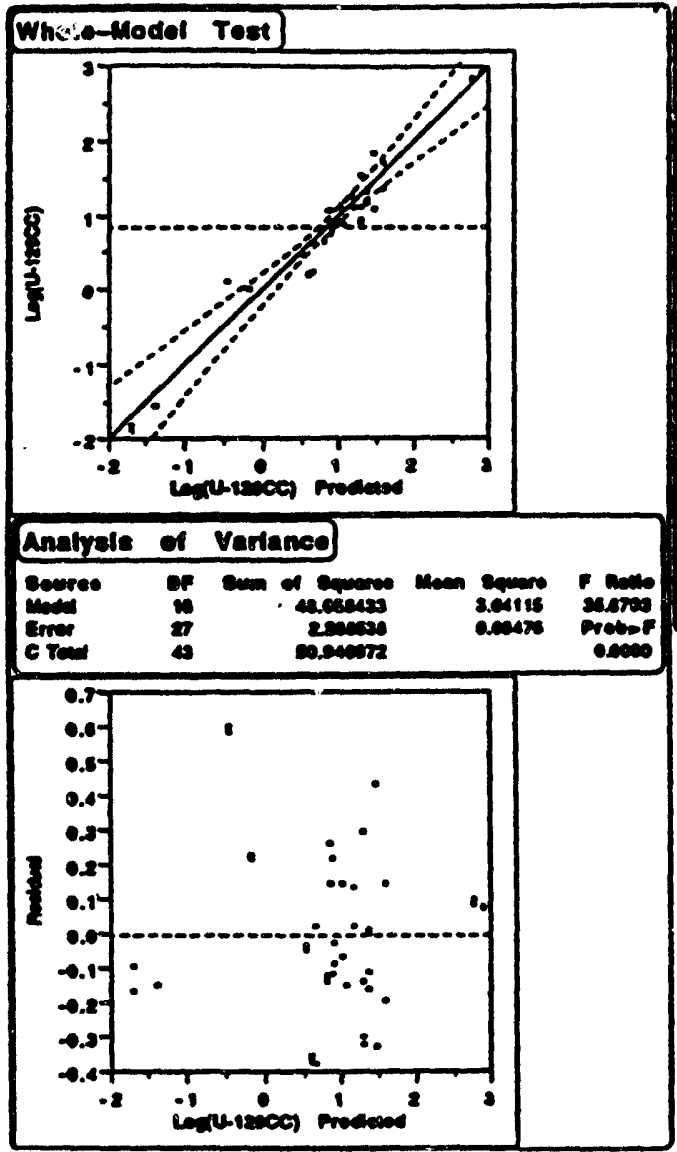


Exhibit 13: Plot of Confidence Intervals for Previous Study's Uranium Solublilties by Bottle Based on Full Model and Initial Levels of the Factors

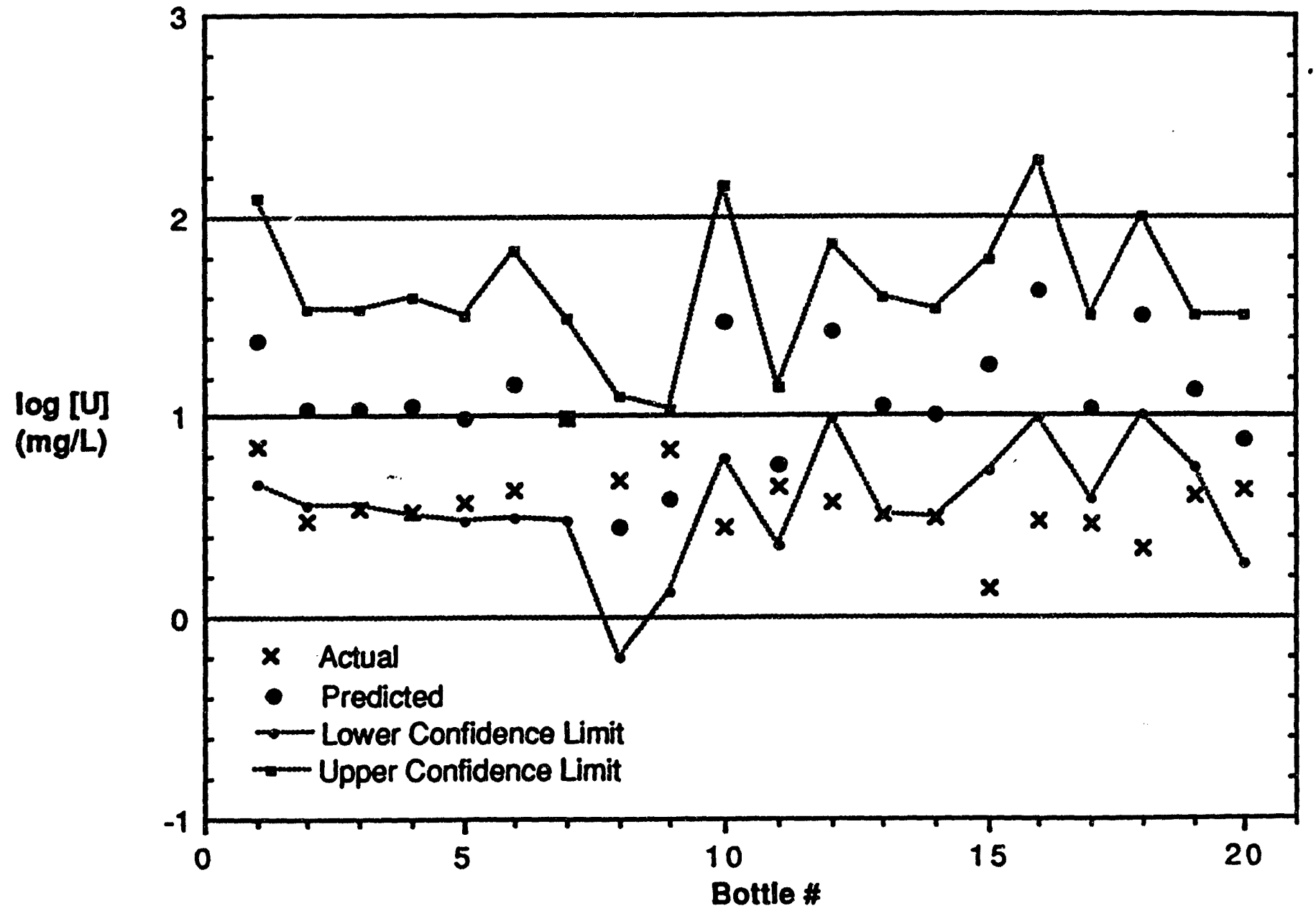


Exhibit 14: Plot of Prediction Intervals for Previous Study's Uranium Solubilities by Bottle Based on Full Model and Initial Levels of the Factors

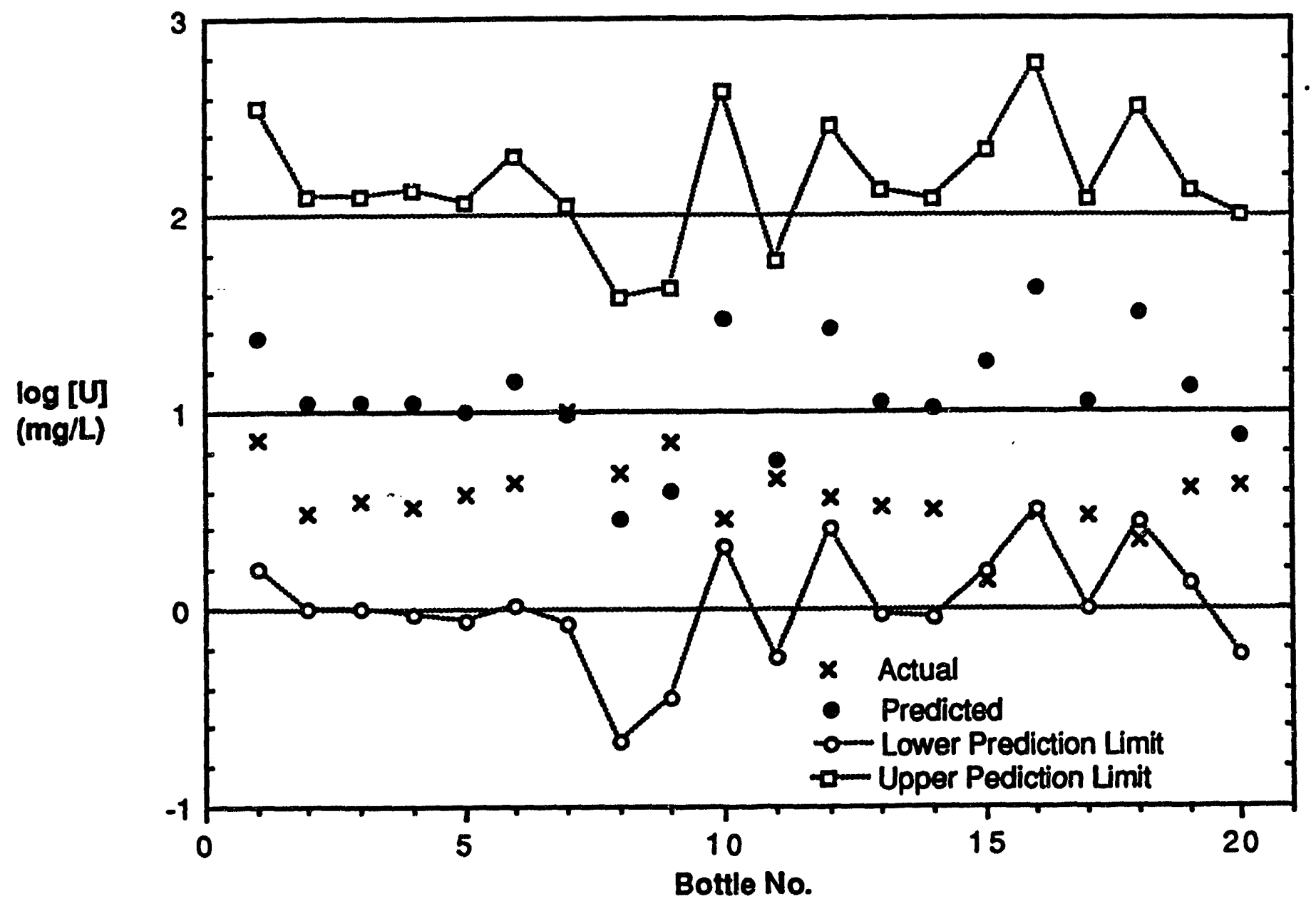


Exhibit 15: Plot of Confidence Intervals for Previous Study's Uranium Solubllities by Bottle Based on Reduced Model and Initial Levels of the Factors

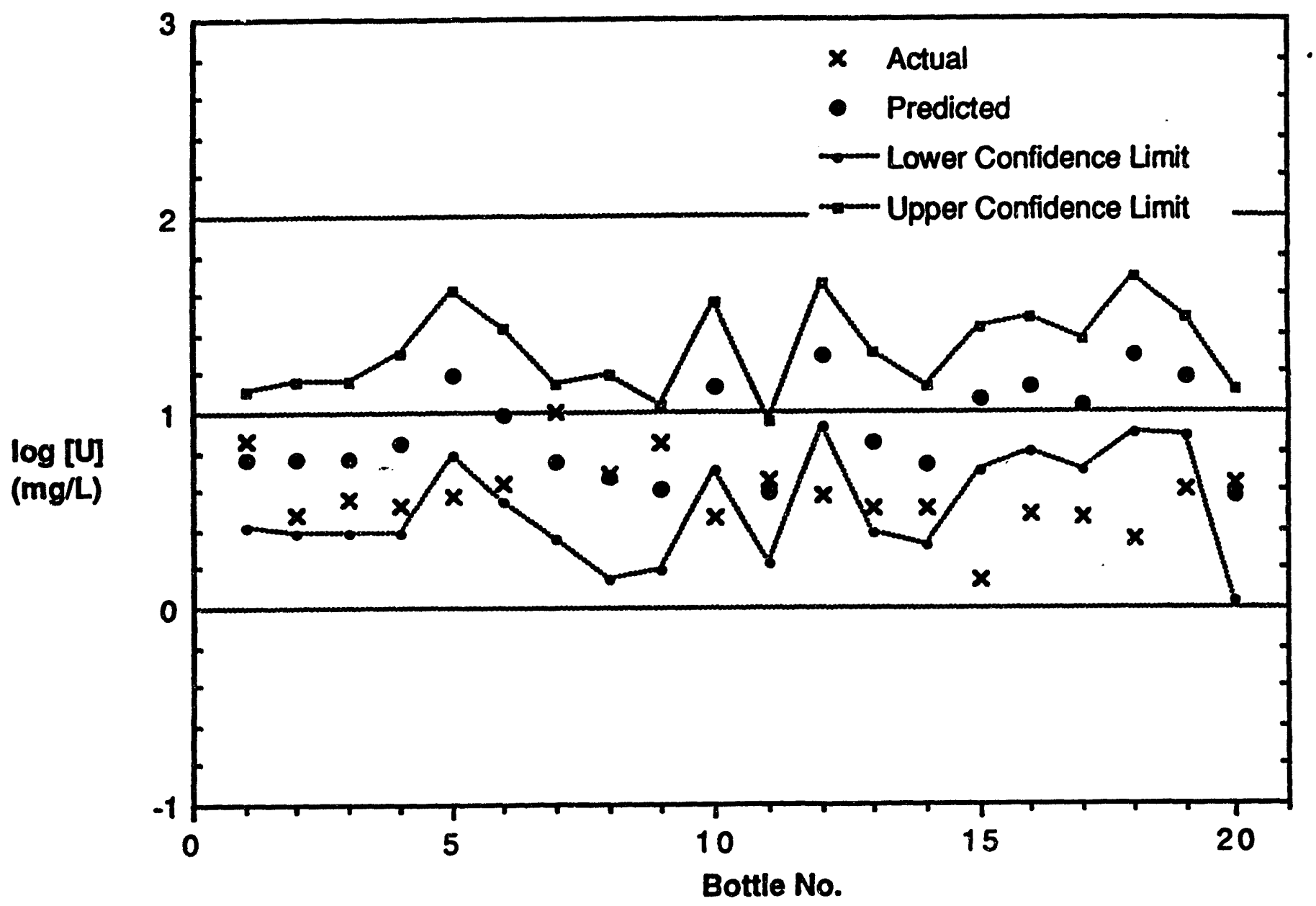


Exhibit 16: Plot of Prediction Intervals for Previous Study's Uranium Solubilities by Bottle Based on

Reduced Model and Initial Levels of the Factors

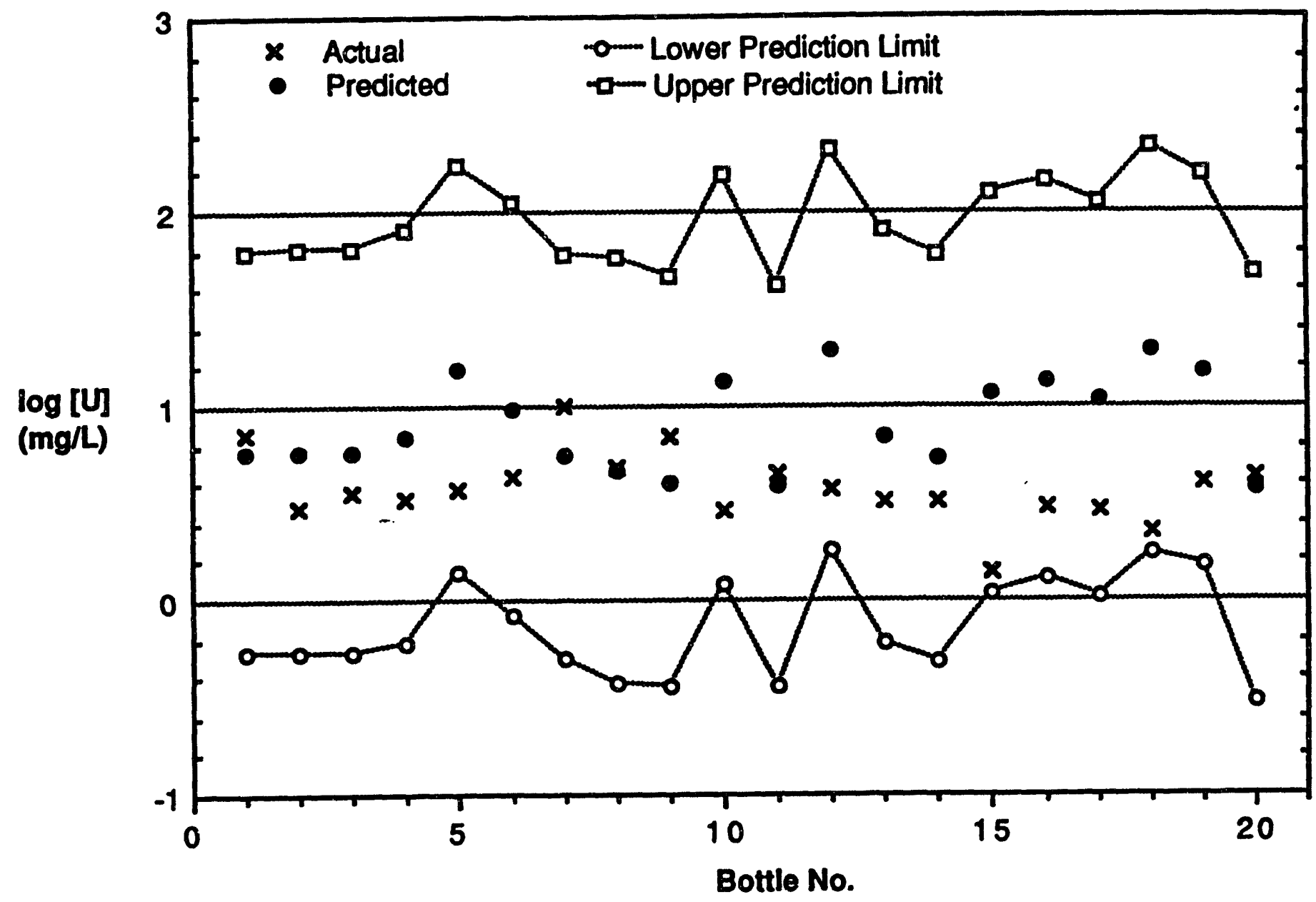


Exhibit 17: Plot of Confidence Intervals for Previous

Study's Uranium Solubilities by Bottle Based on Full Model and Final Levels of the Factors

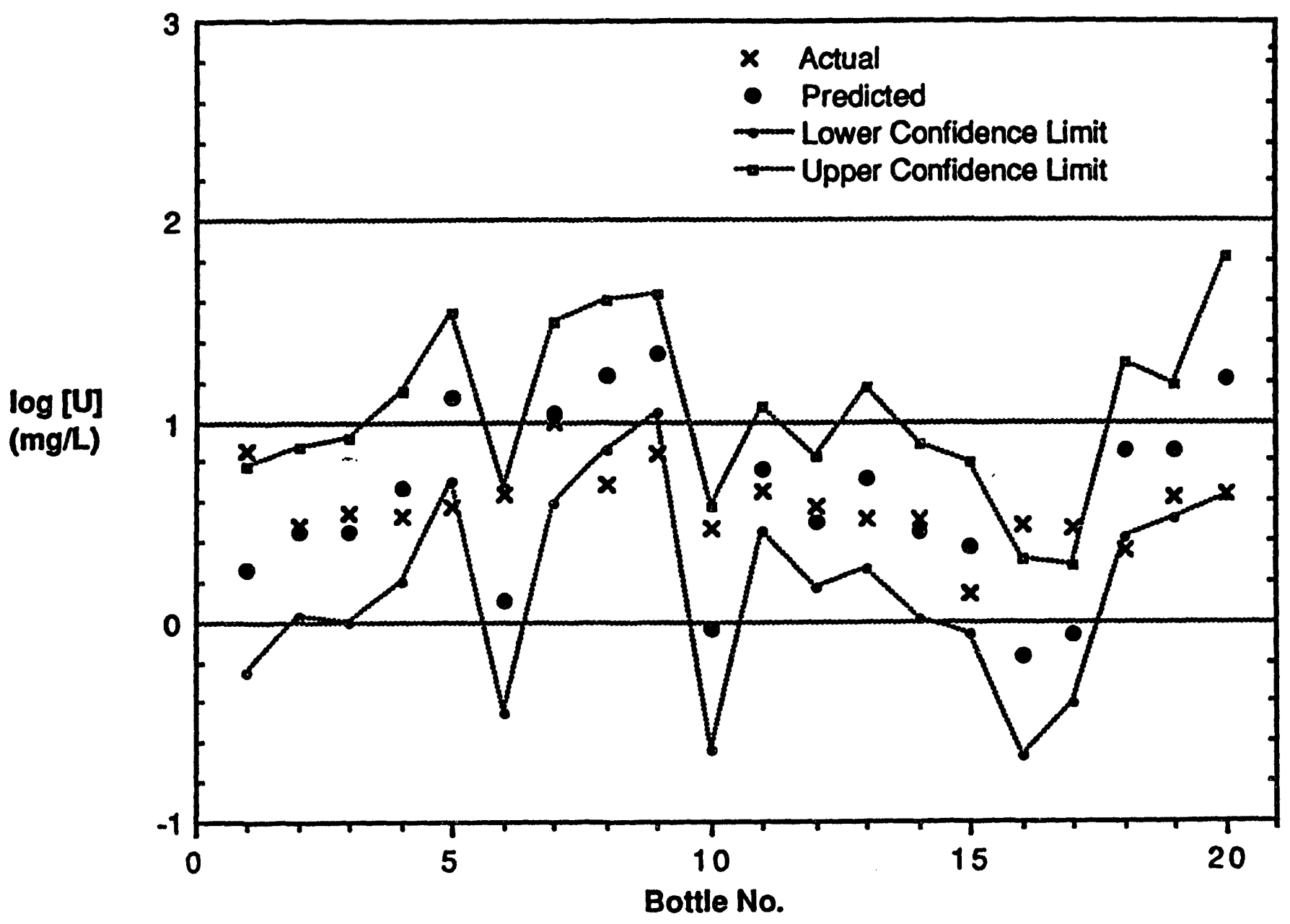


Exhibit 18: Plot of Prediction Intervals for Prevlous Study's Uranium Solubilities by Bottle Based on Full Model and Final Levels of the Factors

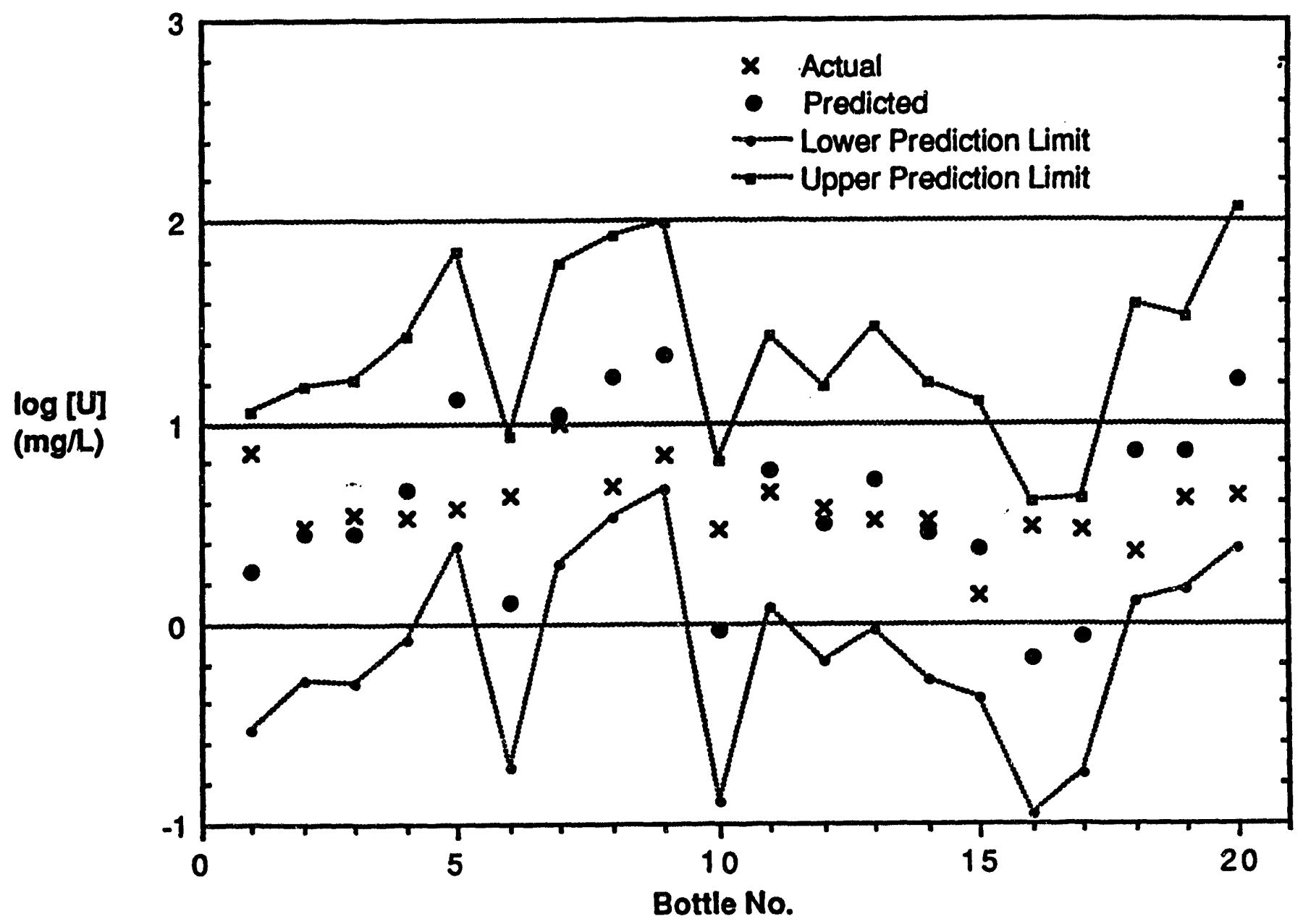




\section{Exhlbit 19: Uranlum Concentration Versus Hydroxide} Concentration

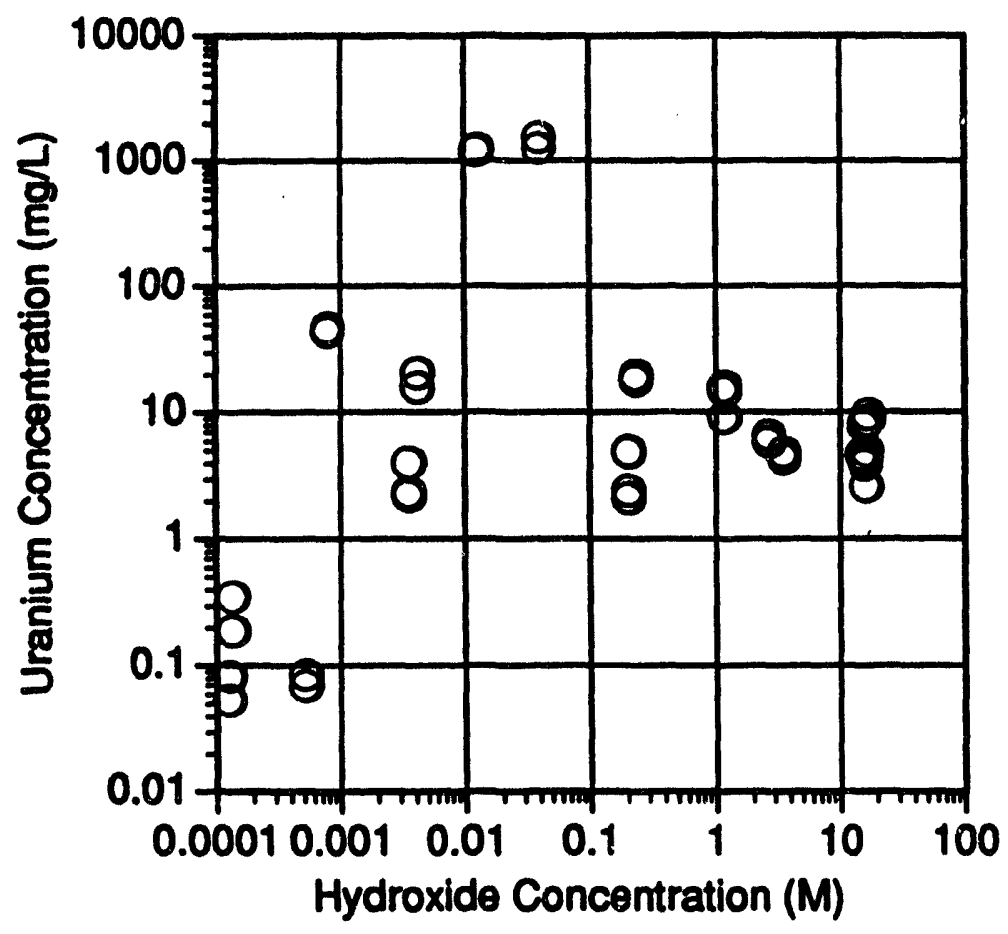


Exhibit 20: Uranium Concentration Versus Nitrate and Hydroxide Concentrations

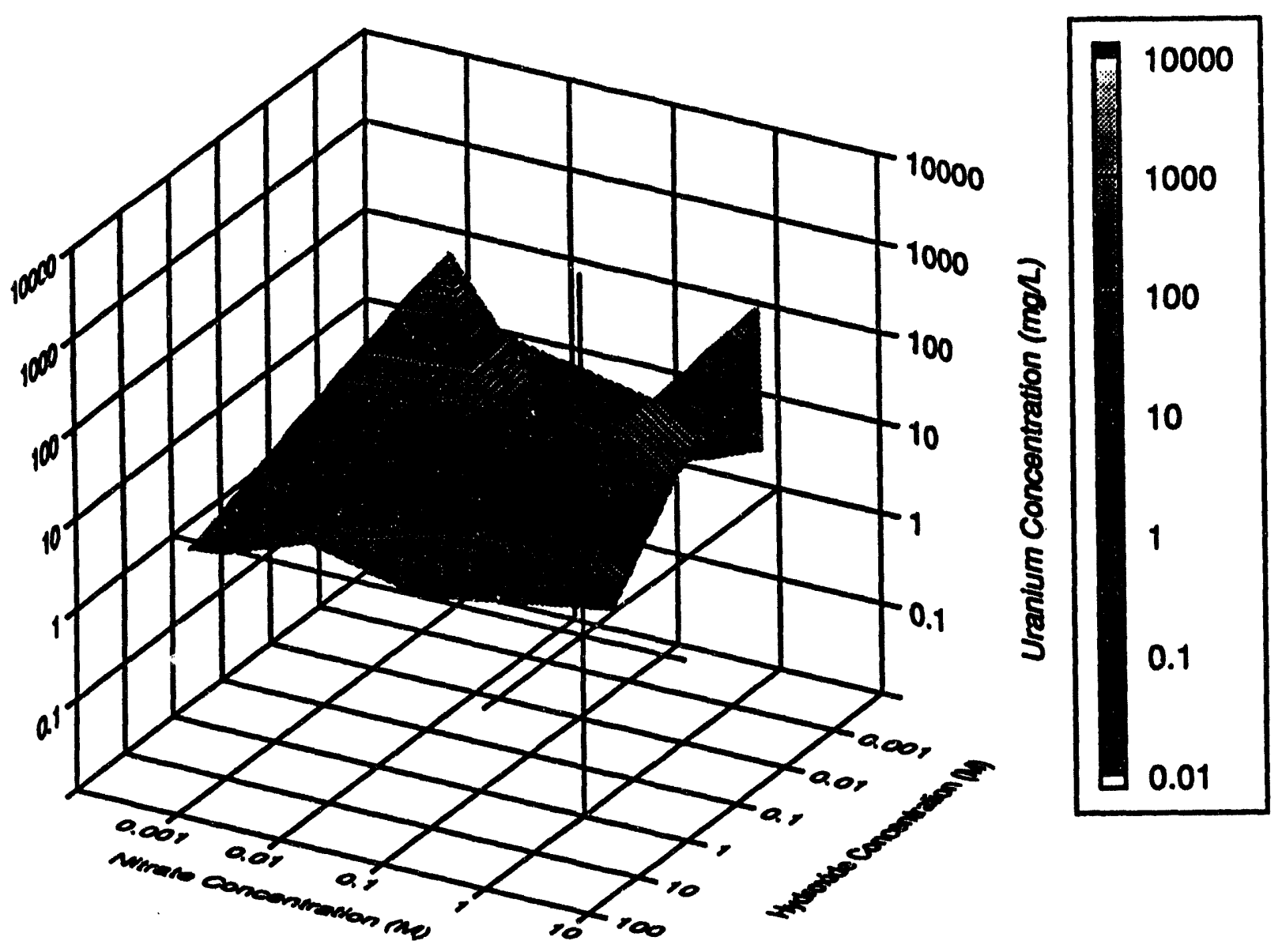


Exhibit 21: Uranium Concentration Versus Nitrite and Hydroxide Concentrations

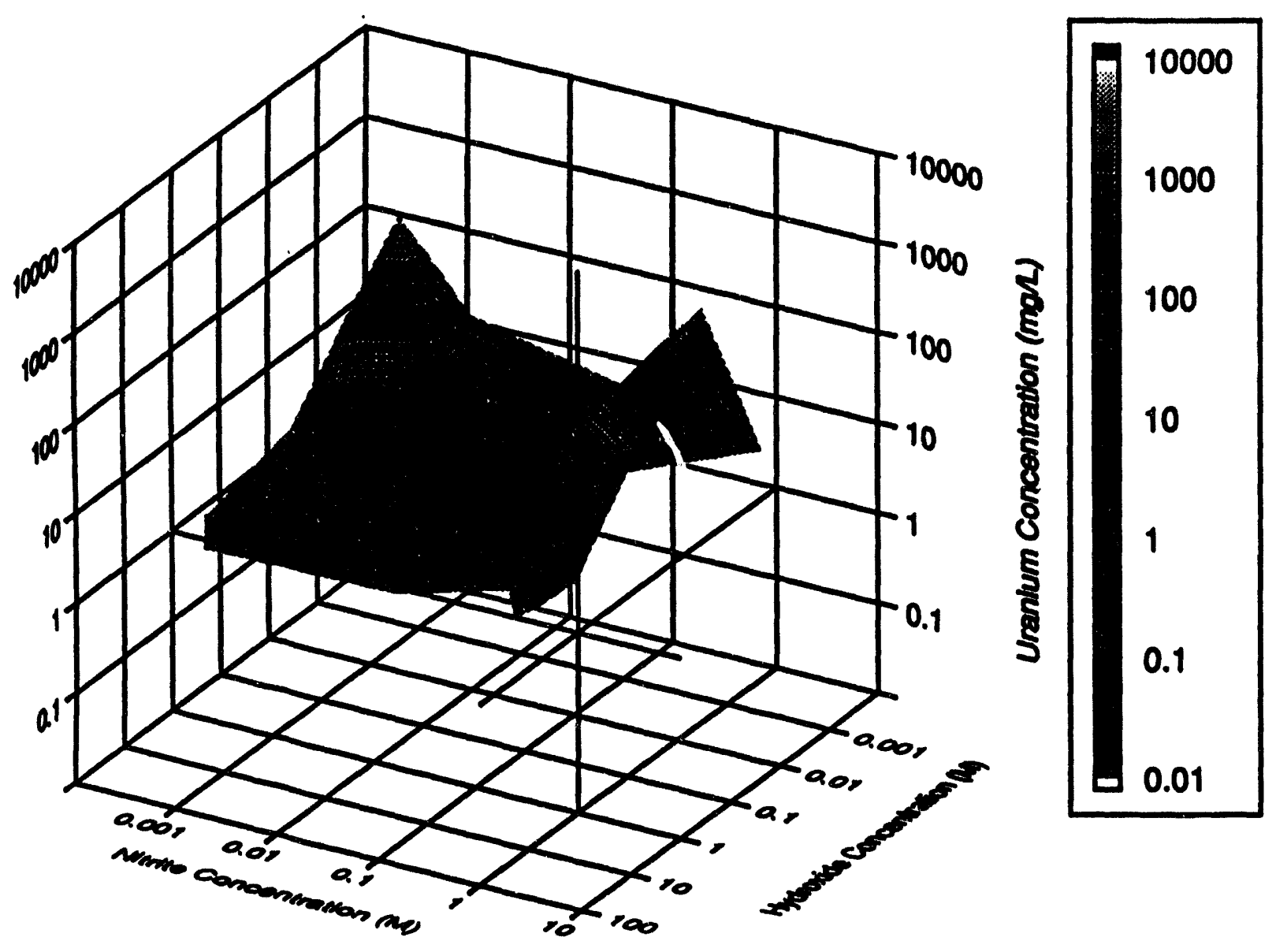


Exhiblt 22: Uranium Concentration Versus Carbonate and Hydroxide Concentrations

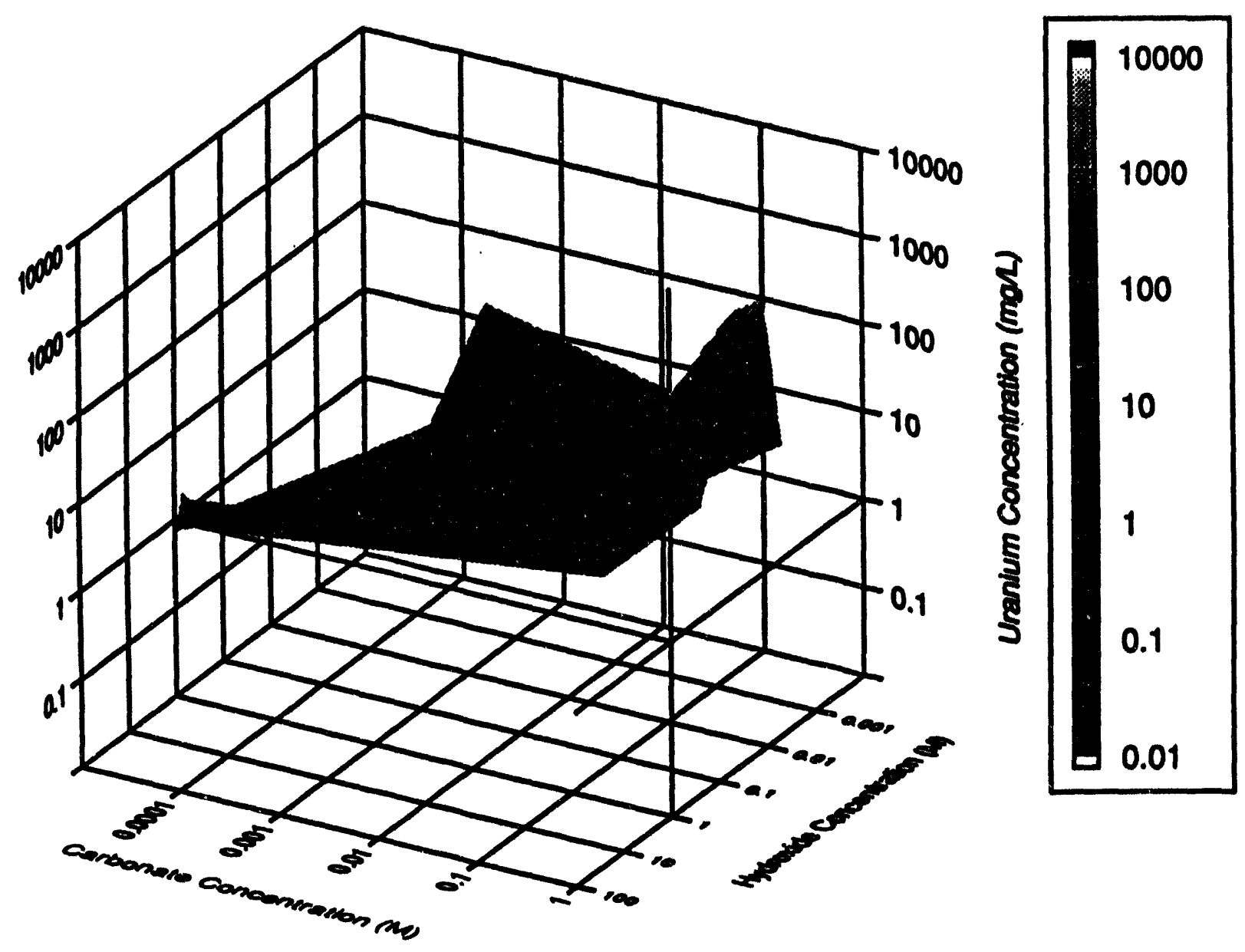




\section{Exhiblt 23: Uranium Concentration Versus Sulfate and} Hydroxide Concentrations

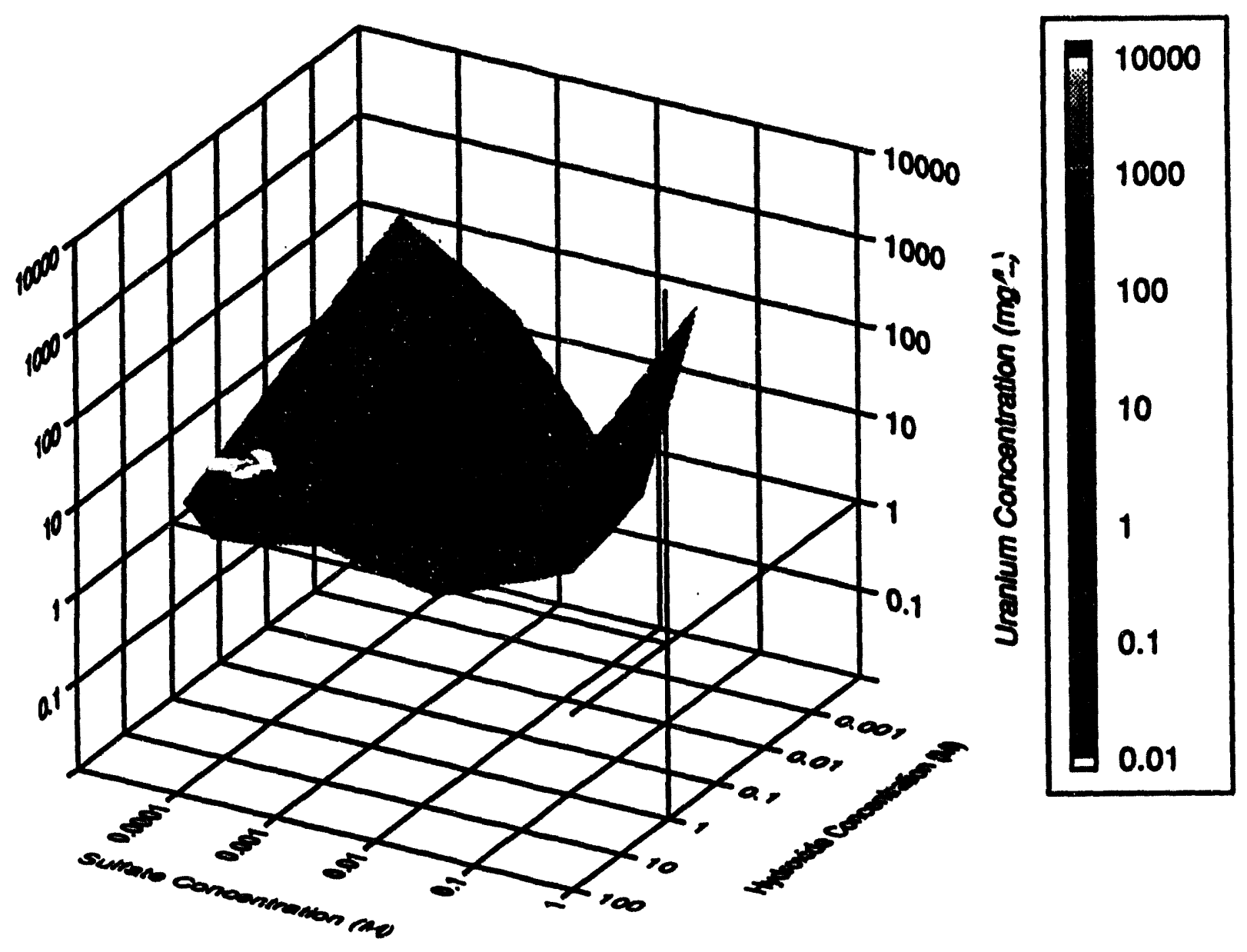


Exhibit 24: Uranium Concentration Versus Aluminate and Hydroxide Concentrations

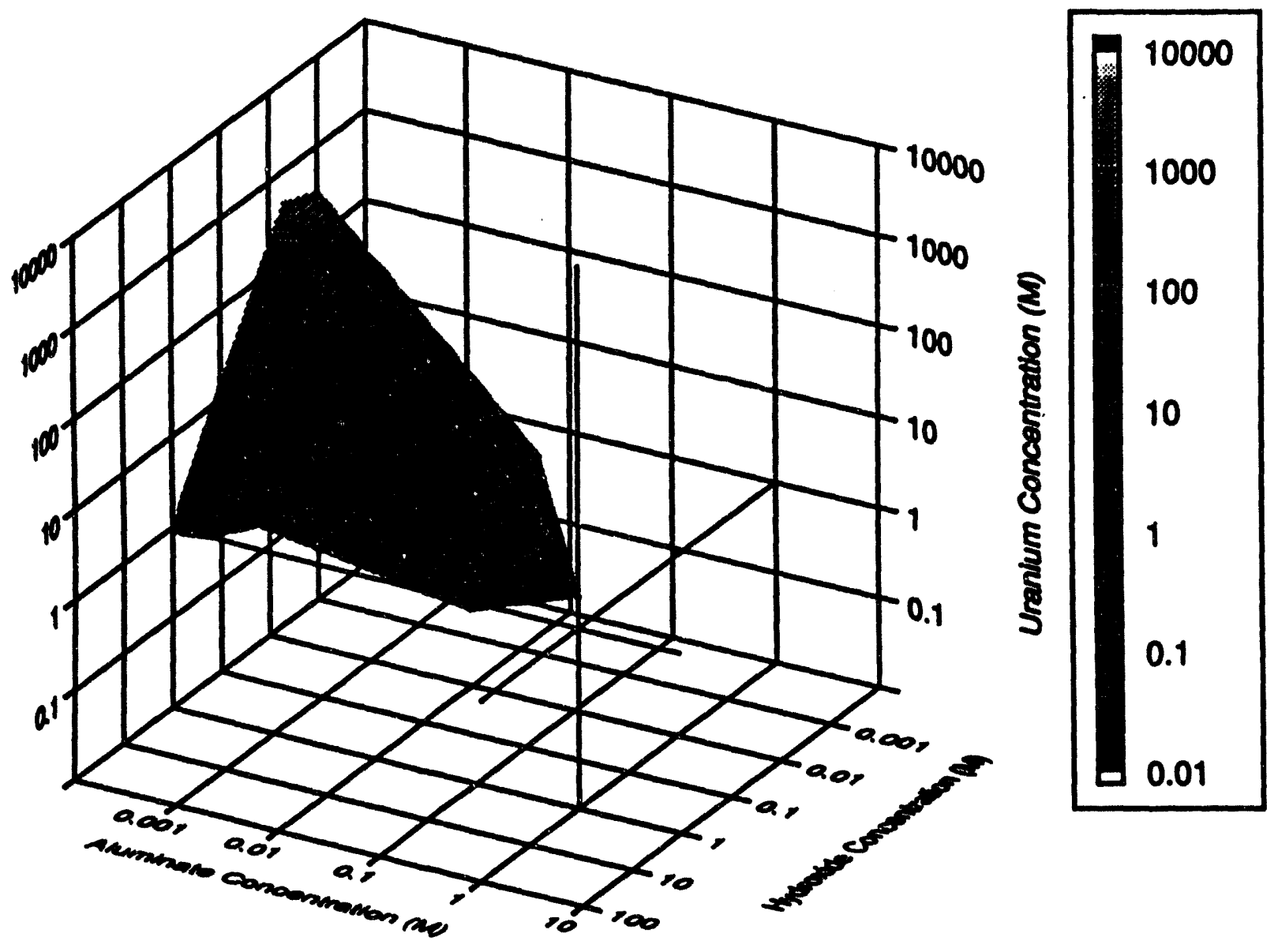


Exhlblt 25: Predicted Uranium Concentration for Decreasing Nitrate/Nitrite and

Hydroxide/Carbonate Ratlos

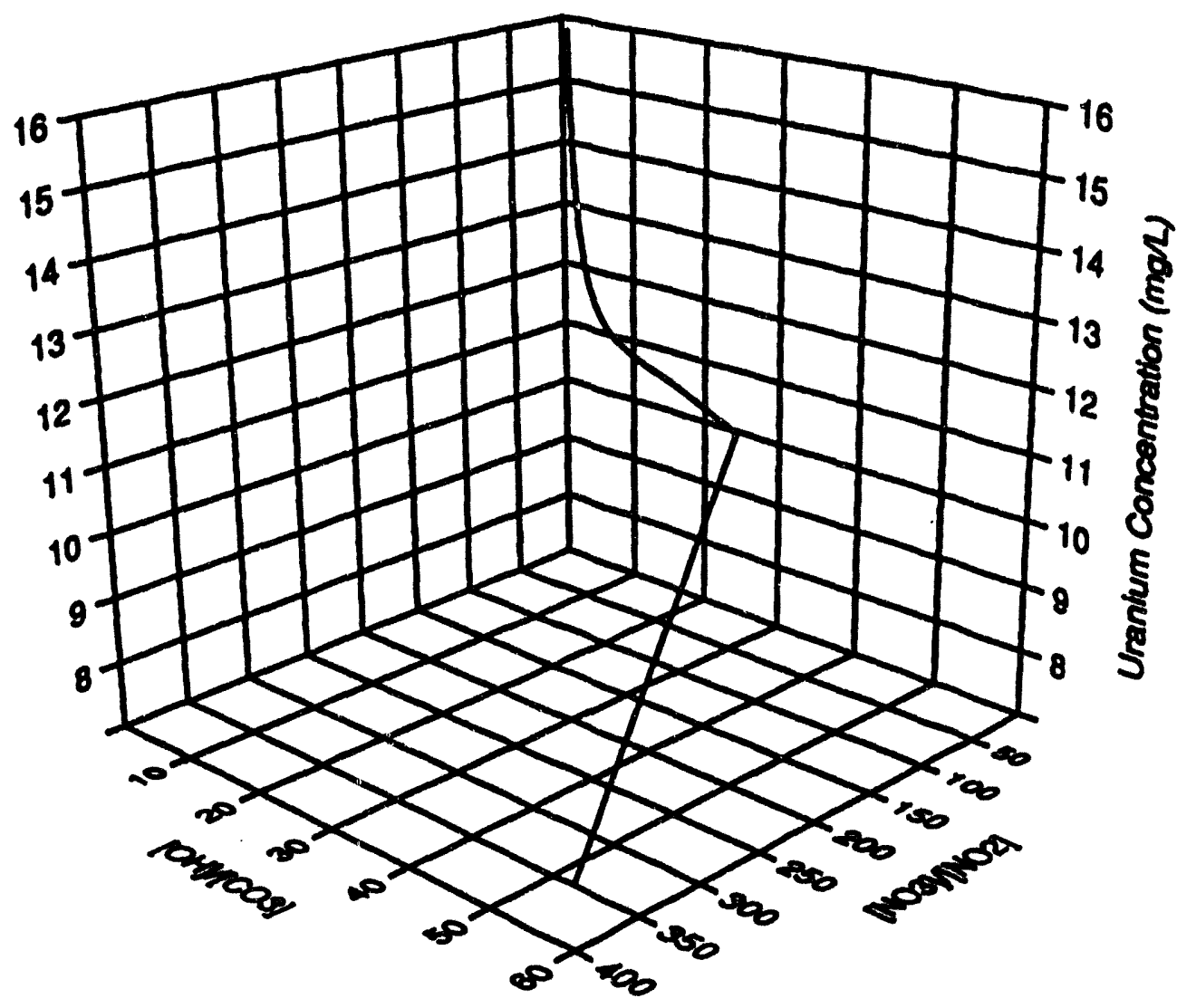


Exhibit 26: Uranium Concentration Versus Hydroxide Concentration Expanded-Matrix and ITP-Matrix Solutions

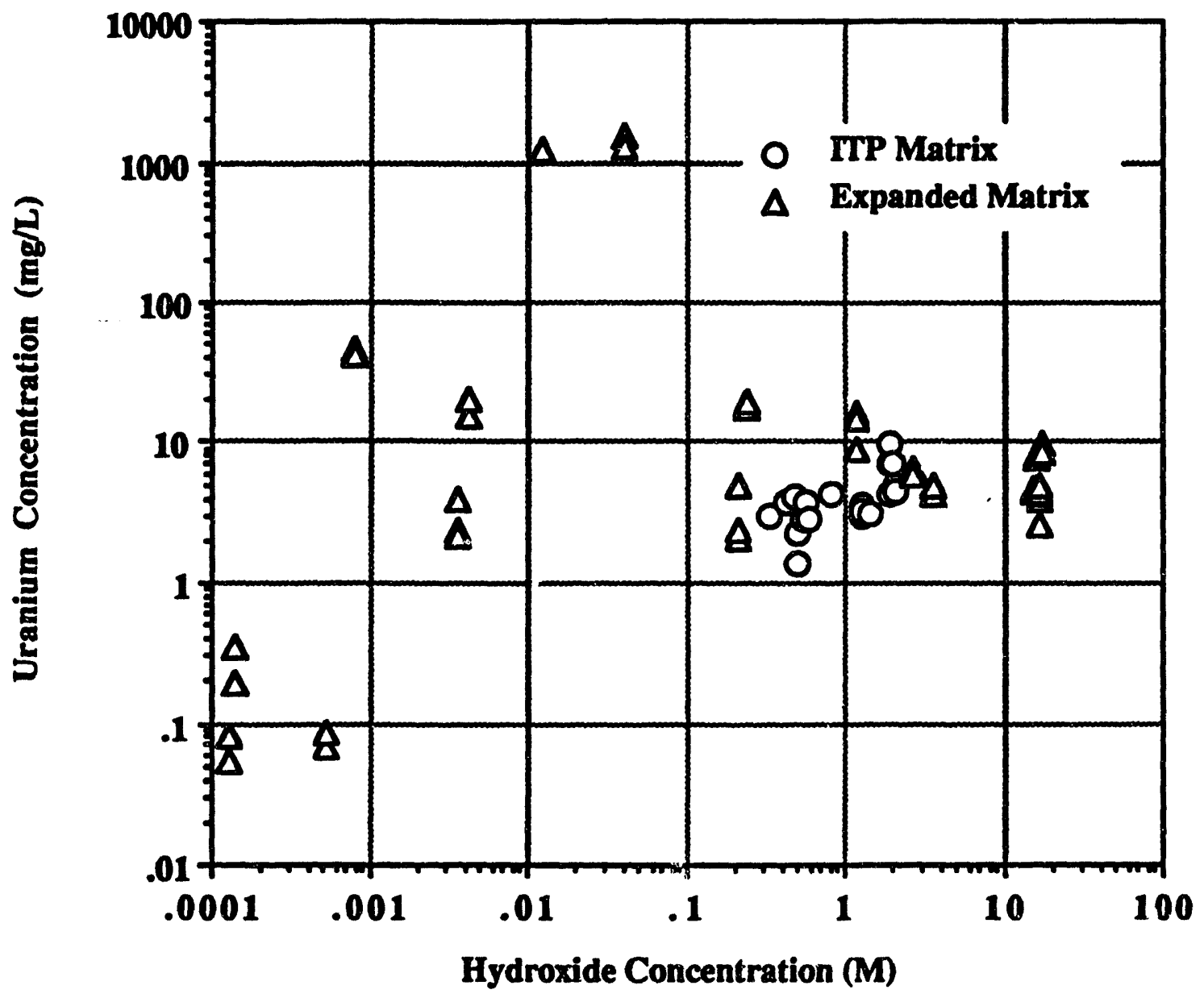



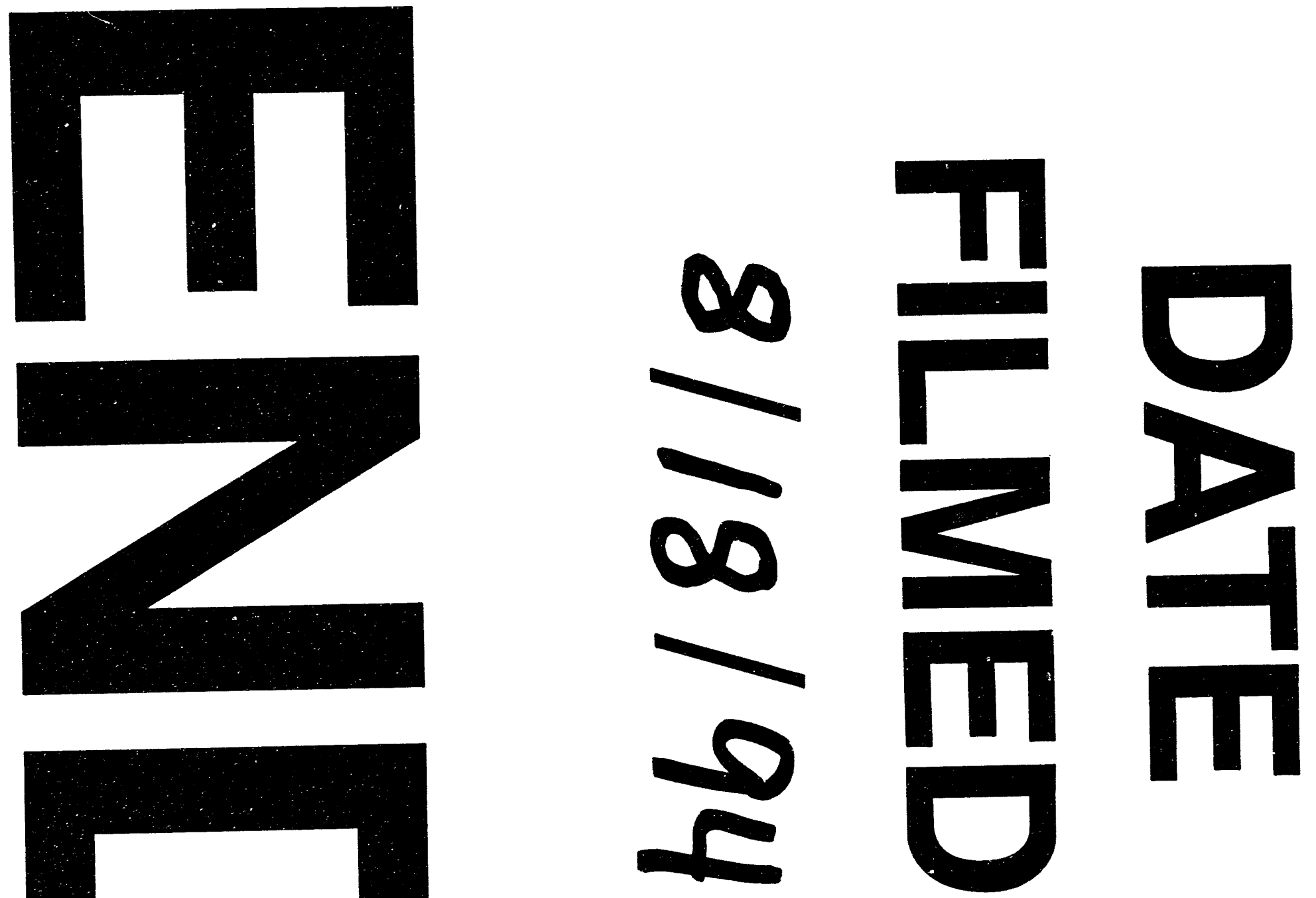
